Florida International University FIU Digital Commons

7-7-2011

\title{
In situ AFM Imaging of Nanoparticle- Cellular Membrane Interaction for a Drug Delivery Study
}

Rakesh Guduru

Florida International University, rgudu001@fiu.edu

DOI: $10.25148 /$ etd.FI1 1072505

Follow this and additional works at: https://digitalcommons.fiu.edu/etd

\section{Recommended Citation}

Guduru, Rakesh, "In situ AFM Imaging of Nanoparticle- Cellular Membrane Interaction for a Drug Delivery Study" (2011). FIU Electronic Theses and Dissertations. 422.

https://digitalcommons.fiu.edu/etd/422 


\title{
FLORIDA INTERNATIONAL UNIVERSITY
}

Miami, Florida

\section{IN SITU AFM IMAGING OF NANOPARTICLE-CELLULAR MEMBRANE INTERACTION FOR A DRUG DELIVERY STUDY}

\author{
A thesis submitted in partial fulfillment of the \\ requirements for the degree of \\ MASTER OF SCIENCE \\ in
}

BIOMEDICAL ENGINEERING

By

Rakesh Guduru 
To: Dean Amir Mirmiran

College of Engineering and Computing

This thesis, written by Rakesh Guduru, and entitled In situ AFM Imaging of NanoparticleCellular Membrane Interaction for a Drug Delivery Study, having been approved in respect to style and intellectual content, is referred to you for judgment.

We have read this thesis and recommend that it be approved.

Dwayne McDaniel

Anthony McGoron

Yen-Chih Huang

Steven J. Melnick

Chenzhong Li, Major Professor

Date of Defense: July 7, 2011

The thesis of Rakesh Guduru is approved.

Dean Amir Mirmiran

College of Engineering and Computing

Interim Dean Kevin O'Shea

University Graduate School

Florida International University, 2011 


\section{DEDICATION}

I dedicate my thesis to my friends and family, especially my wife for supporting me throughout my professional and personal life. 


\section{ACKOWLEDGMENTS}

I would like to thank my professors, family and friends without whose help and support, the completion of this work would never have been possible. Amongst these, I want to specially thank Dr. Dwayne McDaniel, my advisor at the Applied Research Center of Florida International University for his constant encouragement, valuable guidance and sponsorship throughout my Master's. I also want to express my gratitude towards Dr. Chenzhong Li who provided me the platform to do my research and Dr. Anthony McGoron for his worthy suggestions and for providing the nanoparticles for my experiments. I also want to thank Dr. Yen-Chih Huang and Dr. Steven Melnick for their support.

I would like to extend my appreciation to Supriya Srinivasan for her assistance with my experiments. 


\title{
ABSTRACT OF THE THESIS \\ IN SITU AFM IMAGING OF NANOPARTICLE-CELLULAR MEMBRANE INTERACTION FOR A DRUG DELIVERY STUDY
}

by

\author{
Rakesh Guduru \\ Florida International University, 2010 \\ Miami, Florida \\ Professor Chenzhong Li, Major Professor
}

Nanoparticles (NPs) play a crucial role in delivering therapeutic drugs to cancer cells. Understanding the interaction of NPs with cell surfaces and their internalization is imperative to develop a fully efficient drug delivery vehicle. In this study, atomic force microscopy (AFM) was used to evaluate the dynamic interactions of non-targeted and targeted poly (lactic-co-glycolic acid) (PLGA) NPs with ovarian cancer cells in native environmental conditions. Results demonstrated that the cells incubated in targeted NPs solution for 3 hours showed a $112 \%$ increase in cell surface roughness, whereas cells incubated in non-targeted NPs showed only a 38\% increase. Cell surface roughness, when incubated for 6 hours, was higher for non-targeted NPs. The changes in cell membrane surface roughness were also monitored for NPs encapsulated with a doxorubicin drug. Based on the results it was concluded that the targeted NPs will attach to the cell membrane and internalize faster than the non-targeted NPs. 
1. INTRODUCTION

2. BACKGROUND 3

2.1 NPs in drug delivery 3

2.2 Interaction of NPs with cell membrane 3

2.2.1 Effect of surface properties of NPs with cell membrane 4

2.3 Atomic force microscopy

$\begin{array}{ll}\text { 2.3.1 Introduction } & 7\end{array}$

2.3.2 AFM working principle $\quad 8$

2.3.3 Operation modes of the AFM 9

2.3.4 Types of AFM images $\quad 12$

2.3.5 Advantages of AFM 13

$\begin{array}{ll}\text { 2.3.6 Disadvantages of AFM } & 14\end{array}$

$\begin{array}{ll}\text { 2.3.7 AFM studies on live cells } & 14\end{array}$

3. STATEMENT OF PURPOSE 16

3.1 Research objective 16

$\begin{array}{ll}3.2 \text { Hypothesis } & 17\end{array}$

3.3 Experimental hypothesis 17

4. MATERIALS AND METHODS 18

$\begin{array}{ll}4.1 \text { Chemicals } & 18\end{array}$

4.2 Cell culture Materials 18

4.3 Preparation of NPs 19

4.3.1 Preparation of DOX loaded and void PLGA NPs (d-PLGA and b-PLGA) 19

4.3.2 Preparation of antibody conjugated NPs (ab-PLGA) 20

$\begin{array}{ll}4.4 \text { Characterization of NPs } & 20\end{array}$

$\begin{array}{ll}\text { 4.4.1 Size characterization } & 20\end{array}$

4.4.1.1 Size characterization using AFM 20

4.4.1.2 Size characterization using Malvern Zetasizer $\quad 21$

$\begin{array}{ll}\text { 4.4.2 Charge characterization } & 21\end{array}$

4.4.3 Estimation of doxorubicin loading efficiency 21

4.4.4 Antibody conjugation efficiency estimation 22

4.5 Coating the glass coverslips using Fibronectin and Poly-L-Lysine 23

4.5.1 Sterilization of coverslips 23

$\begin{array}{ll}\text { 4.5.2 Fibronectin coating } & 23\end{array}$

4.5.3 Poly-L-Lysine coating 24

4.6 Cell cultures 25 
4.7 Cell plating for AFM imaging 26

4.8 Incubation of NPs with SKOV-3 cells 26

4.9 AFM instrument and analysis $\quad 27$

4.9.1 AFM liquid cell 27

$\begin{array}{ll}\text { 4.9.1.1 Liquid cell setup } & 28\end{array}$

4.9.1.2 Procedure for AFM imaging in fluids 31

4.9.2 Qualitative analysis using AFM 33

4.9.2.1 Amplitude image $\quad 34$

$\begin{array}{ll}\text { 4.9.2.2 Phase image } & 35\end{array}$

4.9.3 Quantitative analysis using AFM 36

4.9.3.1 Roughness analysis of cell surface membrane using AFM 36

4.9.3.2 Power spectral density 37

4.9.3.2 Particle size analysis on cell surface membrane using AFM 38

5. RESULTS 39

5.1 Characterization of NPs $\quad 39$

$\begin{array}{ll}\text { 5.1.1 Nanoparticle size characterization } & 39\end{array}$

$\begin{array}{ll}\text { 5.1.1.2 Size characterization using AFM } & 39\end{array}$

5.1.1.2 Size characterization using Malvern Zetasizer $\quad 40$

$\begin{array}{ll}\text { 5.1.2 Charge characterization } & 40\end{array}$

5.1.3 Estimation of doxorubicin loading efficiency 41

5.1.4 Estimation of antibody conjugation efficiency 41

$\begin{array}{ll}\text { 5.1.5 NPs surface roughness characterization } & 41\end{array}$

5.2 Qualitative analysis using AFM 43

5.2.1 Phase imaging 43

5.2.2 Amplitude imaging $\quad 44$

$\begin{array}{ll}5.3 \text { Quantitative analysis using AFM } & 50\end{array}$

$\begin{array}{ll}\text { 5.3.1 Roughness analysis } & 50\end{array}$

5.3.2 Time based 2D power spectral density $\quad 54$

$\begin{array}{ll}\text { 5.3.3 Particle analysis } & 57\end{array}$

$\begin{array}{ll}\text { 6. DISCUSSION } & 62\end{array}$

6.1 Qualitative analysis using AFM 63

6.1.1 Phase imaging 63

6.1.2 Amplitude imaging $\quad 64$

6.2 Quantitative Analysis using AFM $\quad 65$

6.2.1 Average roughness $\left(\mathrm{R}_{\mathrm{a}}\right) \quad 66$

$\begin{array}{ll}\text { 6.2.2 Power spectral density } & 69\end{array}$

$\begin{array}{ll}\text { 6.2.3 Particle analysis } & 70\end{array}$

7. CONCLUSION AND FUTURE WORK 71

8. BIBLIOGRAPHY 73 


\section{LIST OF TABLES}

TABLE

PAGE

Table 1: Typical Parameter Settings for DNPS Probes in Liquid Tapping Mode Imaging33

Table 2: Average Size and Charge, Drug Loading Percentage and Antibody Conjugation Efficiency of NPs. Note: All the Data Represented as Mean \pm SD ................................ 41

Table 3: The Mean NP Surface Roughness and Standard Deviation .............................. 42 Table 4: Surface Roughness Values for SKOV-3 Cells without NP Treatment (incubation $\mathrm{t}=0)$ 52

Table 5: Average Surface Roughness Values for SKOV-3 Cells with NPs Treatment (incubation $\mathrm{t}=1$ hours). 53

Table 6: Average Surface Roughness Values for SKOV-3 Cells with NPs Treatment (incubation $\mathrm{t}=3$ hours). .53

Table 7: Average Surface Roughness Values for SKOV-3 Cells with NPs Treatment (incubation $\mathrm{t}=6$ hours) .53

Table 8: Average Surface Roughness Values for SKOV-3 Cells with NPs Treatment (incubation $\mathrm{t}=24$ hours). 53

Table 9: Percentage Change in Roughness Values of SKOV-3 Cells Before and After Incubating in NPs Solution and Their Corresponding P-value Significance (compared with untreated cells) is calculated From Student's t-test. .54

Table 10: Total Power of SKOV-3 Cell Surface at Various Incubation Time Periods ...... 56 Table 11: NPs height Obtained Using Particle Analysis Performed on SKOV-3 Cells after 1 Hour Incubation Time (Note: particle analysis) 59

Table 12: NPs height Obtained Using Particle Analysis Performed on SKOV-3 Cells after 3 Hour Incubation Time. 59

Table 13: NPs height Obtained Using Particle Analysis Performed on SKOV-3 Cells after

6 Hour Incubation Time. 60

Table 14: NPs height Obtained Using Particle Analysis Performed on SKOV-3 Cells after 24 Hour Incubation Time. 60

LIST OF FIGURES 
Figure 1: Breast cancer cells (SK-BR-3) and gold NPs carrying different surface charge. A) PVA-coated and citrate-coated NPs showing low interaction affinity towards the cell membrane while B) poly (allyanime hydrochloride)-coated NPs showing high affinity [49].

Figure 2: AFM working principle.

Figure 3: Path of the AFM cantilever raster scanning the tip across a sample surface in (A) contact mode, (B) non-contact mode and (C) tapping mode.

Figure 4: Incubation of coverslips with fibronection solution in a Six-well plate under atmospheric hood at $37^{\circ} \mathrm{C}$. 24

Figure 5: The cell culture flask containing the SKOV-3 cells in Mc'Coys 5A media...... 25

Figure 6: DNPS AFM probe with all four cantilevers...............................................27

Figure 7: Veeco's specialized fluid cell module designed for multimode AFM []. ..........28

Figure 8: Liquid drop held by the surface tension at the bottom of tip holder[85]............29

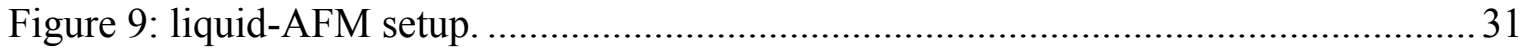

Figure 10: Schematic representation of AFM amplitude image generation......................35

Figure 11: Phase lag created while raster scanning the AFM tip from region A to region $B$

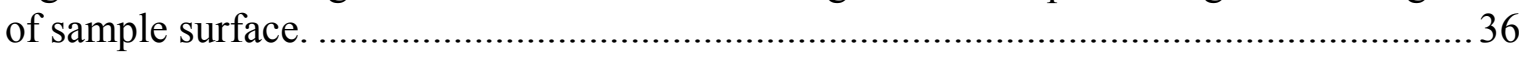

Figure 12: ab-PLGA nanoparticle size characterization using AFM particle analysis....... 40

Figure 13: Box statistics roughness analysis of the b-PLGA nanoparticle........................ 42

Figure 14: Phase image of untreated SKOV-3 cell surface on left and b-PLGA NPs treated (6 hours) SKOV-3 cell surface on right. Red arrow points the b-PLGA NPs on cell surface.

Figure 15: Amplitude image of SKOV-3 cell surface without NPs (incubation time zero). The size of the image on left is $20 \mu \mathrm{m} \times 20 \mu \mathrm{m}$ and on right is $5 \mu \mathrm{m} \times 5 \mu \mathrm{m}$. The above images were taken in data scale $0.3 \mathrm{~V}$ and color table 7.

Figure 16: Amplitude image of SKOV-3 cell surface with ab-PLGA NPs (incubation time 3 hours). The size of the image on left is $20 \mu \mathrm{m} \times 20 \mu \mathrm{m}$ and on right is $5 \mu \mathrm{m} \times 5 \mu \mathrm{m}$. The images were taken in data scale $0.3 \mathrm{~V}$ and color table 7. 46

Figure 17: Amplitude image of SKOV-3 cell surface with d-PLGA NPs (incubation time 3 hours). The size of the image on left is $20 \mu \mathrm{m} \times 20 \mu \mathrm{m}$ and on right is $7 \mu \mathrm{m} \times 7 \mu \mathrm{m}$. All the images were taken in data scale $0.3 \mathrm{~V}$. Note: image on right shows that cell surface is wrinkled

Figure 18: Amplitude image of SKOV-3 cell surface with b-PLGA NPs (incubation time 3 hours). The size of the image on left is $30 \mu \mathrm{m} \times 30 \mu \mathrm{m}$ and on right is $5 \mu \mathrm{m} \times 5 \mu \mathrm{m}$. The above images were taken in data scale $0.3 \mathrm{~V}$ and color table 2 . 
Figure 19: Amplitude image of SKOV-3 cell surface with ab-PLGA NPs (incubation time 6 hours). The size of the image on left is $20 \mu \mathrm{m} \times 20 \mu \mathrm{m}$ and on right is $5 \mu \mathrm{m} \times 5 \mu \mathrm{m}$. The above images were taken in data scale $0.3 \mathrm{~V}$ and color Table 2. 48

Figure 20: Amplitude image of SKOV-3 cell surface with b-PLGA NPs (incubation time 6 hours). The size of the image on left is $20 \mu \mathrm{m} \times 20 \mu \mathrm{m}$ and on right is $5 \mu \mathrm{m} \times 5 \mu \mathrm{m}$. The above images were taken in data scale $0.3 \mathrm{~V}$ and color Table 2. 48

Figure 21: Amplitude image of SKOV-3 cell surface with d-PLGA NPs (incubation time 6 hours). The size of the image on left is $10 \mu \mathrm{m} \times 10 \mu \mathrm{m}$ and on right is $5 \mu \mathrm{m} \times 5 \mu \mathrm{m}$. The above images were taken in data scale $0.3 \mathrm{~V}$ and color table 2. Note: Cells incubated in dPLGA NPs solution appeared small and contracted.

Figure 22: Phase image of SKOV-3 cell surface with d-PLGA NPs (incubation time 6 hours). The size of the image on left is $7 \mu \mathrm{m} \times 7 \mu \mathrm{m}$. Note: cell membrane surface showing no particles on the surface.

Figure 23: Amplitude image of SKOV-3 cell surface with b-PLGA NPs solution on left and ab-PLGA NPs solution on right (incubation time 24 hours). The size of the image on left and right is $5 \mu \mathrm{m} \times 5 \mu \mathrm{m}$ and $4 \mu \mathrm{m} \times 4 \mu \mathrm{m}$ on right. The above images were taken in data scale $0.3 \mathrm{~V}$ and color table 2. Note: SKOV-3 cells incubated in d-PLGA nanoparticle solution were not alive to perform AFM imaging. 50

Figure 24: SKOV-3 cell surface average roughness histogram when incubated with bPLGA, ab-PLGA and doxorubicin loaded PLGA plotted against incubation time. Note: cells incubated in the b-PLGA NPs solution for 24 hours were not alive to perform A. ...52

Figure 25: Change in power spectral density of SKOV-3 cells without $(\mathrm{t}=0)$ and with NPs with respect to time. 56

Figure 26: 2D PSD on entire scanned area of SKOV-3 cell without any NPs (incubation $\mathrm{t}=0$ ). Note: PSD is plotted on $\mathrm{X}$ - axis (scale $10^{-3}$ to $10^{2}$ ) Vs wavelength on Y-axis (scale 10 to $10^{-2}$ ). 56

Figure 27: 2D PSD on entire scanned area of SKOV-3 cell incubated in d-PLGA NPs solution (incubation $\mathrm{t}=6$ hours). Note: PSD is plotted on $\mathrm{X}$ - axis (scale $10^{4}$ to $10^{8}$ ) Vs wavelength on $\mathrm{Y}$-axis ( scale $10^{2}$ to $10^{-1}$ ). 57

Figure 28: Particle analysis performed on SKOV-3 cells incubated in d-PLGA nanoparticle solution for 3 hour. Size of the image is $1 \mu \mathrm{m} \times 1 \mu \mathrm{m}$. Note: the particle analysis region was selected based on the corresponding phase contrast image. 58

Figure 29: Particle analysis performed on SKOV-3 cells incubated in b-PLGA nanoparticle solution for 24 hour. Note that the particle height of d-PLGA nanoparticle on the cell surface is around $40.37 \mathrm{~nm}$. 59

Figure 30: NPs height variation on the SKOV-3 cells with respect to incubation time.....61 
Figure 31: (a) b-PLGA NPs binding to the cell surface membrane randomly and (b) ab-

PLGA particles attached to the receptors present on the cell surface membrane.............. 69 


\section{LIST OF ACRONYMS}

$\begin{array}{ll}\text { AFM } & \text { Atomic Force Microscope } \\ \text { SEM } & \text { Scanning Electron Microscope } \\ \text { TEM } & \text { Transmission Electron Microscope } \\ \text { NPs } & \text { Nanoparticles } \\ \text { PSPD } & \text { Position Sensitive Photo Detector } \\ \text { DC } & \text { Direct Current } \\ \text { PLGA } & \text { Poly (lactic-co-glycolic acid) } \\ \text { PSD } & \text { Power Spectral Density } \\ \text { DOX } & \text { Doxorubicin } \\ \text { PBS } & \text { Phosphate Buffered Saline } \\ \text { DMSO } & \text { Dimethly Sulfoxide } \\ \text { DPBS } & \text { Dulbecco's Phosphate Buffered Saline }\end{array}$

b-PLGA Bare poly (lactic-co-glycolic acid)

ab-PLGA antibody conjugated poly (lactic-co-glycolic acid)

d-PLGA Doxorubicin loaded poly (lactic-co-glycolic acid) 


\section{INTRODUCTION}

Nanoparticles (NPs) are currently employed as vehicles to deliver therapeutic payloads such as drugs, genes, and stem cells to the diseased sites $[1,2,3]$. NP based delivery provides key advantages such as targeting, and time-controlled release of agents. Targeted NPs aim to provide an effective dose to the disease site while minimizing the effect on healthy tissues. Thus, using targeted therapies, a lower concentration of the therapeutic agent can prove effective while minimizing the side-effects. Understanding interactions and the internalization of NPs with cell membranes could be instrumental in developing efficient drug carriers. NPs can be synthesized with different physical properties and chemical functionalities depending on biomedical/nanomedicinal applications. The changes in characteristics of nanomaterials may influence its interaction with biological membranes. However, there is no practical approach to estimate this effect in native environmental conditions of the cell. Atomic force microscopy (AFM) has proven to be a powerful tool in studying a wide variety of biological samples such as cells $[4,5]$ tissues $[5,6]$ and biomaterial $[7,8]$ living in native environmental conditions. More recently, AFM has been used to study the dynamics of gold NP interaction with cancerous cell surface membranes [9]. AFM has a significant edge over other imaging techniques such as scanning electron microscopy (SEM), transmission electron microscopy (TEM) and fluorescence imaging, in evaluating NP interaction with biological samples [10]. AFM can perform imaging in native cellular conditions, allowing for a true evaluation of the dynamics of NP interaction with living cells which is not possible with SEM or TEM. AFM image data can be represented in three dimensions (3D) which assists in measuring height variations due to the interaction 
of NPs on the cell surface. Image data obtained from SEM or TEM is in two dimensions (2D) and lacks the ability to provide this information. Imaging the NPs cell membrane interactions using a fluorescence microscope, demands NPs to be fluorescently labeled. Data obtained using this approach cannot differentiate internal particles from particles attached on the surface and thus, cannot be used to study internalization dynamics. However, time-based cell surface membrane studies using AFM have demonstrated the capability to show internalization phenomenon of various NPs $[11,12,13]$.

This research is focused on monitoring the dynamic topographical changes within the cell membrane of ovarian cancer cells (SKOV-3) over a period of 24 hours due to the interaction of non-targeted, targeted, and drug loaded PLGA poly (lactic-co-glycolic acid) (PLGA) NPs. PLGA NPs were selected as the model system due to their biocompatible and biodegradable nature and their ability to carry both hydrophilic and hydrophobic therapeutics agents $[14,15]$. Doxorubicin (DOX) was selected for this study due to its high anti-cancer therapeutic potential. In the United States, ovarian cancer is the seventh most common type of cancer that occurs in women between the ages 40-65. SKOV-3 cells are known to compromise their sensitivity towards doxorubicin drug, due to improper activity of apoptotic protease activating factor 1 long with inactive caspase 3 or caspase 9 (protease which initiates cell apoptosis) [16,17]. This resistance cannot be overcome by increasing the dosage of doxorubicin because of toxic dose dependent side effects. Target specific drug loaded NPs carry the drug to only target specific sites, thereby increasing the local concentration of the drug at diseased areas and thereby, achieving similar results with a lower drug dosage and with reduced side effects [18]. 


\section{BACKGROUND}

\subsection{NPs in drug delivery}

Success of designing a drug delivery system for cancer treatment demands high local drug concentration at the target site while minimizing toxic side effects. Nanocarriers (nanometer sized) loaded with chemotherapeutic agents have shown to improve the cancer treatment $[19,20,21]$. NPs contain a therapeutic agent dispersed in a polymer matrix or encapsulated inside a polymer shell, adsorbed or covalently bonded to the surface. Different types of nanoparticle based drug delivery systems have been designed in order to achieve therapeutic efficiency in reaching the targeted diseased tissue. These include dendrimers [22,23], polymeric micelles [24,25], liposomes [26,27], hollow microcapsules [28], solid lipid NPs [29], and solid core shell NPs [30,31]. There are

numerous methods for preparing these NPs $[32,33,34]$. Most of these methods use either harsh organic solvents or unstable emulsion for their production. This may account for inefficient drug delivery causing toxic side effects to the body. Fabricating the NPs for effective time release at targeted locations while decreasing the harmful side effects will mitigate the problems associated with the traditional chemotherapy.

\subsection{Interaction of NPs with cell membrane}

The success of NPs in drug delivery processes depends on the extensive understanding of their interaction with cell membrane and their intricate components. The plasma membrane is the primary site of contact between the NPs and the cell. Nanoparticle-membrane interactions are widely affected by the surface properties of the 
NPs such as size, shape and charge [35]. Hong et al, showed the disruption of the plasma membrane when treated with NPs bearing positively charged groups (such as polymer: polyethylenimine and polyamidoamine) on their surfaces [36,37]. This disruption is distinguished by the formation of nanoscale holes which in turn enhances the membrane permeability. The nanoscale hole formation was proposed by the Mecke et al, using atomic force microscopy [38]. The NPs which induced nanoscale hole formations could further internalize through endocytosis. In addition to the hole formation, NPs also aggregate at the cell surface. This aggregation causes cell impair by not communicating with its surrounding environment [39].

\subsubsection{Effect of surface properties of NPs with cell membrane}

All NPs will be immediately absorbed on the surface of cells/tissues and will be later internalized depending upon the surface characteristics of the NPs such as a) size and shape, b) charge, and c) surface chemistry [40]. The molecules present on the surface of the NPs helps in targeting specific cell type or cell populations. The molecules present on the surface will also play a major role in defining the size, structure and flexibility of the NPs.

a) Size and shape of the NPs: The size and shape of the NPs are amongst the primary properties which greatly influence cellular internalization. Hela cells showed a maximum uptake of gold NPs of 50nm size when compared with $14 \mathrm{~nm}$ and 74 nm sized particles $[41,42]$. This suggests that there might be an optimal size for an efficient uptake by cells. The effect of shapes of NPs on internalization was 
also studied. Spherical shaped NPs showed five times more uptake than rod shaped NPs indicating that elongated particles require more time for cellular endocytosis [42]. Studies have shown that the size of NPs also affects the binding and activation of several membrane receptor proteins expression [43]. For example larger NPs can hold more antibodies on their surface (higher protein to NPs ration) there by increasing the binding sites on the surface of NPs [44]. The size characterization of NPs will also depend on the medium in which the measurements are carried out (i.e, physiological conditions). For example, alkylation of the media changes the hydrodynamic size (from $15.3 \mathrm{~nm}$ to $13 \mathrm{~nm}$ ) of polyesthyleneimine (PEI) conjugated with quantum dots (QDs) [45].

b) Charge of the NPs: The charge of the NPs will have an influence on their interaction with the cell membrane and will further affect cellular internalization. A positively charged NP will bind to the negatively charged glycocalyx present on the cell membranes and the negatively charged NP will bind to the positively charged proteins on the cell membrane. This type of interaction is called as an electrostatic interaction [46]. Charge on the particles could be exploited to carry cargo inside the cell. For example, a negatively charged DNA strand can be carried by a positively charged particle [47].

c) Surface chemistry: Size, shape and charge of NPs will significantly affect their interaction with cells; but the properties such as stability, cell membrane interaction and targeted specificity are primarily determined by the type of molecules (functional groups) present on the surface of the NPs. Tagging the NPs with functional groups will not only deliver therapeutic agents to the desired site 
efficiently but also prevent nonspecific interactions thereby minimizing the side effects. Figure 1 explains that the positively charged particles had a higher interaction with a negatively charged membrane and consequently showed higher internalization. Neutral and negatively charged particles showed significantly less adsorption and cellular internalization. Negatively charged NPs are believed to internalize through cationic sites (few in number when compared with anionic sites) on the plasma membrane $[48,49]$.
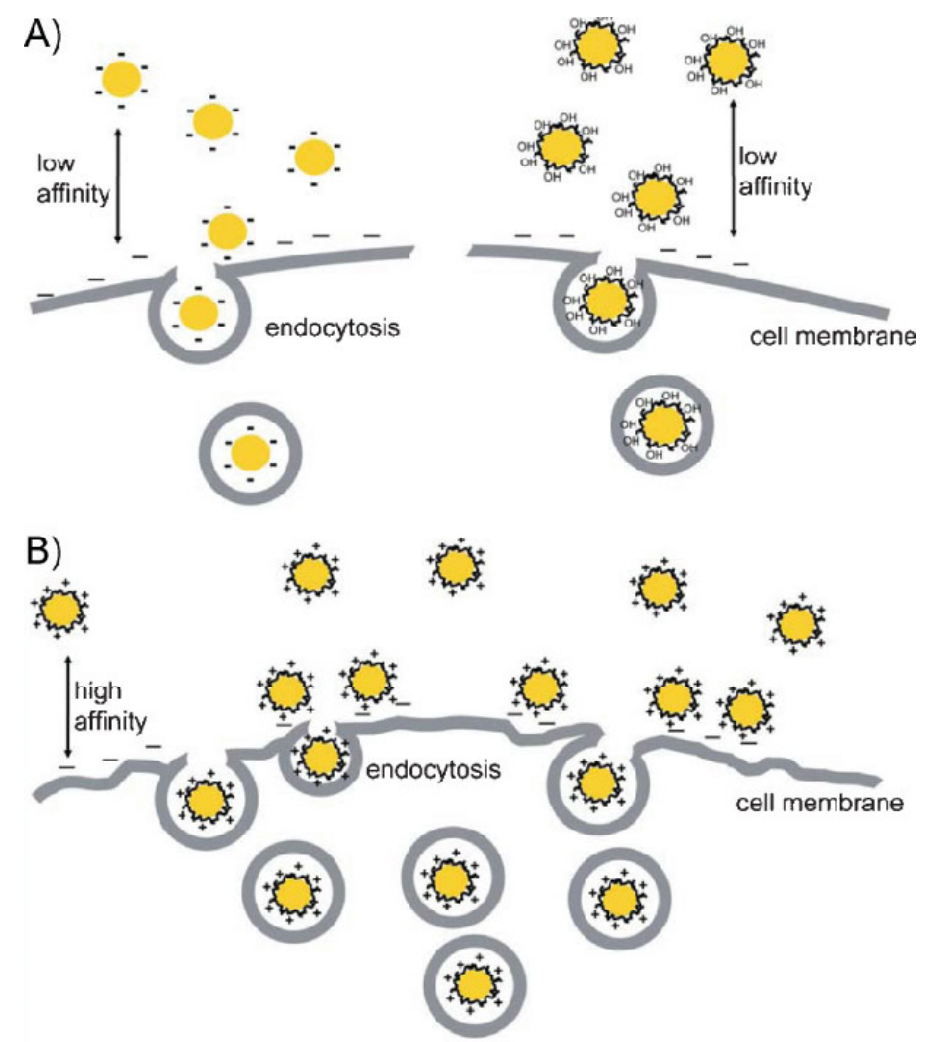

Figure 1: Breast cancer cells (SK-BR-3) and gold NPs carrying different surface charge. A) PVA-coated and citrate-coated NPs showing low interaction affinity towards the cell membrane while B) poly (allyanime hydrochloride)-coated NPs showing high affinity [50]. 


\subsection{Atomic force microscopy}

\subsubsection{Introduction}

AFM is a powerful tool used in characterizing a surface at nanometer scale spatial resolution. It is perhaps the precursor of the scanning probe microscope (SPM). SPM was first developed at an IBM research facility (Zurich) by Binning and Rohrer in 1980. Later in 1986, Binning and his colleagues introduced the AFM. Conventional light microscopes are limited by their wavelength of radiation that is approximately $200 \mathrm{~nm}$. High resolution images are obtained using high energy electrons in the electron microscope. Imaging the sample in an electron microscope demands a thin conductive layer on the surface of the specimen and should be performed under vacuum. This sample preparation procedure may restrict its application to biological samples. However, AFM does not require conductive coating for imaging the specimen and can perform imaging in any environment. In AFM, the image is generated by monitoring the interaction force between the probe and the specimen as the probe raster scans over the sample specimen. The resolution of the image depends on several parameters ranging from the sharpness of the probe to the environment in which the scanning is performed. Additional information can be obtained from the book titled, "Atomic Force Microscopy for Biologists" [51].

Many biologists have shown that AFM is an excellent tool for imaging as well as studying the dynamic processes at the biological membrane in their natural physiological conditions [52]. Morphological studies of cell membrane structures at nanometer scale spatial resolution in their native states by light microscopy are limited by their 
wavelength. Although in recent years electron microscopy was able to image biological samples at angstrom level, the sample preparation techniques involve freezing, fixing and a special conductive coating prior to imaging. These sample preparation techniques may cause morphological changes on the surface making it difficult to identify the structures at nanometer resolution. Recently, new structures (porosomes) were identified at the plasma membrane of pancreatic acinar cells and their real time dynamics were monitored during exocytosis process using AFM [53]. In recent years AFM is being used extensively in studying the cellular surfaces, biomolecules, organelles, and intra-cellular structures, revealing the cellular and sub-cellular structures at nanometer spatial resolution. The most important and major contribution of AFM in biology is its ability to study the real time cellular dynamics under native physiological conditions of cells with high resolution.

\subsubsection{AFM working principle}

Like all other SPMs, AFM uses a sharp tip to raster scan across the sample surface to generate an image. Typically the probe tip is made of silicon or silicon nitride which is mounted on a cantilever spring and is used to scan the surface of the sample with a constant force [54]. To monitor the tip movements, a laser beam is focused on to the back of the cantilever (tip is present at the edge of the cantilever) and it is reflected to a position sensitive photo detector (PSPD), this is depicted in Figure 2. The topography image is measured by the up and down motion of the cantilever. Monitoring the phase shift in amplitude of cantilever's oscillation generates the phase image. 


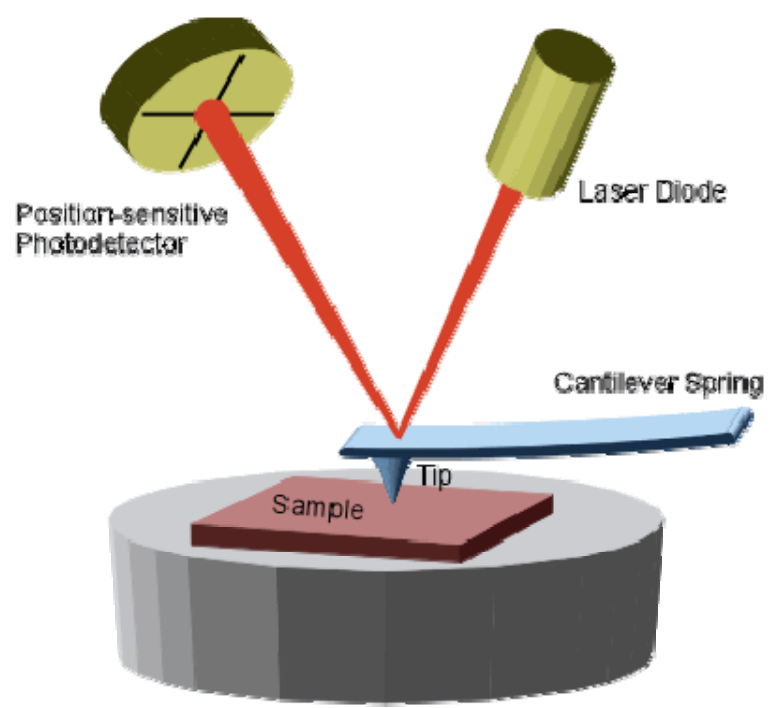

Figure 2: AFM working principle.

To image biological samples, scanning should be performed at the lowest possible imaging force $(\sim 1 \mathrm{nN})$ as elastic properties play a significant role in imaging soft biological samples. A $1 \mathrm{nN}$ loading force was found to have an influence in imaging biological samples $[55,56]$. A sub-angstrom resolution image can only be obtained at a loading force of piconewtons which is not possible with the current state of technology. A recently developed photonic force microscopy requires only a few piconewtons of loading force for imaging biological samples at the cost of image resolution [57]. Hence, generating a sub-angstrom image resolution is currently impossible.

\subsubsection{Operation modes of the AFM}

AFM can be operated in three different modes: a) contact mode b) non-contact mode and c) tapping mode. 


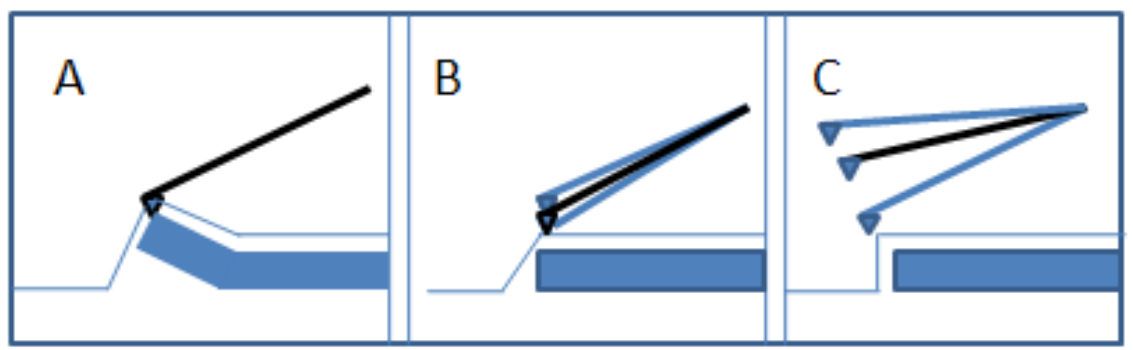

Figure 3: Path of the AFM cantilever raster scanning the tip across a sample surface in (A) contact mode,,

(B) non-contact mode and (C) tapping mode.

a) Contact mode: This mode is the most commonly used in force microscopy. In this mode, the tip is raster scanned over a sample surface in close contact (1-2 nm) and the deflection of the tip is constantly measured by the PSPD. The direct current (DC) feedback amplifier compares the measured values of deflection with the desired value of deflection (set by the user). If the measured value is different from the desired value, the DC amplifier applies voltage to the piezo which further raises or lowers the sample position relative to the cantilever position to obtain the desired value of deflection. A height image (topography) is generated from the voltage applied to the piezo during raster scan over a specific scan area. Contact mode can be operated in any environmental condition (liquid, gaseous, vacuum). Performing AFM in contact mode under ambient conditions may sometimes be difficult because of the presence of humidity. Humidity causes capillary condensation on the sample surface which increases the interaction force between the tip and the sample surface and hinders the scanning process. The effect can be mitigated by decreasing the tracking force between the tip and the sample; this can be achieved by performing scanning in ultrahigh vacuum (UHV) 
or in liquids. Figure 3a. shows the interaction of the probe tip with the sample surface in contact mode.

b) Non-contact mode: In this mode, the tip is raster scanned over the sample surface at $5-15 \mathrm{~nm}$ range. Operating AFM in this mode under ambient conditions is easier because the tip is tracking the surface at a higher distance from the surface when compared to the contact mode. This will essentially decrease the effect caused by capillary condensation. In this mode, the tip oscillates over a small range to detect sample surface forces by measuring the change in oscillating frequency, amplitude and phase of the cantilever.

c) Tapping mode: In this mode, the tip oscillates over a sample surface at a very high distance $(>20 \mathrm{~nm})$ to overcome the problems associated with capillary condensation, adhesion, friction, electrostatic forces and thereby decreases the drag between the tip and the sample. This is a powerful AFM technique which generates high resolution topographical images for a wide variety of samples. In this technique a piezoelectric crystal oscillates the cantilever at the resonance frequency of the cantilever at amplitude as high as $20 \mathrm{~nm}$. During scanning, the piezo drives the vertically oscillating tip towards the surface of the sample until it barely taps the surface. Tip oscillation decreases due to the intermittent contact of the tip with the surface. Reduction in amplitude of oscillation is used to identify and measure surface features of the sample. The amplitude of oscillation of the tip is measured by the detector to generate high-resolution topography, amplitude and phase images. Tapping mode prevents the tip from sticking to the surface, scratching the sample surface, and breakage of tips which is very common in 
contact and non-contact modes of operation. Also, shear forces are greatly reduced since the applied force is always vertical. Tapping mode operation in liquid is used to scan biological samples which are usually very soft in their living conditions, whereas other modes (contact and non-contact) will disrupt the cell surface.

\subsubsection{Types of AFM images}

Using AFM, one can gather a wide variety of information depending upon the modes of operation and the sample type. Below is a list of information generated using the AFM:

a) Topographical image: Topography images provide height information of the sample surface. These images can be obtained in all the modes of operation.

b) Phase imaging: Phase images are generated by the contrast caused by the material differences including adhesion and visco-elasticity. These images can be obtained only in tapping mode.

c) Magnetic force image: This image provides information about the gradient distribution of the magnetic force over a sample surface. It can be obtained by operating the AFM in a special mode called LiftMode ${ }^{\mathrm{TM}}$ (an additional electronic module called Extender is required for this mode).

d) Electric force image: This image provides information about the gradient distribution of the electric field over a sample surface and is also performed in LiftMode $^{\mathrm{TM}}$ (Extender is required). 
e) Surface potential image: This image provides information about the surface potential difference over the sample surface and is performed in LiftMode ${ }^{\mathrm{TM}}$ (Extender is required).

f) Force volume image: A force volume image contains a series of force curves obtained over an entire desired sample surface area. Each force curve is measured at unique $\mathrm{x}-\mathrm{y}$ coordinate and is combined into a 3 dimensional array or volume of force curves.

g) Frictional image: This image provides information regarding the chemical variation across the sample surface. The image is generated by monitoring the lateral deflection of the tip.

NOTE: LiftModeTM is a two-pass technique that generates two types of images separately. One is a topography image using Tapping mode and another is the magnetic or electric force image using information generated from the topographical image (patented by Veeco Metrology).

\subsubsection{Advantages of AFM}

Below are several advantages of using AFM over other imaging techniques such as SEM, TEM and immunofluorescence.

1) Ability to perform in vivo analysis of the cellular membrane dynamics of living cells, tissues, viruses and bacteria in their native physiological conditions $[58,59,60,61,62,63,64,65]$.

2) No special coating is required to make the sample conductive. 
3) Provides $3 D$ mapping of the sample.

4) Biological sample does not require fixation.

5) Analysis can be conducted in a gas and liquid environment or in a vacuum.

6) Less expensive.

\subsubsection{Disadvantages of AFM}

1) Complex setup

2) Requires skilled labor

3) Requires sample to be properly attach to the surface

4) Time consuming

\subsubsection{AFM studies on live cells}

In recent years, AFM was successfully employed in studying the morphology of various kinds of living cells. Using AFM, a systematic rearrangement of cytoplasm was observed (lamellipodia formation) in MDCK and live carcinoma cells [66]. Ongoing filament dynamics were determined underneath the cell membrane in living glia cells and hipocampal neurons [67,68]. Recently, AFM was employed in studying membrane spreading and granula motions of activated human platelets [69]. 4\% paraformaldehydefixed astrocytes showed a fibrillar network of medial midbrain astrocytes which is a neuritic growth preventer using AFM [70]. AFM imaging of soft samples can be very difficult to perform. These types of samples need to be hardened prior to imaging which can be achieved by several sample fixation techniques [71]. AFM was used in studying fine structural changes in live neurons obtained from pond snail (from central ganglia) 
[72]. AFM was also the first research tool to reveal structural and mechanical properties of isolated stereocilia of living sensory cells. This study showed typical V-shaped ciliary bundles at the tips of isolated stereocilia [73]. Using AFM, morphological and growth dynamical changes were examined in NIH $3 \mathrm{~T} 3$ and $\mathrm{PC} 12$ cells $[74,75]$. In this study, PC12 cells were examined over a long period of time to determine the neuritic process, bead like growth cone formation and deformation (50 to $700 \mathrm{~nm}$ wide). Force modulation was also performed at the cone formation to determine its mechanical properties over time. Growth and budding dynamics of saccaromyces cerevisiae (yeast) were determined by using AFM on 3\% agar immobilized cells. A permanent budding scar was observed for the first time using AFM. Further, the AFM based real time yeast budding dynamics also showed that daughter cells take longer to dissociate from the mother cell [76].

AFM performed on the stimulated rat leukemia cell surface (basophiles) demonstrated the appearance of pits $(1.5 \mu \mathrm{m}$ diameter $)$ on the plasma membrane. The authors suggest that the intensive stimulation of these cells and membrane retrieval mechanism result in formation of pit like structures. Thus, AFM enabled the study of dynamics of stimulation of plasma membrane and identification of pits in live rat leukemia cells [77]. Using AFM, mechanical properties (elasticity) of osteoblasts cultured on various surfaces such as metal, glass and polystyrene were compared $\left.{ }^{78}\right]$. This study demonstrated the use of AFM's force modulation technique in determining the adhesion of live cells with various substrates. This information may be useful in developing new medical implants. 


\section{STATEMENT OF PURPOSE}

Developing fully efficient drug delivery vehicles could potentially improve the bioavailability of drugs to the targeted regions thereby curing the diseased tissue efficiently and simultaneously minimizing the side effects. Recent developments in their surface functionalization to target them to specific sites on cancer cells is tremendously increasing, which demands development of new and more specific tools to evaluate their

efficiency in interaction and distribution on cell surface (in-situ). As a result, it is important to evaluate the efficiency of these NPs in reaching the targeted sites. Interaction of NPs with the surface of the cell membrane will affect the cell surface roughness. In this work, NP-membrane interaction was monitored by measuring the cell surface roughness. Three different types of NPs were used for this study: 1) bare PLGA NPs (b-PLGA), 2) PLGA NPs encapsulated with a doxorubicin drug (d-PLGA), and 3) PLGA NPs conjugated with anti-HER-2 antibodies (ab-PLGA). PLGA NPs were selected as the model system due to their biocompatible and biodegradable nature and their ability to carry both hydrophilic and hydrophobic therapeutics agents $[79,80]$. Doxorubicin was selected as our model drug as it is widely used anthracycline antibiotic used against solid tumors, such as ovarian cancers [81].

\subsection{Research objective}

The primary objective of this research is to evaluate the dynamic cellular membrane changes using AFM when SKOV-3 cells are treated with non-targeted PLGA 
NPs (bare PLGA NPs without any surface functionalization), targeted PLGA NPs (functionalized with anti HER2 antibodies to target the receptors present on ovarian cancer cells) and PLGA NPs encapsulated with a therapeutic drug.

\subsection{Hypothesis}

It is hypothesized that the interaction of NPs with the surface of the cell membrane will affect its roughness. Using phase imaging, roughness analysis, power spectral density (PSD) and particle analysis, it is possible to visualize the NP-membrane interaction phenomenon and also measure the dynamic change in NP size on the surface of the living cell throughout the internalization process.

\subsection{Experimental hypothesis}

It is hypothesized that:

1. The change in surface chemistry (presence and absence of ligands) of the NPs will affect their interaction with the cell membrane and will further affect the roughness measurements.

2. Drug encapsulated NPs will significantly affect interactions with the cell surface as well as cell viability and will further affect the roughness of the cell membrane.

3. The incubation time will significantly affect the interaction with the cell membrane and will further affect the roughness of the cell membrane. 


\section{MATERIALS AND METHODS}

In this research, NPs and their interaction with the surface of the cell membrane were characterized using qualitative and quantitative AFM analysis. We used particle analysis to characterize the true hydrodynamic size of the b-PLGA, ab-PLGA and dPLGA NPs in the McCoy's 5A media. To determine the change in surface roughness of the NPs before and after antibody conjugation, we performed the roughness analysis of the NPs. To visualize interaction of NPs with the cell membrane at different incubation periods ( $\mathrm{t}=1,3,6 \& 24$ hours) we performed qualitative analysis i.e. amplitude image, height imaging and phase imaging. We also performed roughness analysis, power spectral density and particle analysis to quantitatively measure the interaction and dynamic size change of NPs throughout the internalization process.

\subsection{Chemicals}

Fibronectin (Mw: 220kDa; Sigma- Aldrich), Hanks balanced salt solution (SigmaAldrich), PLGA (L:G molar ratio: 50:50, Mw: 40000-75000; Sigma-Aldrich) and IgG (Anti HER-2 monoclonal antibody; Sigma Aldrich), Polyvinyl alcohol (PVA, 87 - 89\% hydrolyzed; 13kDa-23kDa; Sigma-Aldrich). 5-Minute Epoxy (Devcon)

\subsection{Cell culture Materials}

Ovarian carcinoma cell lines (SKOV-3) were obtained from ATCC, McCoy’s 5A medium, fetal bovine serum (FBS), Dulbecco's Phosphate-Buffered Saline (DPBS), 
Penicillin-Streptomycin were obtained from Sigma Aldrich. Coverslips $(12 \mathrm{~mm}$, diameter) were purchased from SPI Supplies. Pipettes and pipette tips were purchased from Fisher Scientific.

\subsection{Preparation of NPS}

\subsubsection{Preparation of DOX loaded and void PLGA NPs (d-PLGA and b-PLGA)}

(DOX) loaded PLGA NPs were prepared by using single emulsion oil in water solvent evaporation method described previously [82]. Briefly, the organic phase comprised of PLGA (40 mg), DOX HCl (2 mg) and triethylamine (20 $\mu \mathrm{l})$ was dissolved in a mixture of methanol and dichloromethane $(1: 3 \mathrm{v} / \mathrm{v}, 4 \mathrm{ml})$. This organic phase was emulsified with aqueous phase containing 3\% polyvinyl alcohol (PVA) (surfactant). The emulsion was sonicated at $29 \mathrm{~W}$ power intensity for 2 minutes (Cole Palmer, Vernon Hills, Illinois). Organic solvents used for emulsion preparation were removed through solvent evaporation in a Rotavapor (Buchi, New Castle, Delaware) at $40^{\circ} \mathrm{C}$. The NPs were centrifuged at 12,200 rpm for 30 minutes. The free drug (i.e., DOX) in the supernatant was removed; the pellets were washed with deionized water and centrifuged again for 30 minutes. The washing procedure was carried out four times to remove the excess surfactant and drug. After centrifugation, the pellets were freeze dried and lyophilized for 48 hours. Void PLGA NPs were prepared by a method similar to the one stated above without using the drug. 


\subsubsection{Preparation of antibody conjugated NPs (ab-PLGA)}

ab-PLGA NPs were prepared using a method previously reported [82]. The lyophilized NPs were re-suspended in PBS buffer (pH 7.4). The particles were incubated with $1 \mathrm{ml}$ of $2 \mathrm{mM} \mathrm{N}$-(3-dimethylaminopropyl)- N'-ethylcarbodiimide hydrochloride (EDC) and $2.0 \mathrm{mM} \mathrm{N}$-hydroxysuccinimide (NHS) at $4^{\circ} \mathrm{C}$. The particles were then centrifuged at $12,200 \mathrm{rpm}$ at $6^{\circ} \mathrm{C}$ for 30 minutes. The pellets were washed with PBS buffer $(\mathrm{pH}$ 7.4) and centrifuged again. This procedure was repeated twice to remove

excess free antibody and reagents used. The pellets were then freeze-dried and lyophilized.

\subsection{Characterization of NPS}

NPs were characterized for hydrodynamic size, charge, roughness, DOX loading efficiency and antibody conjugation efficiency.

\subsubsection{Size characterization}

\subsubsection{Size characterization using AFM}

In order to determine the true size of the b-PLGA, d-PLGA and ab-PLGA NPs, AFM sectional analysis was performed in McCoy's 5A media at room temperature. For imaging NPs in a liquid media, it is very important to attach NPs to the substrate to avoid accidental attachment of NPs to the AFM probe tip (note: particles must have greater affinity towards the sample surface than to AFM tip. This will assist in obtaining high resolution images). In this study, we used poly-L-lysine coated glass surfaces (coating 
procedure is listed in Section 4.5.3) for enhancing the particle attachment to the surface and obtaining high resolution images.

\subsubsection{Size characterization using Malvern Zetasizer}

Size of NPs was also measured by dynamic light scattering (DLS) using a Malvern Zetasizer (Malvern Instruments, Worcestershire, UK). All size measurements were conducted at $25^{\circ} \mathrm{C}$ in distilled water. Each sizing measurement was performed in triplicate $(\mathrm{n}=3)$.

\subsubsection{Charge characterization}

Zeta potential was measured again by DLS using the Malvern Zetasizer. All size measurements were conducted at $25^{\circ} \mathrm{C}$ in distilled water. Each charge measurement was performed in triplicate $(\mathrm{n}=3)$.

\subsubsection{Estimation of doxorubicin loading efficiency}

The lyophilized NPs (d-PLGA) were dissolved in dimethly sulfoxide (DMSO) and the fluorescence spectrum of DOX was evaluated using a Fluorolog-3 spectrofluorometer (Horiba Jobin Yvon, Edison, New Jersey). Samples were serially

diluted (1:2, 1:4, 1:8, 1:16, 1:32 dilutions) until linearity in the fluorescence intensity of DOX was achieved. The maximum fluorescence intensities were blank subtracted from DMSO and were fitted to a linear model. The concentration of DOX was estimated from the calibration curve of DOX prepared previously using the same instrument. The percent 
NP yield and the percent drug loading efficiency were calculated using equation (1) and (2).

$$
\begin{aligned}
& \text { Nanoparticle yield } \%=\frac{\text { Mass of nanoparticles recovered }}{\text { Mass of PLGA and DOX used for preparation }} \times 100 \\
& \text { Drug loading } \%=\frac{\text { amount of DOX in nanoparticles }}{\text { amount of nanoparticles obtained by the process }} \times 100
\end{aligned}
$$

\subsubsection{Antibody conjugation efficiency estimation}

Antibody conjugation efficiency was estimated using the method explained by Mo and Lim [83]. $1 \mathrm{mg}$ of lyophilized particles was dissolved in $0.5 \mathrm{ml} \mathrm{DMSO}$ and $1 \mathrm{ml}$ of $0.5 \%(\mathrm{v} / \mathrm{v}) \mathrm{SDS} / \mathrm{NaOH}$. The mixture was incubated for 4 hours. Further, $1 \mathrm{ml}$ of the aforementioned solution (sample) was mixed with $1 \mathrm{ml}$ of Bicinchonic acid working reagent and used for estimating protein content in the lyophilized particles. Briefly, the mixture of the sample and working reagent was incubated at $60^{\circ} \mathrm{C}$ for 60 minutes. The absorbance of this mixture was measured using a Cary spectrophotometer (Varian, Palo Alto, California) at $562 \mathrm{~nm}$. The calibration curve was prepared for a Bovine Serum Albumin standard in concentrations of $0-40 \mu \mathrm{g} / \mathrm{ml}$ in the same proportion of DMSO and salinated SDS. Unconjugated NPs were used as the control. The conjugation efficiency was estimated as micrograms of protein (antibody) per milligram NPs. 


\subsection{Coating the glass coverslips using Fibronectin and Poly-L-Lysine}

\subsubsection{Sterilization of coverslips}

Coverslips were completely submerged in nitric acid solution $(\sim 50 \mathrm{ml})$ for approximately 1 hour. After incubation, nitric acid was quickly removed from the beaker without removing the coverslips. The beaker containing coverslips was placed under

running distilled water for approximately 15 minutes. Once thoroughly rinsed, coverslips were stored in centrifugal tubes containing 95\% ethanol solution under a sterile hood. NOTE: Two $50 \mathrm{ml}$ centrifugal tubes can hold a case of coverslips. Centrifugal tubes containing the coverslips were stored at room temperature and shaken for 30 minutes before use.

\subsubsection{Fibronectin coating}

In a biosafety hood, the sterilized coverslips were transferred into six-well plate one by one from the $50 \mathrm{ml}$ centrifugal tube using sterilized forceps (Note: Proper care was taken to ensure that there were no scratches on the coverslips while placing in the well and only one glass coverslip was placed in the well at a time). The six-well plate containing coverslips was kept under the hood overnight without covering to ensure that the coverslips were completely dry. $100 \mu \mathrm{l}$ of fibronectin solution $(1 \mathrm{mg} / \mathrm{ml}$ in Hanks balanced salt solution) was added to each coverslip and the coverslips were completely covered by the fibronectin solution. 


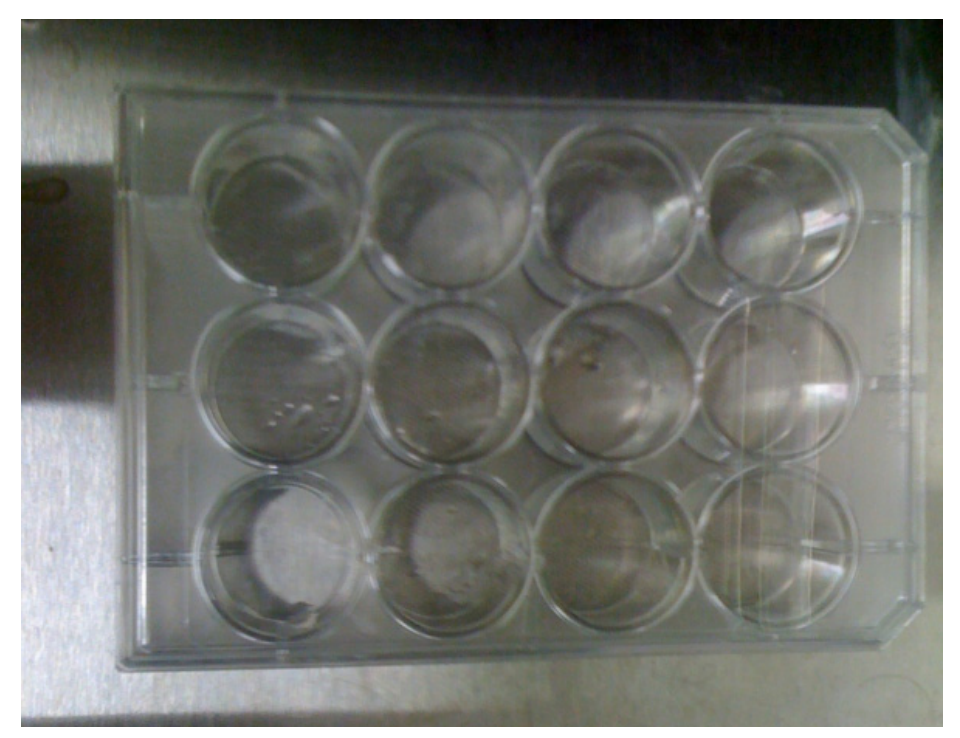

Figure 4: Incubation of coverslips with fibronection solution in a Six-well plate under atmospheric hood at $37^{\circ} \mathrm{C}$

Coverslips were incubated with fibronectin solution at $37^{\circ} \mathrm{C}$ for at least 45 minutes but incubating overnight gave better results (shown in Figure 4). Cells were placed on the coverslips for growth and to enhance primary cell attachment for AFM imaging. Note: Thawing and freezing of diluted fibronectin is not preferred as break down of protein may occur. The coverslips coated with the fibronectin can be stored at $2-8^{\circ} \mathrm{C}$ for $2-4$ weeks in sterile sealable bags.

\subsubsection{Poly-L-Lysine coating}

Preparation of poly-L-lysine solution: $0.1-1 \mathrm{mg}$ of poly-1-lysine (MW of 30,000$70,000)$ must be diluted in $1 \mathrm{ml}$ of borate buffer $(0.15 \mathrm{M}$ and $\mathrm{pH} 8.3) .100 \mu 1$ of poly-1lysine solution must be pooled over the sterile glass coverslip and incubated for $24 \mathrm{hrs}$ at room temperature. Once incubated, the excess solution must be aspirated using 
micropipette and the glass coverslip should be washed using PBS buffer three times. Poly-L-lysine coated coverslips can be stored up to 2 weeks at $4^{\circ} \mathrm{C}$.

\subsection{Cell cultures}

SKOV-3 cell lines were cultured in tissue culture flasks maintained at $37^{\circ} \mathrm{C}$ in a humidified atmosphere with 5\% $\mathrm{CO}_{2}$ (in air). These were grown in McCoy's 5A media with 10\% FBS and 1\% Penicillin-Streptomycin as shown in Figure 5. The cells were grown until they reached confluence and were later treated with trypsinase $(3 \mathrm{ml})$ for about 5 minutes till all of them detached from the surface. Later, McCoy's media (4.5 ml) was added to the flask to neutralize any further effect of trypsin. The neutralized media was subjected to centrifugation for about 4 minutes at 1500 RMP. The pellet was discarded leaving the precipitate inside the centrifugal tubes.

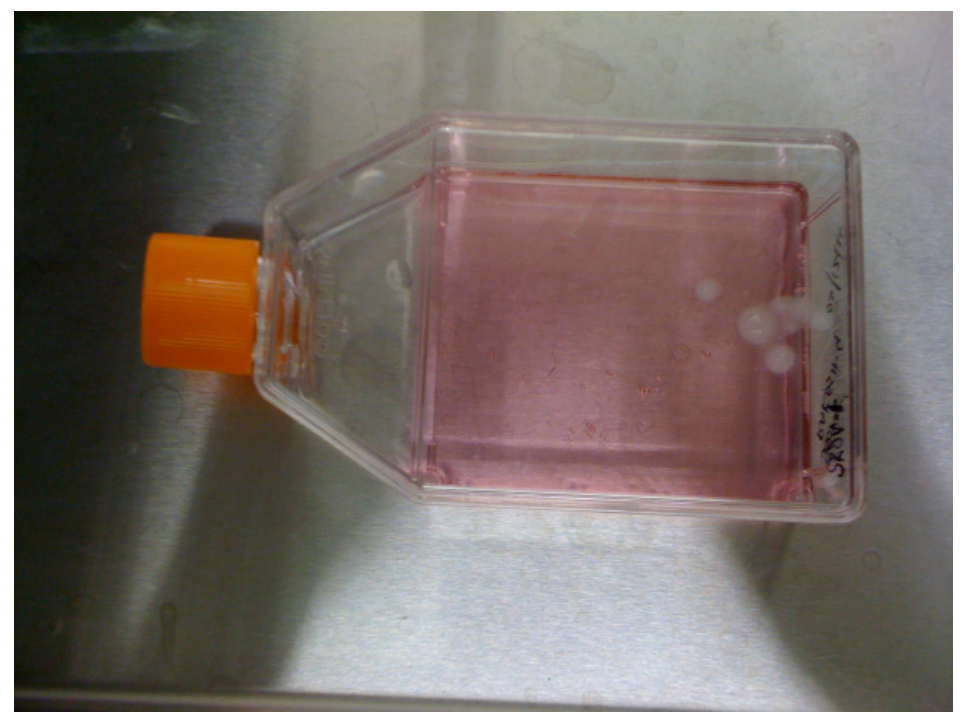

Figure 5: The cell culture flask containing the SKOV-3 cells in Mc'Coys $5 \mathrm{~A}$ media. 
A $6 \mathrm{ml}$ of McCoys 5A media was added to the precipitate and mixed well for proper distribution of cells in the media. The media containing cells was further plated for AFM imaging. The process was repeated several times throughout the experimental analysis.

\subsection{Cell plating for AFM imaging}

A $6 \mathrm{ml}$ solution (from section 4.6) containing the SKOV-3 cells was now distributed equally ( $1 \mathrm{ml}$ in each well) in a six-well plate containing the fibronectin coated glass coverslips. Precautions were taken to ensure that the cells were plated directly on the coverslips. The plated cells were incubated for 1 or 2 days depending upon the cell confluence. Further, treatment of cells was carried out after the cells had reached confluence.

\subsection{Incubation of NPS with SKOV-3 cells}

Once the glass coverslips were fully confluent with SKOV-3 cells in the six-well plate, the media in each well was replaced by $1 \mathrm{ml}$ McCoy's $5 \mathrm{~A}$ media containing desired PLGA particles at $200 \mu \mathrm{g} / \mathrm{ml}$ concentration. The concentration of particles was kept low intending not to saturate the cellular uptake [84]. Cells were incubated with NPs for specific periods of time $(1 \mathrm{hr}, 3 \mathrm{hr}, 6 \mathrm{hr}$, and $24 \mathrm{hr})$ in an incubator. After completing the incubation time, coverslips with SKOV-3 cells and NPs were washed thrice with DPBS buffer to ensure through removal of dead cells and loosely attached NPs. Note: Dead cells and loosely attached particles could possibly interfere with the tip and may hinder the AFM scanning. 


\subsection{AFM instrument and analysis}

Qualitative and quantitative image analysis was performed using Multimode AFM with Nanoscope IIIa controller (Veeco Metrology, CA). Offline image analysis was performed using Nanoscope offline image analysis software version 5.13r1. Glass cover slips with fully confluent SKOV-3 were glued to a magnetic stainless disk and mounted on the AFM stage for imaging. Imaging was performed under tapping mode using a nonconductive, short and narrow silicon nitride $\left(\mathrm{Si}_{3} \mathrm{~N}_{4}\right)$ probes highly recommended for imaging soft samples. Figure 6 shows cantilever ' $\mathrm{C}$ ' for DNPS probe with spring constant $0.32 \mathrm{~N} / \mathrm{m}$ that was used for AFM imaging.

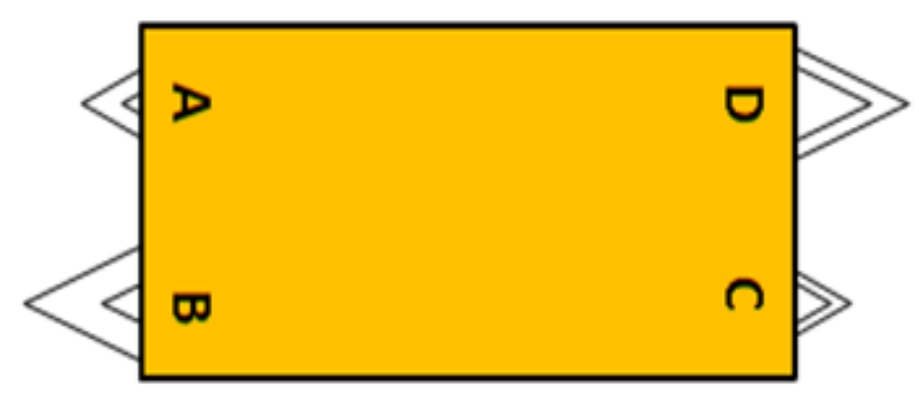

Figure 6: DNPS AFM probe with all four cantilevers.

\subsubsection{AFM liquid cell}

Drying of biological samples is the biggest concern in performing AFM imaging. This problem is not only restricted to AFM but even for other imaging techniques such as SEM, TEM, etc. 


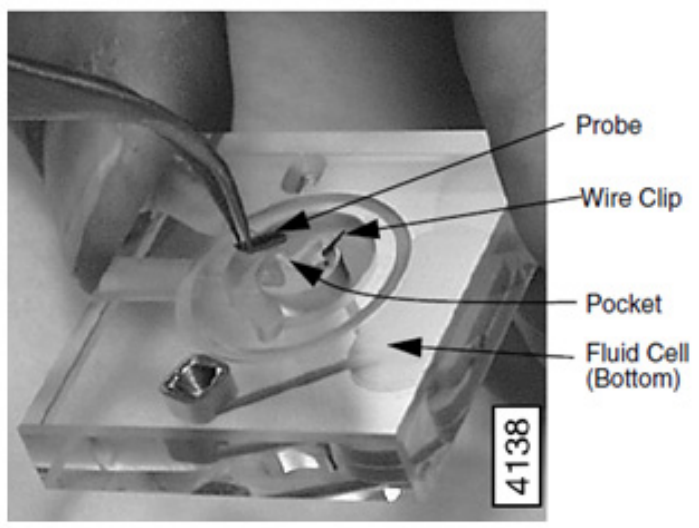

Figure 7: Veeco's specialized fluid cell module designed for multimode AFM [85].

Many techniques have been developed to overcome this effect but most of them are complicated and have poor outcome. With AFM the solution for this problem becomes much simpler by performing AFM imaging in fluid. Performing AFM imaging in tapping mode has proved to give better results than other imaging modes (i.e. contact mode and noncontact) [86]. Imaging biological samples using AFM tapping mode in liquid is growing tremendously with constant improvements in image resolution. The AFM liquid cell consists of a glass piece with a wire clip to hold the AFM probe tip (shown in Figure 7) and the piezo element to create acoustic waves which causes the fluid medium to oscillate the cantilever. The glass piece helps pass the laser without any disturbance through the unstable liquid surface.

\subsubsection{Liquid cell setup}

AFM liquid cell setup is a very crucial step in obtaining a good image. Performing AFM in liquid is more challenging and more difficult compared to AFM in air. Proper precautions must be taken to ensure that there is no spill or leakage of liquid on to the 
scanner. O-ring minimizes the chance of liquid spill or leakage and further helps in containing the sample without evaporation. Steps listed below are recommended for obtaining a good AFM image.

a) An O-ring is installed into the liquid cell glass piece recessed groove. This will ensure that scanner is protected from spillage.

b) Pre-wet the liquid cell before placing into the AFM head. A syringe filled with McCoy's 5A medium is pumped through the ports (on the glass assembly). The syringe must be pumped just enough to flood the liquid cell ports with medium, allowing liquid to ooze from the bottom of the liquid cell. A small portion of liquid is held at the bottom as shown in the Figure 8 . This step gets rid of the air bubbles from the media and allows laser light to pass through the media without causing interference. Note: Presences of air bubbles between the tip and the surface will never engage the AFM to scan the surface.

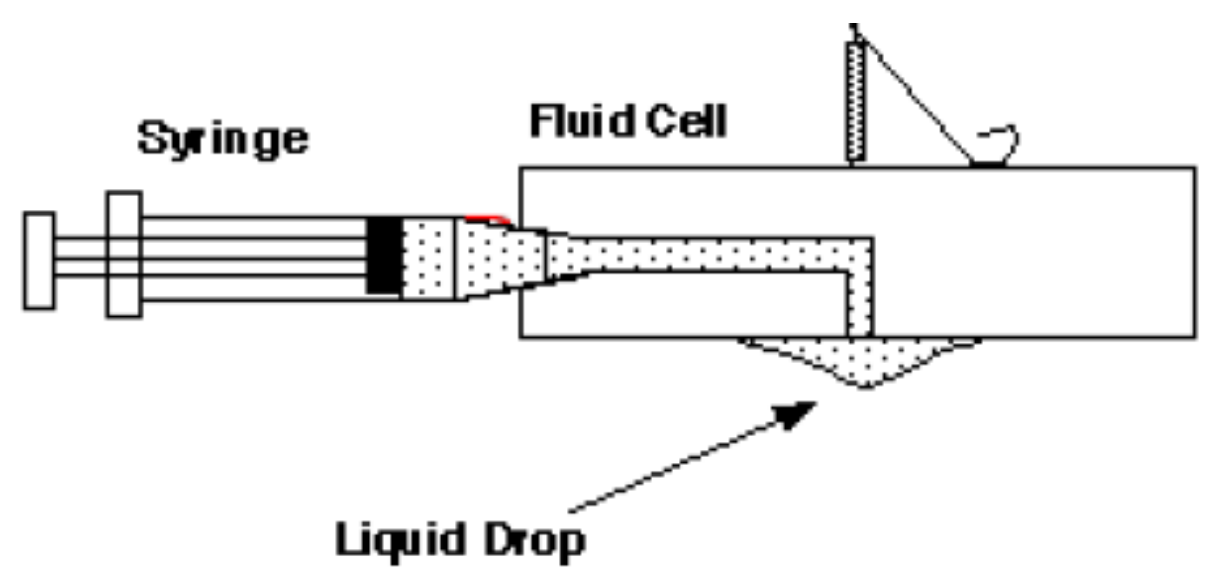

Figure 8: Liquid drop held by the surface tension at the bottom of tip holder[85]. 
c) Place the metallic disc with SKOV-3 cells (from section 4.7) inside the head of AFM.

d) Carefully insert the liquid cell inside the head and lower the cell until it reaches the proximity of sample surface. Adjust the sample surface so that the O-ring is exactly on top of the sample surface. This minimizes the spill of the liquid.

e) Secure the liquid cell to the AFM head and carefully inject the McCoy's medium into the liquid cell $(100 \mu 1)$. Check if there is any spill on the scanner with a filter paper. Small amount of medium is frequently supplied to the SKOV-3 cells to keep them alive. Cells maintained in this fashion will be in a good condition for at least six hours. By supplying $5 \% \mathrm{CO}_{2}$ and by maintaining optimal growth temperature some of the researchers performed AFM analysis for more than 48 hours.

f) Align the laser deflection and engage the AFM to scan and record qualitative and quantitative data. 


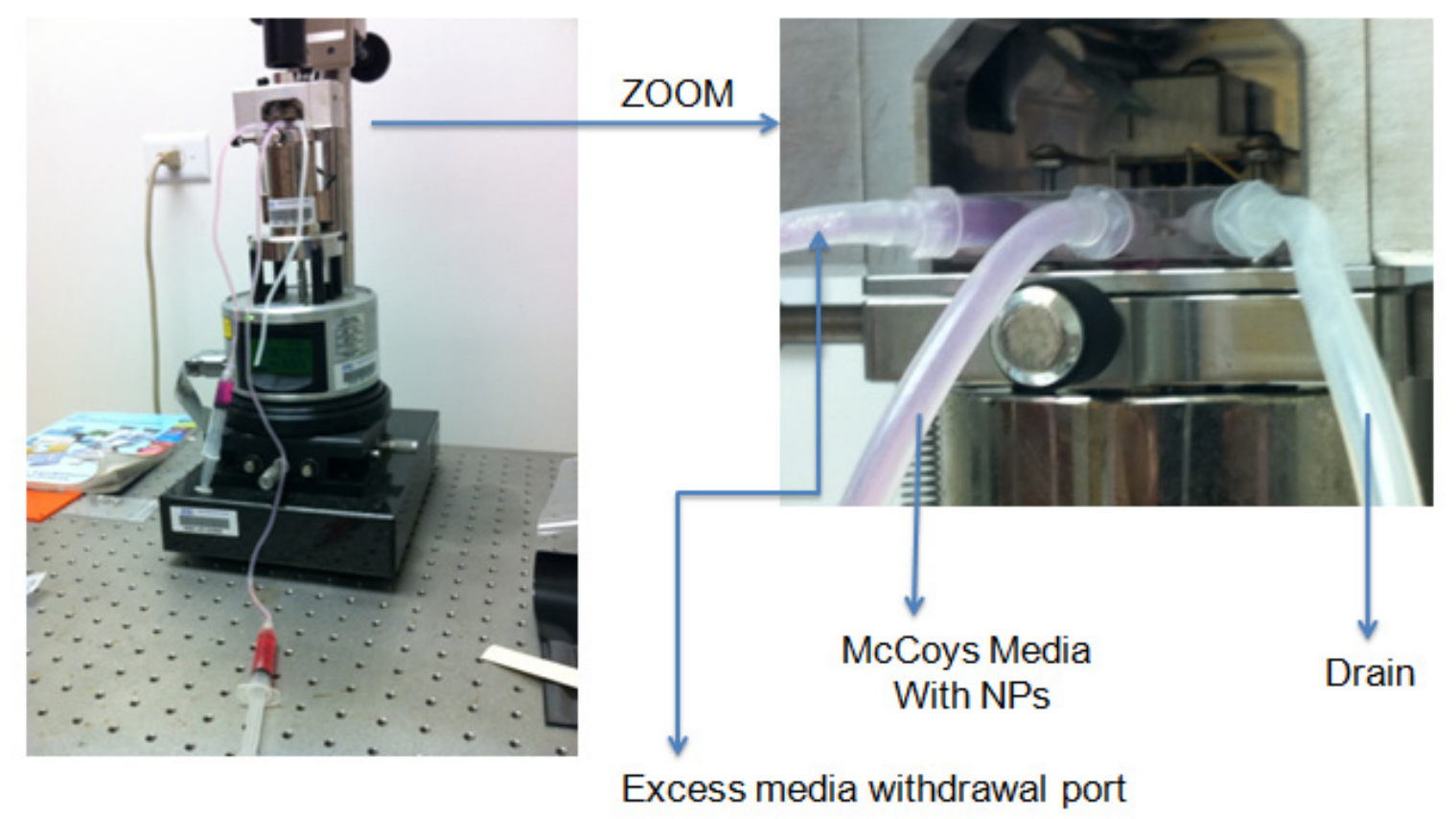

Figure 9: liquid-AFM setup.

\subsubsection{Procedure for AFM imaging in fluids}

AFM was performed under tapping mode in fluid to image the SKOV-3 cells under their native environmental conditions. Performing tapping mode in fluids eliminates lateral forces that could potentially damage the soft and fragile samples. The steps involved in obtaining a high resolution image are listed below:

a) The laser was aligned on the cantilever ' $\mathrm{C}$ ' of DNPS probe; this cantilever gives best results in imaging soft samples in liquid tapping mode.

b) Before engaging the AFM, the scan size of sample was set to $1 \mathrm{~nm}$ to minimize the sample damage and 'sweep control' function was used to tune the cantilever to a resonating peak between 7 to $12 \mathrm{kHz}$. Good results were produced when cantilever frequency was set around $\sim 9 \mathrm{kHz}$. Note: The auto tune function should 
not be used for tuning the cantilever as its resonance is largely damped under liquid. Setting the scan size more than $10 \mathrm{~nm}$ may damage the sample due to very low amplitude engage set point $(\sim 0.0 \mathrm{~V})$.

c) Once the tip was engaged to scan the surface, it's resonating frequency was readjusted to the peak value using 'real time cantilever tuning' function as inter molecular forces change the resonating frequency of the probe.

d) The amplitude setpoint was adjusted. It is one of the key steps in obtaining a high resolution image. This was done by slowly increasing the setpoint until the probe tip retracted from the surface which was also monitored by observing $\mathrm{Z}$ position indicator. At this point, in 'scope-view' window both trace and retrace curves became unstable and widely separated. Once the probe tip retracted from the surface, the setpoint was reduced in small decrements. A stable $\mathrm{Z}$ position was observed and the trace and retrace curves were very close when setpoint value was slightly less than the free amplitude. When the probe was barely tracking the surface, the setpoint was slightly decreased further (5-10\%) in order to apply a perfect loading force to scan the surface sample.

e) Image quality was improved by adjusting the integral gain. The integral gain was increased in small increments until noise was observed in amplitude feedback oscillations. Then a perfect integral gain was set by reducing the integral gain by $10-15 \%$ which significantly reduced the noise and also improved the quality of the image.

Once all the parameters were properly adjusted according to the above listed procedure, DNPS probe tips produced excellent images of soft biological samples in 
liquids. The parameters shown in Table 1 produced best topography and amplitude images of SKOV-3 cells using liquid tapping mode AFM.

Table 1: Typical Parameter Settings for DNPS Probes in Liquid Tapping Mode

\section{Imaging}

\begin{tabular}{|c|c|c|c|}
\hline Parameter & Value & Parameter & Value \\
\hline Scan rate & $0.6(\mu \mathrm{m} / \mathrm{s})$ & Drive frequency & $9.17 \mathrm{kHz}$ \\
\hline Scan size (initial) & $1 \mathrm{~nm}$ & Drive phase & $30.61^{\circ}$ \\
\hline Resolution & 256 & Drive amplitude & $300 \mathrm{mV}$ \\
\hline Integral gain (I) & 0.5 & Free amplitude (RMS) & $0.49 \mathrm{~V}$ \\
\hline $\begin{array}{c}\text { Amplitude } \\
\text { Setpoint }\end{array}$ & $0.478 \mathrm{~V}$ & Proportional gain (P) & 0 \\
\hline
\end{tabular}

\subsubsection{Qualitative analysis using AFM}

To confirm the interaction of NPs with cell membrane visually, we captured a series of images of SKOV-3 cells before and after incubating in NPs solution. Throughout the experiments amplitude and height image data was gathered by capturing a series of $50 \mu \mathrm{m} \times 50 \mu \mathrm{m}$ topographical and amplitude images until SKOV-3 cells were located on a sample surface (glass coverslip) in McCoy's 5A media. Once the cells were located, AFM cantilever was positioned on the cell surface. Two different regions of 5 $\mu \mathrm{m} \times 5 \mu \mathrm{m}$ regions were selected on the cell surface to capture topographical, phase and amplitude images. The acquired topographical, phase and amplitude images are a representation of $256 \times 256$ pixel points, with each pixel point corresponding to the distinct height value, material properties, and surface information of the sample. 
Qualitative visualization of interaction of NPs was determined by comparing the amplitude, phase and topographical image data captured on SKOV-3 cell surface before and after incubating in NPs solution $(\mathrm{t}=1, \mathrm{t}=3, \mathrm{t}=6$ and $\mathrm{t}=24$ hours).

\subsubsection{Amplitude image}

From Section 2.3.3 it is clear that in tapping mode, the height image is generated based on the z-actuator movement which is in turn guided by the feedback signal. The input to the feedback system is the error signal (error signal is the difference between the measured amplitude and the setpoint value) generated while probe is scanning the sample surface. The amplitude image is generated directly from the error signal. This image is simultaneously captured side by side along with the height image. The schematic of amplitude image generation is shown in Figure 10. On soft samples, (such as cells and tissues) the amplitude image often distinguishes the sub-surface features much better than the topography image; whereas on hard samples, the amplitude image just highlights the edges of the sub-surface features. Thus, using amplitude imaging one can clearly distinguish the NPs on the soft biological cells or tissues. 


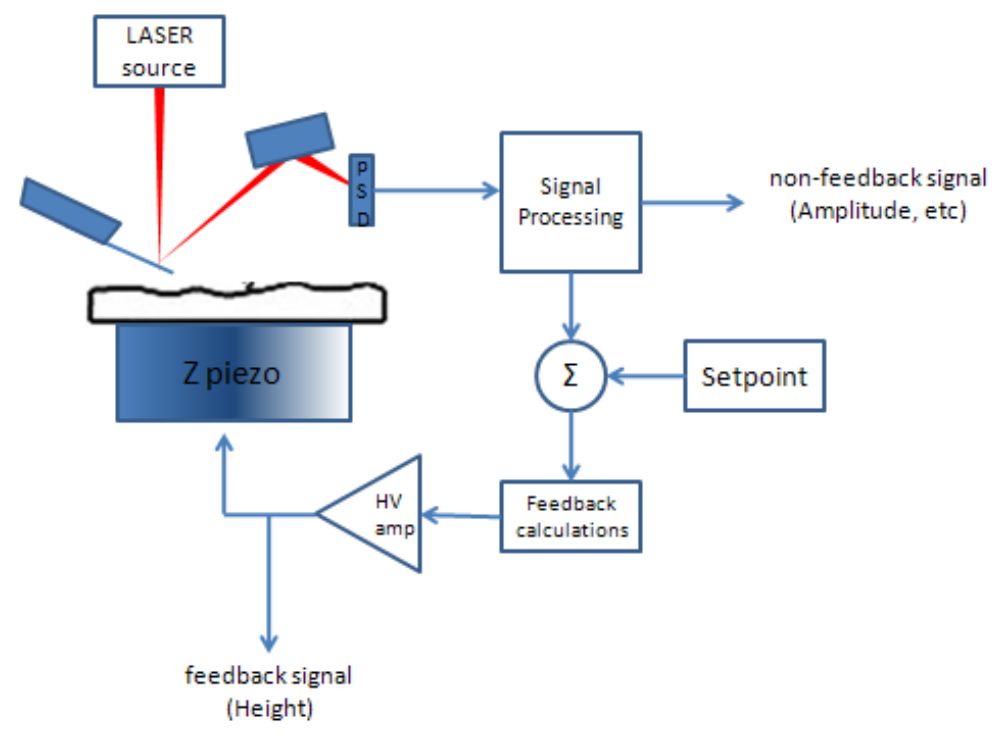

Figure 10: Schematic representation of AFM amplitude image generation.

\subsubsection{Phase image}

Phase imaging is the extension of tapping mode imaging, which provides atomic scale resolution of the sample surface. Phase imaging gives additional information like viscoelasticity, composition, adhesion and frictional properties of the sample rather than topographical image of the sample surface. The applications of phase imaging include differentiating the regions with high and low hardness (elasticity) of the sample surface, identifying contaminants and differentiating components of composite surfaces. The pimage is generated by measuring the phase-lag of cantilever oscillation. When the AFM tip is scanning across the sample surface, variation on sample surface properties such as viscoelasticity and adhesion forces (electrostatic, van der waal's forces, etc) will influence the oscillations of the cantilever, thus changing the phase of oscillation. The 
extender electronics module determines the phase lag by measuring cantilever oscillation relative to the piezo drive.

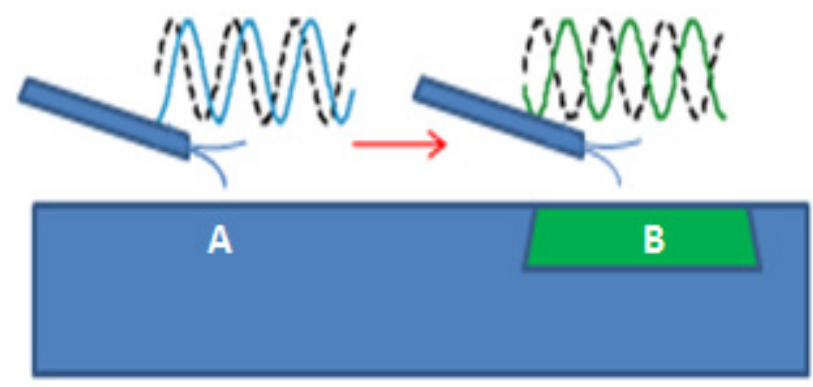

Figure 11: Phase lag created while raster scanning the AFM tip from region A to region $B$ of sample surface.

\subsubsection{Quantitative analysis using AFM}

To confirm the interaction of NPs with the cellular membrane, we also obtained quantitative information of the cell surface by performing offline image analysis. We chose three most suitable surface characterization methods for quantifying AFM image data: 1) average roughness (Ra), 2) PSD and 3) particle analysis, before and after treating the cells with NPs.

\subsubsection{Roughness analysis of cell surface membrane using AFM}

Determining average roughness is the most suitable method for quantifying sample surfaces using topographical images. Roughness values of the cell surface were calculated from the topographical image in an offline mode using Nanoscope Image Analysis software (Version 5.13r1; Veeco Metrology). The roughness value of the 
topographical image was calculated from the statistical mean of the relative height of each pixel. The statistical mean is defined such that an equal number of height pixels lie above and below it. Over a selected region, $\mathrm{R}_{\mathrm{a}}$ (average roughness) values were obtained by taking the average of the absolute values of the perpendicular height deviation $( \pm \mathrm{z})$ from the statistical mean.

$$
\mathbf{R}_{\mathbf{a}}=\frac{1}{\mathrm{~N}} \sum_{\mathbf{j}=1}^{\mathrm{N}}\left|\mathbf{Z}_{\mathrm{j}}\right|
$$

For this equation, $\mathrm{N}$ is the number of scan points and $\mathrm{Z}$ is the vertical distance between the lowest and the highest data points.

\subsubsection{Power spectral density}

Power spectral density of the sample surface is calculated from the height image. Two different surfaces may have same average roughness values because average roughness of a surface is affected by variations in vertical structures and not the horizontal structures $[87,88]$. Average surface roughness is a simple and reliable parameter; but its information is restricted to vertical plane only. Therefore, to fully characterize the surface in both horizontal and vertical plane, power spectral density (PSD) function is used. The PSD function is useful in analyzing amplitude of surface roughness as a function of spatial frequency of the roughness. Spatial frequency is the inverse of the wavelength of the roughness features. The two dimensional power spectral density analysis (2D-PSD) is performed in both $\mathrm{X}$ and $\mathrm{Y}$ direction of the data. It is directly calculated by the Nanoscope software from the AFM image data over the desired scan area. 
The frequency distribution for a digitized profile of length $\mathrm{L}$, consisting of $\mathrm{N}$ points sampled at intervals of $\mathrm{d}_{0}$ is approximated by:

$$
\operatorname{PSD}(f)=\frac{2 d_{0}}{N}\left|\sum_{n=1}^{N} e^{\frac{i 2 \pi}{N}(n-1)(m-1) Z(n)}\right|^{2} \quad \text { for } \quad f=\frac{m-1}{N d_{0}}
$$

where $\mathrm{i}=\sqrt{-1}$, and $\mathrm{f}$ is the frequency range from $\frac{1}{\mathrm{~L}}$ to $\frac{\mathrm{N} / 2}{\mathrm{~L}}$. Practically speaking, the algorithm used to obtain the PSD depends upon squaring the Fast Fourier Transformation of the image to derive the power. Detailed description of PSD calculations can be found in the literature $[89,90]$.

\subsubsection{Particle size analysis on cell surface membrane using AFM}

Particle Analysis defines the particles based on the height of pixel data over a desired scan area. This analysis was designated for analyzing well-isolated particles and gives the histogram of particle size with the standard deviation, which in turn can be useful in identifying the particles based on specific size. 


\section{RESULTS}

In order to determine true hydrodynamic size of NPs in McCoy's media, AFM particle analysis was performed. A surface roughness characteristic of ab-PLGA and bPLGA NPs was also determined by performing roughness measurements on the particle surface. A series of qualitative and quantitative tests were performed in order to determine the dynamic cell membrane interactions of targeted, non-targeted and drug loaded NPs.

\subsection{Characterization of NPS}

NPs were characterized for hydrodynamic size, charge, antibody conjugation efficiency and drug loading efficiency.

\subsubsection{Nanoparticle size characterization}

\subsubsection{Size characterization using AFM}

The mean diameter of the d-PLGA, b-PLGA and ab-PLGA NPs is determined by averaging the particle size measurements performed on three individual particles $(n=3)$ in McCoy's media. From the measurements we determined the average size of d-PLGA, bPLGA and ab-PLGA NPs as $168.1 \mathrm{~nm} \pm 9.6,176.92 \mathrm{~nm} \pm 3.24$ and $231.53 \mathrm{~nm} \pm 5.24$, respectively. It should be noted that the antibody conjugated NPs showed a small increase in diameter (approximately $25 \mathrm{~nm}$ ) compared to bare NPs and this may be due to the conjugation of antibodies on the outer surface of NPs. 


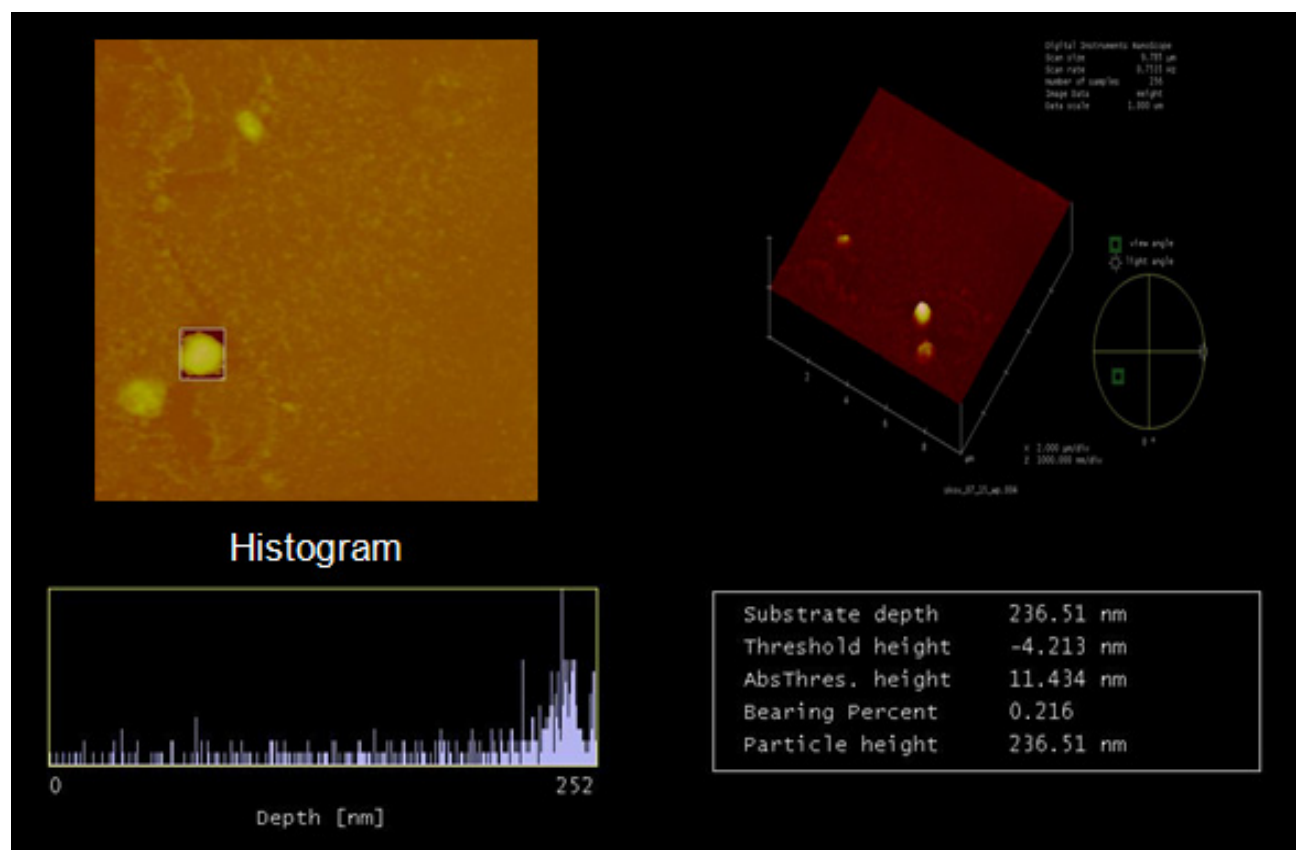

Figure 12: ab-PLGA nanoparticle size characterization using AFM particle analysis.

\subsubsection{Size characterization using Malvern Zetasizer}

The average size measurements were performed triplicates $(n=3)$, were found to be $164.7 \mathrm{~nm} \pm 2.1,167 \mathrm{~nm} \pm 3.0$ and $217.2 \mathrm{~nm} \pm 3.2$ for d-PLGA, b-PLGA and abPLGA respectively. All size measurements were done at $25^{\circ} \mathrm{C}$ in distilled water.

\subsubsection{Charge characterization}

The zeta potential of d-PLGA, b-PLGA and ab-PLGA NPs was found to be -13.2 $\mathrm{mV} \pm 2.3,-14.7 \mathrm{mV} \pm 2.5$ and $-1.2 \mathrm{mV} \pm 2.8$ respectively. It should be noted that the conjugation of antibodies on the outer surface of PLGA NPs resulted in increase in the zeta potential from $-14.7 \mathrm{mV} \pm 2.5$ to $-1.2 \mathrm{mV} \pm 2.8$. The charge of d-PLGA and b-PLGA is almost the same because of the same surface. 


\subsubsection{Estimation of doxorubicin loading efficiency}

The weight/weight $(\mathrm{w} / \mathrm{w})$ doxorubicin loading percentage was estimated as $2.7 \%$ \pm 0.1 using equation (2) (from Section 4.4.3).

\subsubsection{Estimation of antibody conjugation efficiency}

The conjugation efficiency of antibodies with the NPs was determined using the method described in Section 4.4.4. The average efficiency of the antibody conjugated to the NPs was determined as $10.00 \pm 0.66 \mu \mathrm{g}$ per $\mathrm{mg} \mathrm{NP}(\mathrm{n}=3)$.

Table 2: Average Size and Charge, Drug Loading Percentage and Antibody

Conjugation Efficiency of NPs. Note: All the Data Represented as Mean \pm SD

\begin{tabular}{|c|c|c|c|c|}
\hline Formulation & Size $(\mathrm{nm})$ & $\begin{array}{c}\text { Zeta potential } \\
(\mathrm{mV})\end{array}$ & $\begin{array}{c}\text { Drug } \\
\text { loading } \\
(\mathrm{w} / \mathrm{w} \%)\end{array}$ & $\begin{array}{c}\text { Ab- } \\
\text { conjugation } \\
\text { efficiency } \\
(\mu \mathrm{g} / \mathrm{mg} \text { NPs })\end{array}$ \\
\hline $\begin{array}{c}\text { Void NPs } \\
(\mathrm{b}-\text { PLGA) }\end{array}$ & $167.0 \pm 3.0$ & $-14.7 \pm 2.5$ & $\mathrm{~N} / \mathrm{A}$ & $\mathrm{N} / \mathrm{A}$ \\
\hline $\begin{array}{c}\text { Antibody NPs } \\
(\mathrm{ab}-\text { PLGA) }\end{array}$ & $217.2 \pm 3.2$ & $-1.2 \pm 2.8$ & $\mathrm{~N} / \mathrm{A}$ & $10.00 \pm 0.7$ \\
\hline $\begin{array}{c}\text { Dox NPs } \\
(\mathrm{d}-\text { PLGA })\end{array}$ & $164.7 \pm 2.1$ & $-13.2 \pm 2.3$ & $2.7 \pm 0.1$ & N/A \\
\hline
\end{tabular}

Note: NPs were synthesized by Dr. McGoron's staff.

\subsubsection{NPs surface roughness characterization}

AFM surface roughness characterization results show that anti HER2 antibodies conjugated PLGA NP (ab-PLGA) showed average roughness $\left(\mathrm{R}_{\mathrm{a}}\right)$ value $5.240 \mathrm{~nm} \pm 1.87$ $(\mathrm{n}=5)$ which is approximately twice the average roughness value of the b-PLGA NP $\left(\mathrm{R}_{\mathrm{a}}=\right.$ 
$2.718 \pm 0.79$ ) for $n=5$ NPs prepared in one batch. This increase in roughness suggests that the surface of the b-PLGA NPs was successfully covered by the anti HER2 antibodies. The average roughness values of d-PLGA NPs were found to be similar to b-PLGA, indicating that the drug is encapsulated inside the PLGA NPs rather than on the surface. The average surface roughness values of NPs are represented in the Table 3.

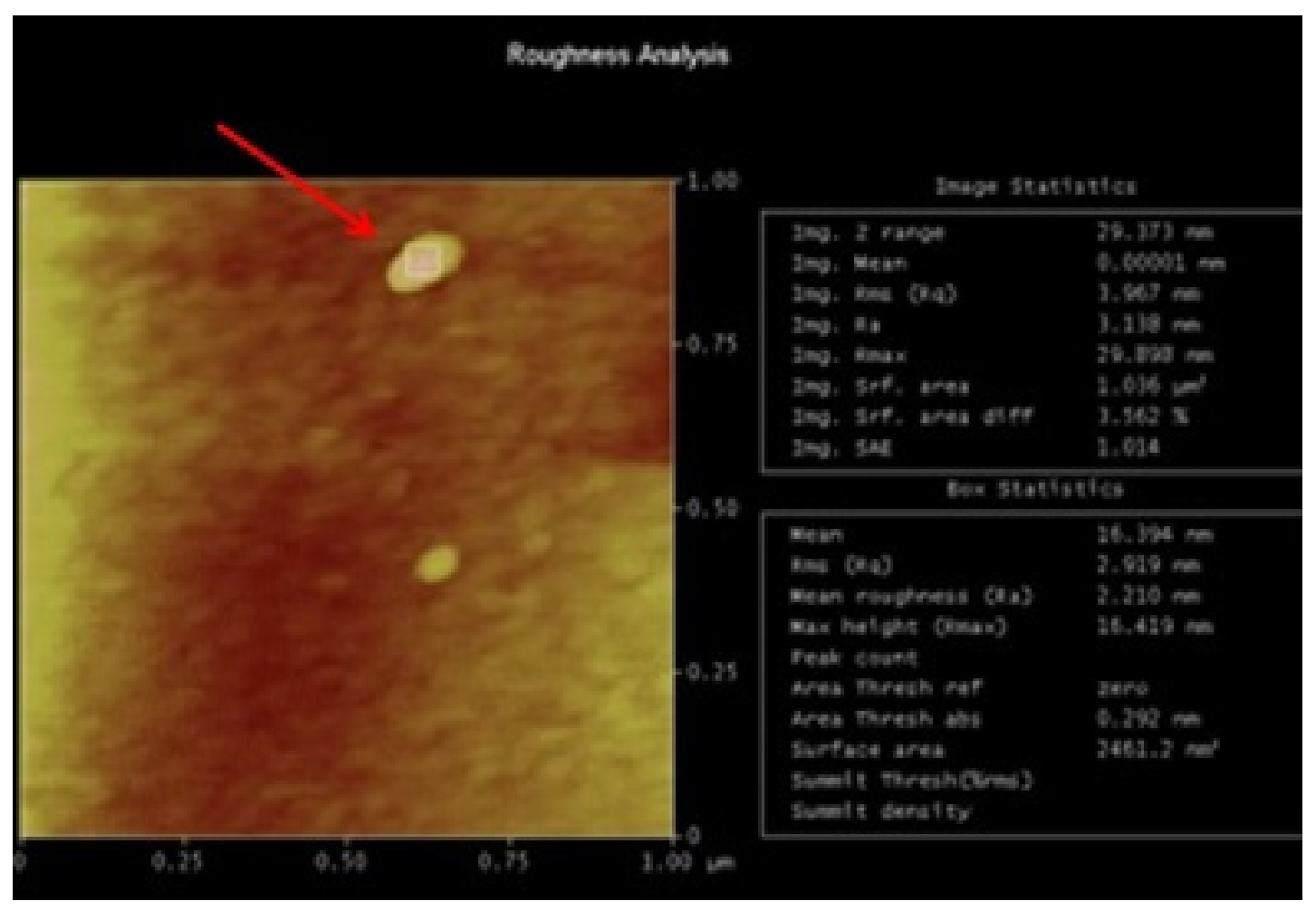

Figure 13: Box statistics roughness analysis of the b-PLGA nanoparticle.

Table 3: The Mean NP Surface Roughness and Standard Deviation

\begin{tabular}{|c|c|c|}
\hline Type of NPs & Mean of $\mathrm{R}_{\mathrm{a}}(\mathrm{nm})$ & $\begin{array}{c}\text { Standard } \\
\text { Deviation }\end{array}$ \\
\hline b-PLGA & 2.718 & 0.79 \\
\hline ab-PLGA & 5.240 & 1.87 \\
\hline d-PLGA & 2.374 & 1.51 \\
\hline
\end{tabular}




\subsection{Qualitative analysis using AFM}

Qualitative visualization of NPs with the cell membrane was evaluated by performing amplitude imaging on the cell surface after treating the cells for specific time period. Phase imaging was performed in order to confirm that the surface height variations were due to the attachment of NPs.

\subsubsection{Phase imaging}

Phase imaging was performed on SKOV-3 cells before and after incubating the cells in NPs solution in order to clearly distinguish the NPs from the cell surface. Height image can only show a height variation on the sample surface but cannot distinguish chemical or physical property variations. The image on the left in Figure 14 clearly shows two different surfaces i.e. one is the glass substrate and the other is the cell surface. As the cell surface is more elastic, the phase image created appears darker (due to less positive phase change) compared to harder samples i.e. glass substrate which appears brighter (confirming more positive phase change). Figure 14 also shows that the cell surface is uniform without any discrepancies (in left image) unlike the image on right where the SKOV-3 cells incubated in b-PLGA NPs solution for six hours shows darker spots (shown by red arrow in the right image) on the cell surface which confirms that the NPs are attached to the cell membrane. A similar trend was also observed when SKOV-3 cells were incubated in ab-PLGA and d-PLGA NPs solution. Note: Phase imaging was done in four trails along with amplitude imaging. 

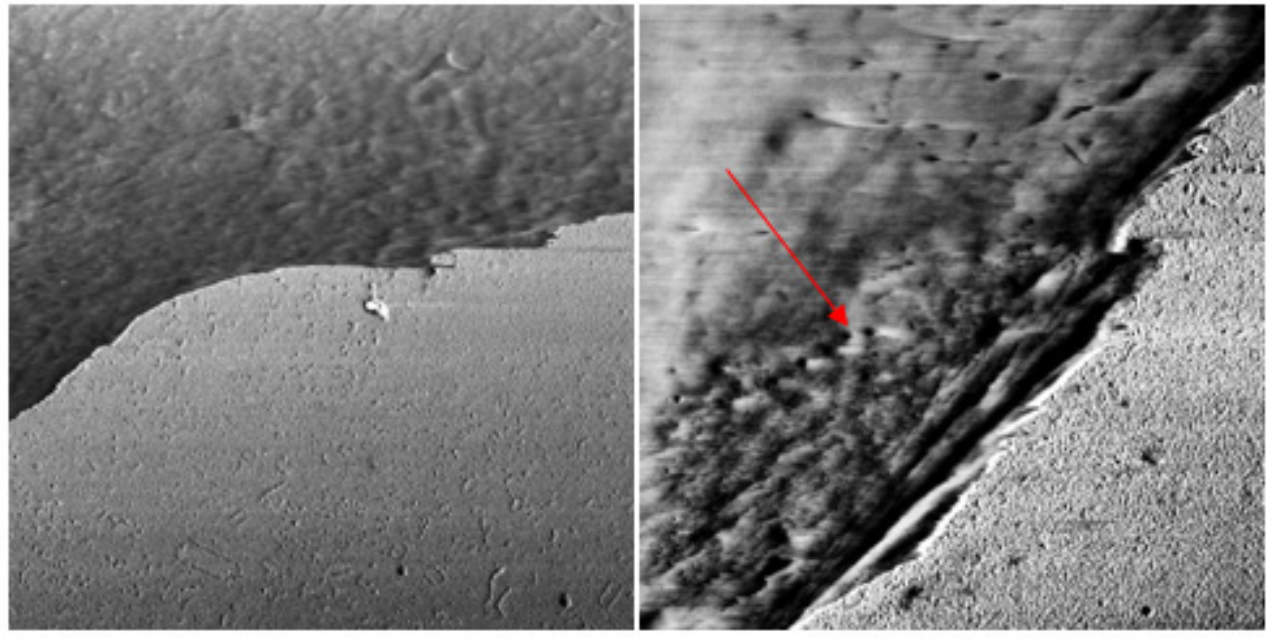

Figure 14: Phase image of untreated SKOV-3 cell surface on left and b-PLGA NPs treated (6 hours) SKOV-3 cell surface on right. Red arrow points the b-PLGA NPs on cell surface.

\subsubsection{Amplitude imaging}

Time lapsed (24 hours) AFM amplitude imaging is performed in order to monitor the dynamic cell membrane changes as a result of interaction of NPs. AFM imaging in liquid allows one to scan the sample surface in native cell conditions and helps in visualizing the interaction phenomenon on the nanometer scale in three dimensions $[91,4,92,93]$. Figure 15 shows a uniform cell surface without NPs in amplitude images obtained on living SKOV-3 cells before incubating them in the NPs solution $(t=0)$. Figure 16 to Figure 23 show the SKOV-3 cell surface membrane with NPs after being incubated in NPs solution (d-PLGA, b-PLGA and ab-PLGA) for four specific incubation times ( $t=1,3,6 \& 24$ hours) obtained using liquid AFM (the procedure for obtaining amplitude images is explained in the Section 4.9.2.1 and the procedure for incubation of NPs with cells is explained in the Section 4.8). Figure 16 clearly demonstrates that the ab-PLGA NPs are attached to SKOV-3 cell membrane after three hours of incubation 
time. This figure also shows that the number of particles that attach on the cell surface was higher as compared to the cells incubated in d-PLGA and b-PLGA for same time period (Figure 17 \& Figure 18 respectively). It is to be noted that the d-PLGA treated cell surface showed wrinkles; this may be due to the toxic effect of DOX. These amplitude images obtained at three hour incubation times indicate the importance of receptor mediated targeted delivery of NPs. Amplitude images obtained at 6 hour incubation showed only a few ab-PLGA NPs on the cell surface (Figure 19) compared to the counter particles (Figure $20 \&$ Figure 21). This indicates that the ab-PLGA NPs were rapidly internalized and thus showed only few particles on the cell surface, whereas cells incubated with d-PLGA and b-PLGA NPs showed the accumulation of NPs on the surface of the cells without being internalized. We also observed that SKOV-3 cells when incubated in the d-PLGA NP solution for 6 hours showed a contracted morphology (Figure 21) and no significant particles on the cell surface (Figure 22); which may be due to the effect of doxorubicin drug on the cell viability (82). The amplitude images obtained at 24 hour incubation period showed one or two particles on the SKOV-3 cell surface after incubating in ab-PLGA NPs solution (Figure 23, right side image) and showed that large number of particles still remained on the cell surface after incubating in b-PLGA NPs solution (Figure 23 left side image). This indicates a complete internalization of ab-PLGA NPs and partial internalization of b-PLGA NPs. NOTE: SKOV-3 cells incubated in d-PLGA solution for 24 hours were not viable to perform AFM studies. This may be due to the toxic effects of drug (doxorubicin) leaching out from the NPs. 

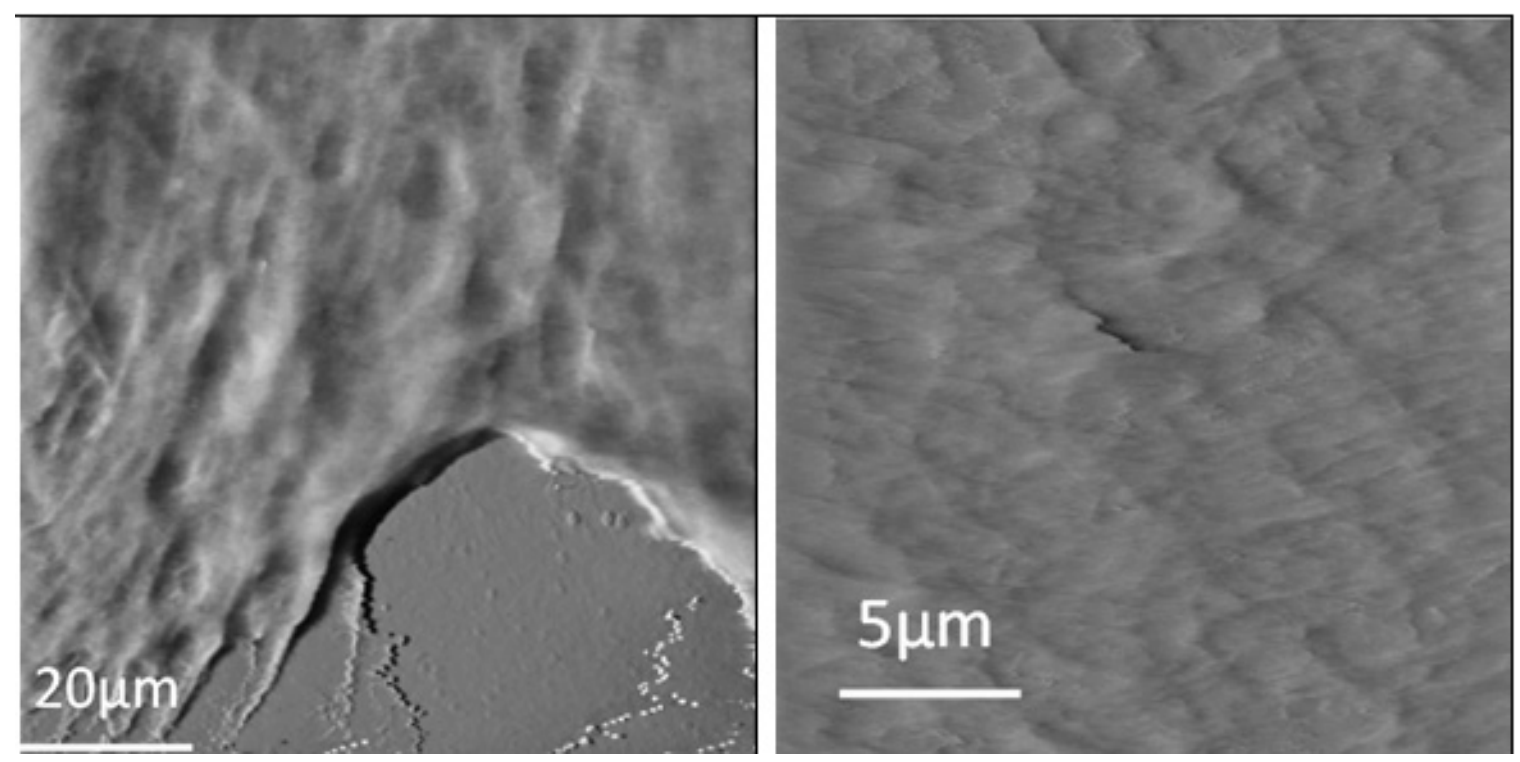

Figure 15: Amplitude image of SKOV-3 cell surface without NPs (incubation time zero). The size of the image on left is $20 \mu \mathrm{m} \times 20 \mu \mathrm{m}$ and on right is $5 \mu \mathrm{m} \times 5 \mu \mathrm{m}$. The above images were taken in data scale $0.3 \mathrm{~V}$ and color table 7 .
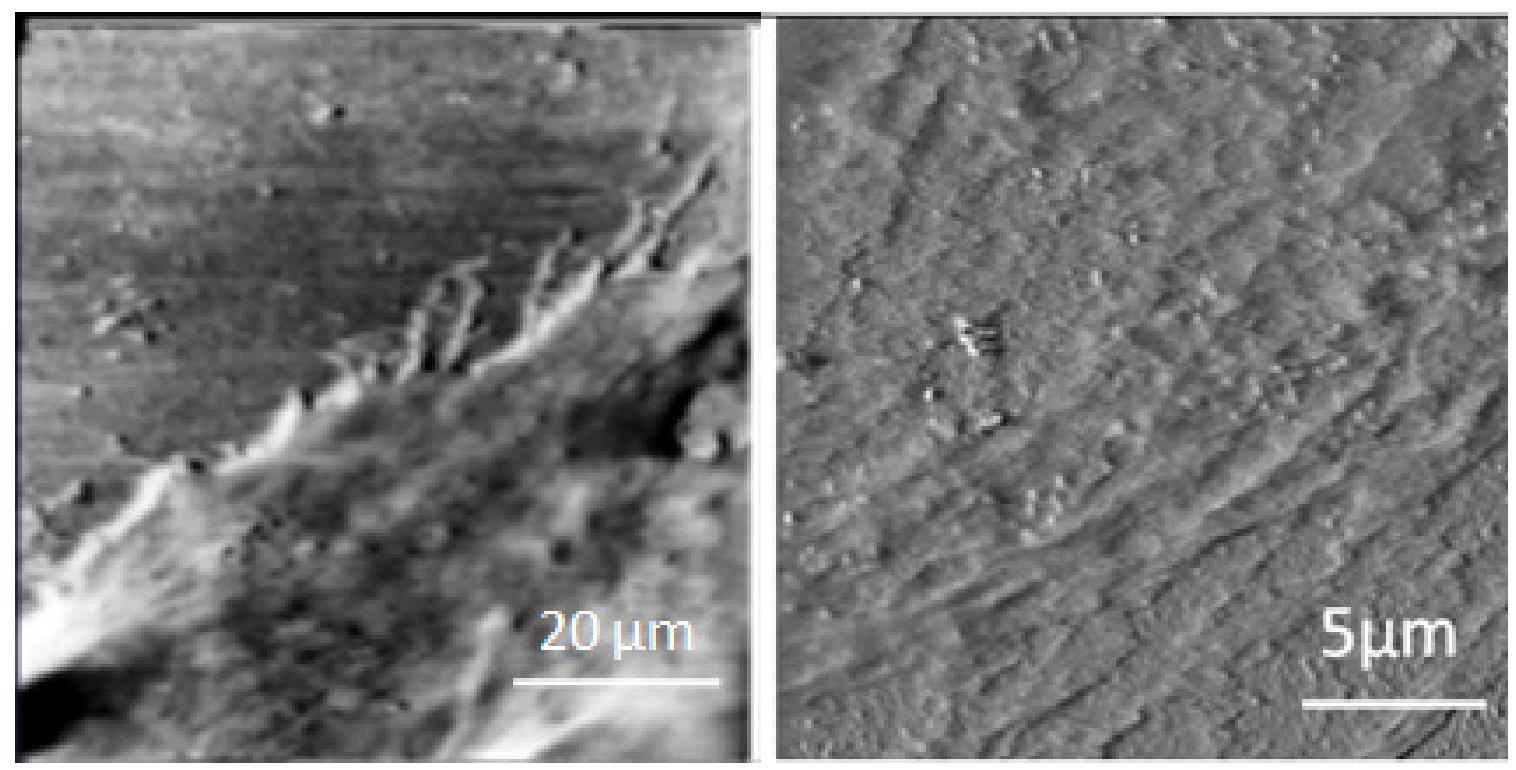

Figure 16: Amplitude image of SKOV-3 cell surface with ab-PLGA NPs (incubation time 3 hours). The size of the image on left is $20 \mu \mathrm{m} \times 20 \mu \mathrm{m}$ and on right is $5 \mu \mathrm{m} \times 5 \mu \mathrm{m}$. The images were taken in data scale $0.3 \mathrm{~V}$ and color table 7 . 

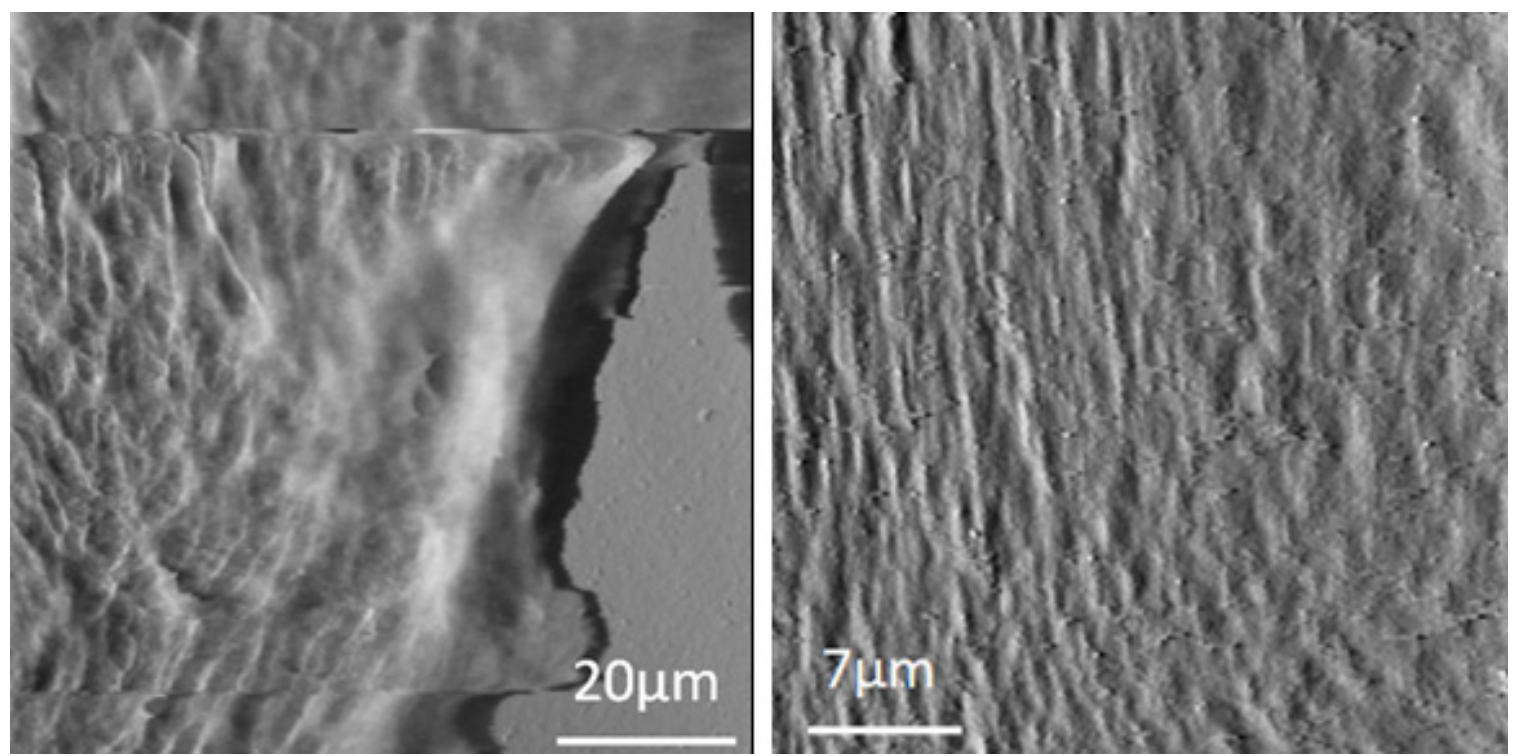

Figure 17: Amplitude image of SKOV-3 cell surface with d-PLGA NPS (incubation time 3 hours). The size of the image on left is $20 \mu \mathrm{m} \times 20 \mu \mathrm{m}$ and on right is $7 \mu \mathrm{m} \times 7 \mu \mathrm{m}$. All the images were taken in data scale $0.3 \mathrm{~V}$. Note: image on right shows that cell surface is wrinkled
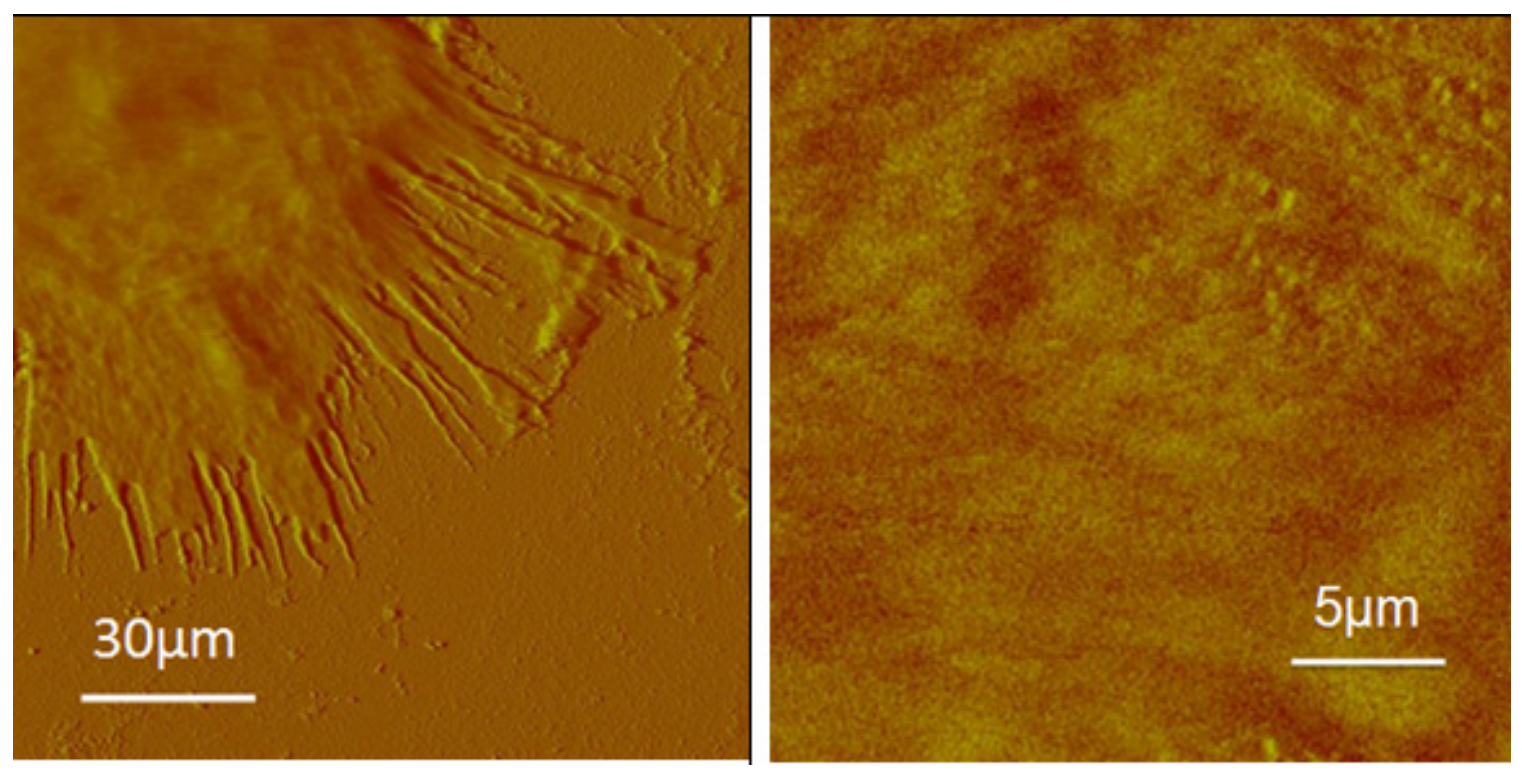

Figure 18: Amplitude image of SKOV-3 cell surface with b-PLGA NPs (incubation time 3 hours). The size of the image on left is $30 \mu \mathrm{m} \times 30 \mu \mathrm{m}$ and on right is $5 \mu \mathrm{m} \times 5 \mu \mathrm{m}$. The above images were taken in data scale $0.3 \mathrm{~V}$ and color table 2. 


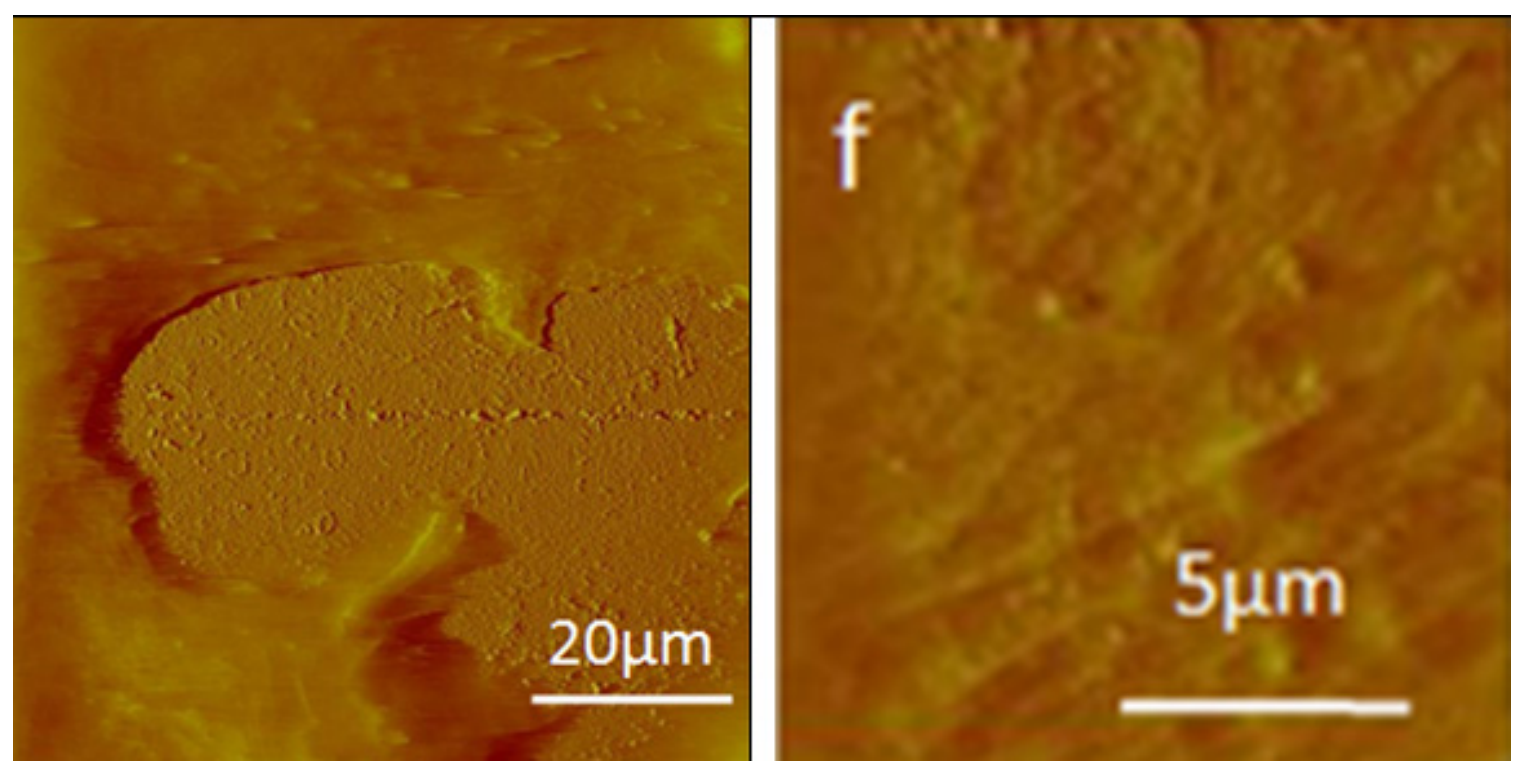

Figure 19: Amplitude image of SKOV-3 cell surface with ab-PLGA NPs (incubation time 6 hours). The size of the image on left is $20 \mu \mathrm{m} \times 20 \mu \mathrm{m}$ and on right is $5 \mu \mathrm{m} \times 5 \mu \mathrm{m}$. The above images were taken in data scale $0.3 \mathrm{~V}$ and color Table 2.

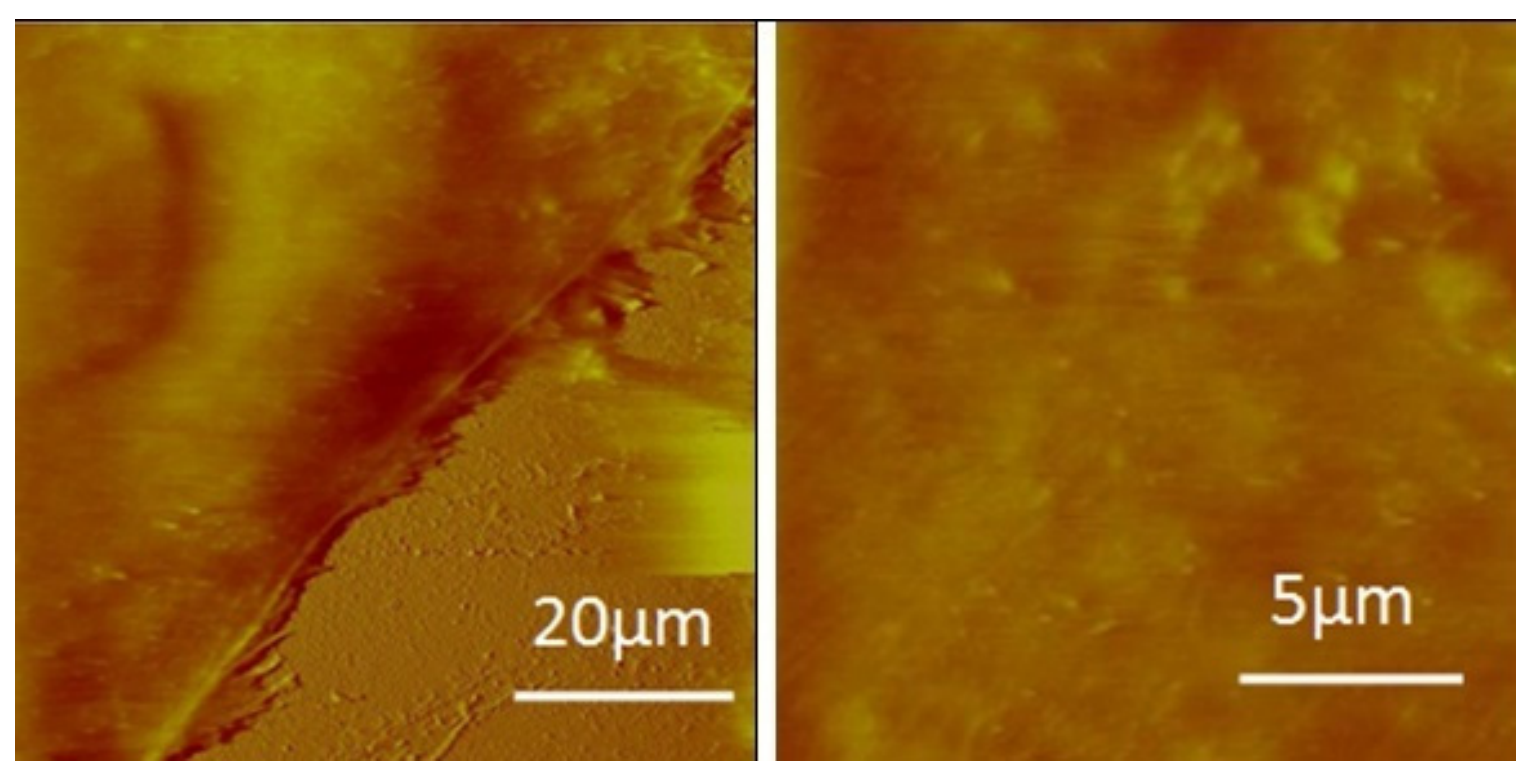

Figure 20: Amplitude image of SKOV-3 cell surface with b-PLGA NPs (incubation time 6 hours). The size of the image on left is $20 \mu \mathrm{m} \times 20 \mu \mathrm{m}$ and on right is $5 \mu \mathrm{m} \times 5 \mu \mathrm{m}$. The above images were taken in data scale $0.3 \mathrm{~V}$ and color Table 2. 

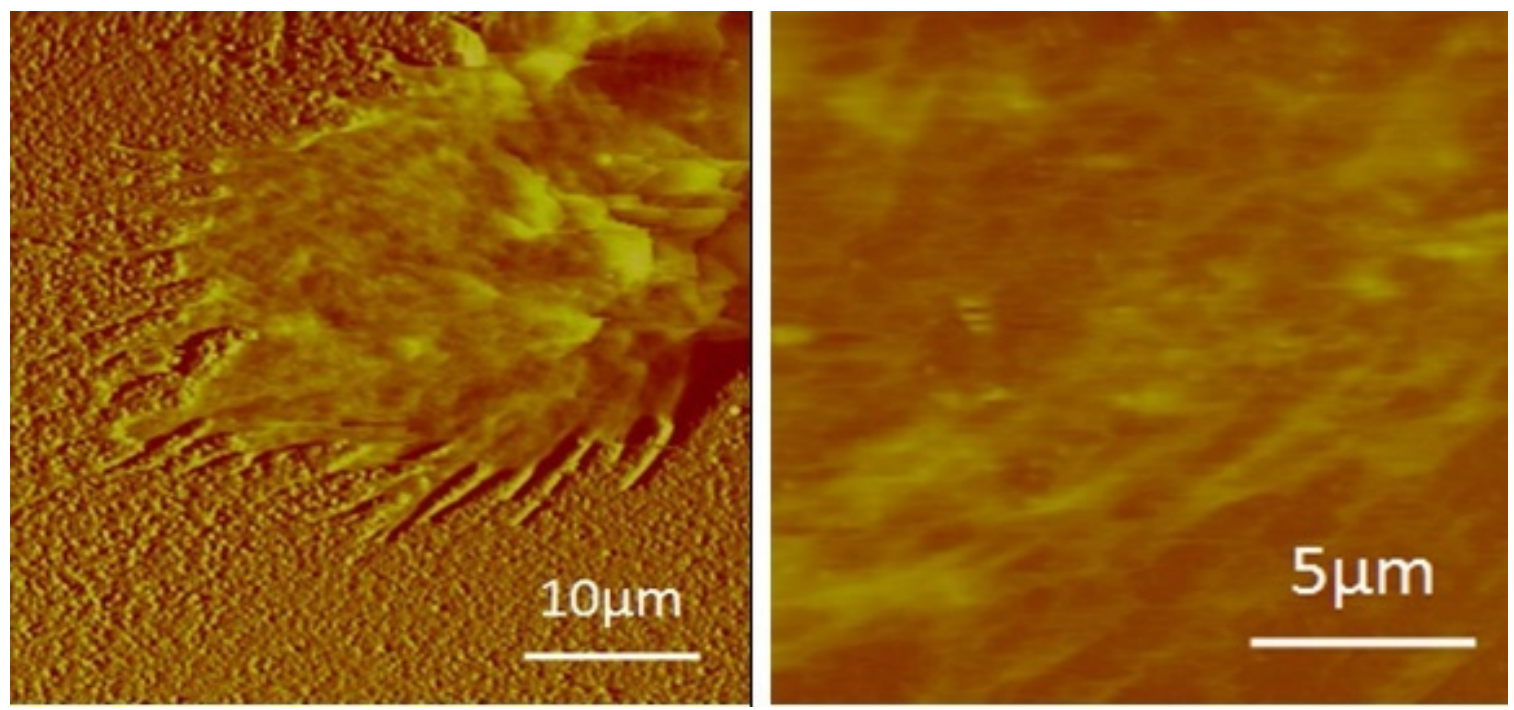

Figure 21: Amplitude image of SKOV-3 cell surface with d-PLGA NPS (incubation time 6 hours). The size of the image on left is $10 \mu \mathrm{m} \times 10 \mu \mathrm{m}$ and on right is $5 \mu \mathrm{m} \times 5 \mu \mathrm{m}$. The above images were taken in data scale $0.3 V$ and color table 2. Note: Cells incubated in d-PLGA NPs solution appeared small and contracted.

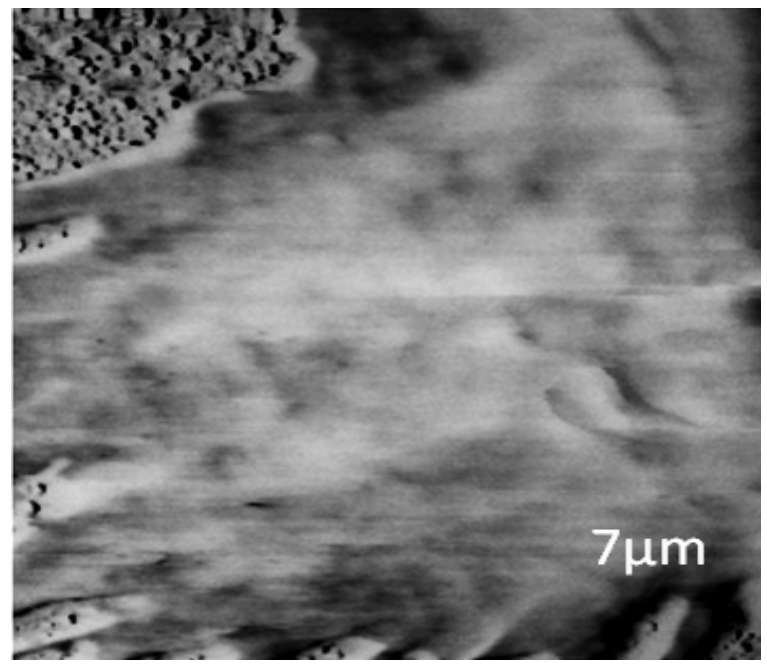

Figure 22: Phase image of SKOV-3 cell surface with d-PLGA NPs (incubation time 6 hours). The size of the image on left is $7 \mu m \times 7 \mu m$. Note: cell membrane surface showing no particles on the surface. 

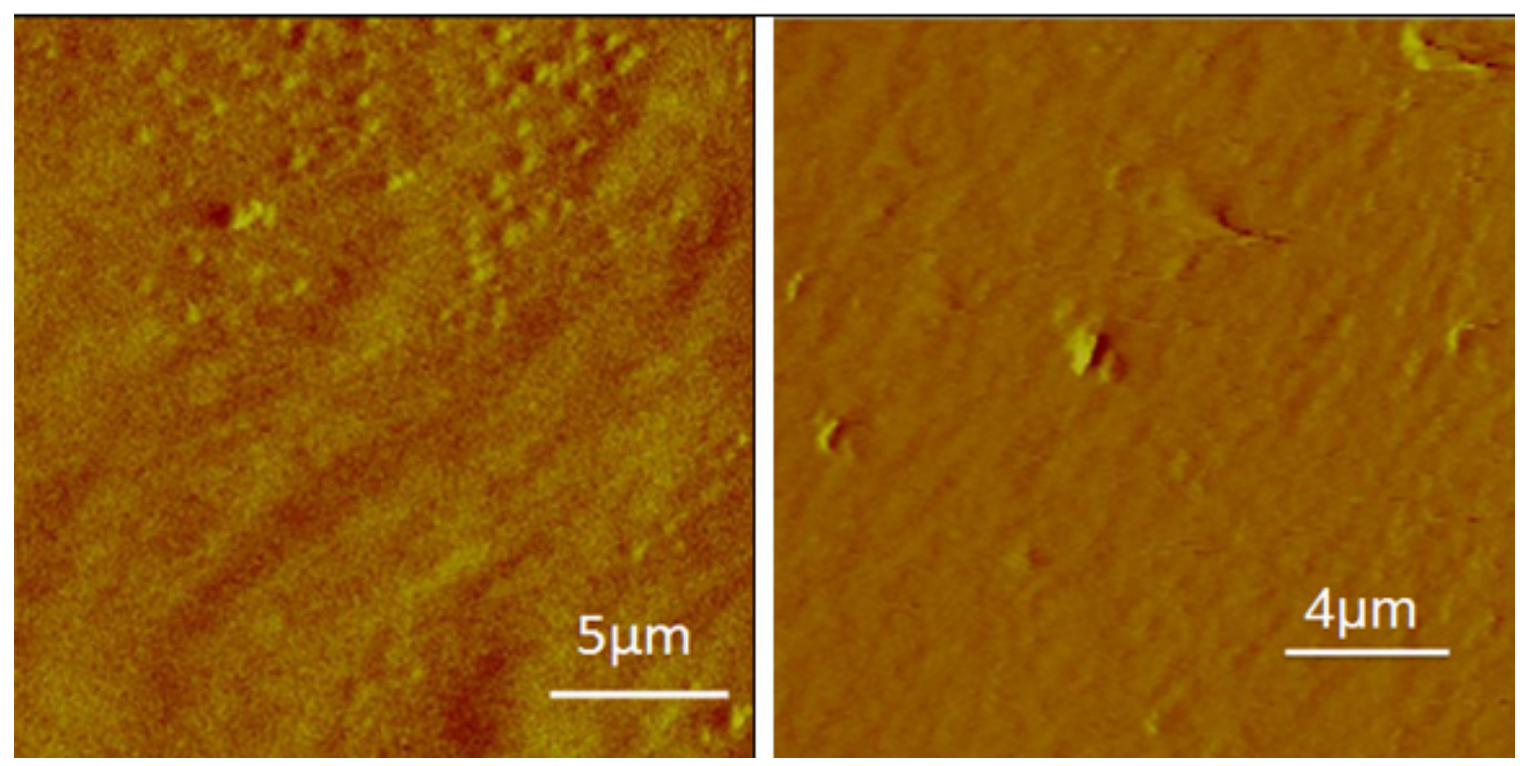

Figure 23: Amplitude image of SKOV-3 cell surface with b-PLGA NPs solution on left and ab-PLGA NPS solution on right (incubation time 24 hours). The size of the image on left and right is $5 \mu \mathrm{m} \times 5 \mu \mathrm{m}$ and $4 \mu \mathrm{m}$

$\times 4 \mu \mathrm{m}$ on right. The above images were taken in data scale $0.3 \mathrm{~V}$ and color table 2. Note: $\mathrm{SKOV-3}$ cells incubated in d-PLGA nanoparticle solution were not alive to perform AFM imaging.

\subsection{Quantitative analysis using AFM}

Quantitative analysis was performed on the cells treated with NPs for specific time periods in order to quantify the interaction of NPs with the cell surface. We used three reliable surface characterization methods to quantify the surface data. These methods include 1) roughness analysis, 2) power spectral density and 3) particle analysis.

\subsubsection{Roughness analysis}

To study the cellular dynamics of the interaction of NPs with the cell membrane, AFM analysis was performed by incubating the SKOV-3 cells with the desired NP solution at a low concentration $(400 \mu \mathrm{g} / \mathrm{ml})$ in order to prohibit saturation of the surface 
of the cell membrane (94). The results from the roughness data showed that the average cell surface roughness $\left(R_{a}\right)$ changes when cells are incubated in NPs solution, and it increases during the attachment of particles and decreases during internalization. The procedure for roughness measurements is clearly explained in Section 4.9.3.1. The $R_{a}$ for cells incubated in a no NPs solution (i.e. $\mathrm{t}=0$ ) is found to be $9.22 \mathrm{~nm} \pm 1.66$ (Table 4). The cell surface showed a higher $\mathrm{Ra}(11.56 \mathrm{~nm} \pm 3.26$ at $1 \mathrm{hr}$ and $19.61 \mathrm{~nm} \pm 3.27$ at 3 hr) for the cells incubated with targeted NPs (ab-PLGA) solution compared to the $\mathrm{R}_{\mathrm{a}}$ of cells incubated in non-targeted (b-PLGA) solution (10.06 $\mathrm{nm} \pm 0.75$ at $1 \mathrm{hr}$ and $\mathrm{R}_{\mathrm{a}} 12.75$ $\mathrm{nm} \pm 2.04$ at $3 \mathrm{hr}$ ) as shown in

Table 5 and Table 6. Cells incubated for 6 hours showed a higher $R_{a}$ when incubated in d-PLGA particle solution compared to b-PLGA particle solution (Table 7).

Cells incubated in the d-PLGA particles solution showed a much higher $R_{a}$ i.e. and $34.95 \mathrm{~nm} \pm 5.48$ (at 6 hours) as compared to other particle solutions (cells incubated in ab-PLGA and b-PLGA). Cells incubated in ab-PLGA particles solution for six or more hours showed a lower $R_{a}$ due to faster internalization and the corresponding amplitude image showed few particles on the cell surface (Figure 23) compared to cells incubated in b-PLGA particles solution. It should be noted that cells were not viable when incubated in the d-PLGA particle solution for a 24 hour incubation period. Fluorescence images of 
SKOV-3 cells showed a higher uptake of the antibody conjugated PLGA particles through over expressed receptors on the cancer cell surface (82). Histogram of roughness values and standard deviation of SKOV-3 cells incubated in NPs solution for different incubation periods is shown in Figure 26. The percentage change in $R_{a}$ of individual SKOV-3 cells treated with NPs when compared to the untreated cells with P-value significance is shown in Table 9.

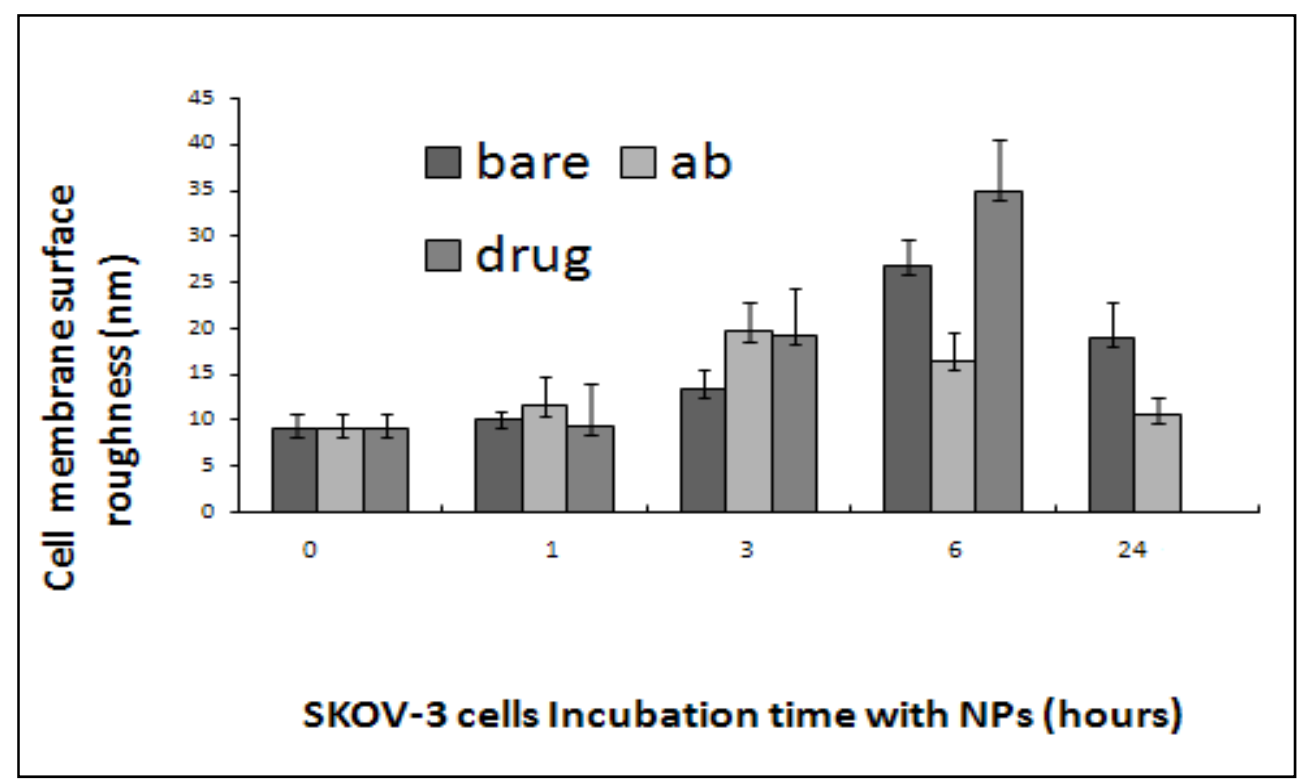

Figure 24: SKOV-3 cell surface average roughness histogram when incubated with $b$-PLGA, ab-PLGA and doxorubicin loaded PLGA plotted against incubation time. Note: cells incubated in the b-PLGA NPS solution for 24 hours were not alive to perform $A$.

Table 4: Surface Roughness Values for SKOV-3 Cells without NP Treatment (incubation $\mathbf{t}=\mathbf{0}$ )

\begin{tabular}{|c|c|c|c|c|c|c|c|c|c|}
\hline \multicolumn{8}{|c|}{ Surface Roughness of SKOV -3 at $\mathrm{t}=0$ hours } & \multirow{3}{*}{ AVG } & \multirow{3}{*}{ SD } \\
\hline \multicolumn{2}{|c|}{ trial 1} & \multicolumn{2}{|c|}{ trial 2} & \multicolumn{2}{|c|}{ trial 3} & \multicolumn{2}{|c|}{ trial 4} & & \\
\hline $\mathrm{R}_{1}$ & $\mathrm{R}_{2}$ & $\mathrm{R}_{1}$ & $\mathrm{R}_{2}$ & $\mathrm{R}_{1}$ & $\mathrm{R}_{2}$ & $\mathrm{R}_{1}$ & $\mathrm{R}_{2}$ & & \\
\hline 7.79 & 9.98 & 10.79 & 12.01 & 8.69 & 8.85 & 6.78 & 8.9 & 9.22 & 1.66 \\
\hline
\end{tabular}


Table 5: Average Surface Roughness Values for SKOV-3 Cells with NPs Treatment (incubation $\mathbf{t}=\mathbf{1}$ hours)

\begin{tabular}{|c|c|c|c|c|c|c|c|c|c|c|}
\hline \multirow{3}{*}{ Type of NPs } & \multicolumn{8}{|c|}{ Surface Roughness of SKOV- 3 at $\mathrm{t}=1$ hours } & \multirow{3}{*}{ AVG } & \multirow{3}{*}{ SD } \\
\hline & \multicolumn{2}{|c|}{ trial 1} & \multicolumn{2}{|c|}{ trial 2} & \multicolumn{2}{|c|}{ trial 3} & \multicolumn{2}{|c|}{ trial 4} & & \\
\hline & $\mathrm{R}_{1}$ & $\mathrm{R}_{2}$ & $\mathrm{R}_{1}$ & $\mathrm{R}_{2}$ & $\mathrm{R}_{1}$ & $\mathrm{R}_{2}$ & $\mathrm{R}_{1}$ & $\mathrm{R}_{2}$ & & \\
\hline ab-PLGA & 16.4 & 9.10 & 12.33 & 13.59 & 8.43 & 15.2 & 8.27 & 9.11 & 11.56 & 3.26 \\
\hline b-PLGA & 10.1 & 10.24 & 9.67 & 11.41 & 10.77 & 9.36 & 9.72 & 9.16 & 10.06 & 0.75 \\
\hline d-PLGA & 7.64 & 8.65 & 9.60 & 7.28 & 10.13 & 9.51 & 13.8 & 9.04 & 9.45 & 4.53 \\
\hline
\end{tabular}

Table 6: Average Surface Roughness Values for SKOV-3 Cells with NPs Treatment (incubation $\mathbf{t}=\mathbf{3}$ hours)

\begin{tabular}{|c|c|c|c|c|c|c|c|c|c|c|}
\hline \multirow{2}{*}{$\begin{array}{c}\text { Type } \\
\text { of NPs }\end{array}$} & \multicolumn{6}{|c|}{ Surface Roughness of SKOV-3 at $\mathrm{t}=3$ hours } & \multirow{3}{*}{ trial 1} & \multicolumn{2}{|c|}{ trial 2} & \multicolumn{2}{c|}{ trial 3} & \multicolumn{2}{|c|}{ trial 4} & \multirow{2}{*}{ AVG } & \multirow{2}{*}{$\mathrm{SD}$} \\
\cline { 2 - 11 } & $\mathrm{R}_{1}$ & $\mathrm{R}_{2}$ & $\mathrm{R}_{1}$ & $\mathrm{R}_{2}$ & $\mathrm{R}_{1}$ & $\mathrm{R}_{2}$ & $\mathrm{R}_{1}$ & $\mathrm{R}_{2}$ & & \\
\hline ab-PLGA & 21.62 & 17.11 & 20.45 & 24.98 & 22.27 & 14.95 & 18.19 & 17.33 & 19.61 & 3.29 \\
\hline b-PLGA & 16.11 & 14.56 & 10.94 & 9.81 & 11.77 & 13.68 & 11.93 & 13.25 & 12.75 & 2.04 \\
\hline d-PLGA & 19.29 & 11.88 & 24.68 & 11.85 & 23.71 & 17.56 & 19.54 & 24.50 & 19.12 & 5.19 \\
\hline
\end{tabular}

Table 7: Average Surface Roughness Values for SKOV-3 Cells with NPs Treatment (incubation $\mathrm{t}=6$ hours)

\begin{tabular}{|c|c|c|c|c|c|c|c|c|c|c|}
\hline \multirow{3}{*}{ Type of NPs } & \multicolumn{8}{|c|}{ Surface Roughness of SKOV-3 at $\mathrm{t}=6$ hours } & \multirow{3}{*}{ AVG } & \multirow{3}{*}{ SD } \\
\hline & \multicolumn{2}{|c|}{ trial 1} & \multicolumn{2}{|c|}{ trial 2} & \multicolumn{2}{|c|}{ trial 3} & \multicolumn{2}{|c|}{ trial 4} & & \\
\hline & $\mathrm{R}_{1}$ & $\mathrm{R}_{2}$ & $\mathrm{R}_{1}$ & $\mathrm{R}_{2}$ & $\mathrm{R}_{1}$ & $\mathrm{R}_{2}$ & $\mathrm{R}_{1}$ & $\mathrm{R}_{2}$ & & \\
\hline ab-PLGA & 14.90 & 17.56 & 12.23 & 19.59 & 13.58 & 14.73 & 18.63 & 20.87 & 16.52 & 3.08 \\
\hline b-PLGA & 22.47 & 26.99 & 26.37 & 29.09 & 26.91 & 22.15 & 28.78 & 31.65 & 26.80 & 3.23 \\
\hline
\end{tabular}




\begin{tabular}{|l|l|l|l|l|l|l|l|l|l|l|}
\hline d-PLGA & 31.56 & 40.89 & 31.21 & 29.45 & 28.44 & 37.62 & 42.90 & 37.58 & 34.95 & 5.48 \\
\hline
\end{tabular}

Table 8: Average Surface Roughness Values for SKOV-3 Cells with NPs Treatment (incubation $\mathbf{t}=\mathbf{2 4}$ hours)

\begin{tabular}{|l|c|c|c|c|c|c|c|c|c|c|}
\hline \multirow{3}{*}{ Type of NPs } & \multicolumn{6}{|c|}{ Surface Roughness of SKOV-3 at $\mathrm{t}=24$ hours } & \multirow{3}{*}{ AVG } & \multirow{2}{*}{$\mathrm{SD}$} \\
\cline { 2 - 11 } & \multicolumn{2}{|c|}{ trial 1} & \multicolumn{2}{c|}{ trial 2} & \multicolumn{2}{c|}{ trial 3} & \multicolumn{2}{|c|}{ trial 4} & \multirow{2}{*}{ AV } \\
\cline { 2 - 11 } & $\mathrm{R}_{1}$ & $\mathrm{R}_{2}$ & $\mathrm{R}_{1}$ & $\mathrm{R}_{2}$ & $\mathrm{R}_{1}$ & $\mathrm{R}_{2}$ & $\mathrm{R}_{1}$ & $\mathrm{R}_{2}$ & & \\
\hline ab-PLGA & 8.95 & 9.18 & 10.09 & 9.21 & 12.21 & 13.52 & 11.39 & 11.36 & 10.74 & 1.65 \\
\hline b-PLGA & 16.62 & 18.5 & 14.23 & 21.48 & 27.34 & 17.54 & 16.35 & 18.99 & 18.88 & 4.02 \\
\hline
\end{tabular}

NOTE: Roughness analysis was performed in four trials choosing one cell at two different regions $\left(\mathrm{R}_{1}\right.$ and $\left.\mathrm{R}_{2}\right)$ under similar experimental condition $(\mathrm{AVG}=$ average and $\mathrm{SD}=$ standard deviation). SKOV-3 cells treated with d-PLGA particles solution were not viable to perform roughness analysis.

Table 9: Percentage Change in Roughness Values of SKOV-3 Cells Before and After Incubating in NPs Solution and Their Corresponding P-value Significance (compared with untreated cells) is calculated From Student's t-test.

\begin{tabular}{|c|c|c|c|c|c|c|c|c|}
\hline \multirow{2}{*}{$\begin{array}{c}\text { Type of } \\
\text { NPs }\end{array}$} & \multicolumn{2}{|c|}{$\mathrm{t}=1$ hour } & \multicolumn{2}{c|}{$\mathrm{t}=3$ hour } & \multicolumn{2}{c|}{$\mathrm{t}=6$ hour } & \multicolumn{2}{c|}{$\mathrm{t}=24$ hour } \\
\cline { 2 - 9 } & $\begin{array}{c}\mathrm{R}_{\mathrm{a}} \\
\text { change } \\
(\%)\end{array}$ & $\begin{array}{c}\mathrm{P}- \\
\text { value }\end{array}$ & $\begin{array}{c}\mathrm{R}_{\mathrm{a}} \\
\text { change } \\
(\%)\end{array}$ & $\begin{array}{c}\mathrm{P}- \\
\text { value }\end{array}$ & $\begin{array}{c}\mathrm{R}_{\mathrm{a}} \\
\text { change } \\
(\%)\end{array}$ & P-value & $\begin{array}{c}\mathrm{R}_{\mathrm{a}} \\
\text { change } \\
(\%)\end{array}$ & $\begin{array}{c}\text { P- } \\
\text { value }\end{array}$ \\
\hline ab-PLGA & 25.37 & 0.091 & 112.68 & $<0.001$ & 79.26 & 0.001 & 16.48 & 0.165 \\
\hline b-PLGA & 9.11 & 0.151 & 38.28 & 0.018 & 158.13 & $<0.001$ & 99.06 & $<0.001$ \\
\hline d-PLGA & 2.49 & 0.848 & 107.37 & 0.002 & 279.06 & $<0.001$ & NA & NA \\
\hline
\end{tabular}




\subsubsection{Time based 2D power spectral density}

Besides the roughness measurements, two dimensional power spectral density (2D-PSD) calculations were performed on a part of SKOV-3 cells $(7 \mu \mathrm{m} \times 7 \mu \mathrm{m})$ treated with b-PLGA, ab-PLGA, and d-PLGA NPs. The total power is calculated from individual amplitude image and tabulated in (Table 10). The results indicate that the SKOV-3 cells treated with b-PLGA NPs showed approximately four fold and fifteen fold increase in total power i.e. from 1.06e-004 $(t=0$ hour) (Figure 26) to $16.13 \mathrm{e}-004(t=6$ hours) respectively. This indicates that b-PLGA NPs are accumulated on the surface of the cell before being significantly internalized. The total power at 24 hour incubation is approximately six times (68.5e-004) indicating inefficient internalization of b-PLGA NPs through the SKOV-3 cell membrane.

Total power of SKOV-3 cells treated with ab-PLGA NPs was approximately eightfold in three hours incubation indicating that more number of ab-PLGA NPs attached to the cell surface than the b-PLGA NPs. Incubating cells further (for 6 hours, in ab-PLGA NPs solution) showed only a $19 \%$ increase in total power which may be either due to the insignificant attachment of NPs or due to the efficient internalization of NPs. Total power of SKOV-3 cells incubated in the d-PLGA NPs solution for 3 hours and 6 hours showed $28.54 \mathrm{e}-0004 \mathrm{~nm}^{2}$ and $2430 \mathrm{e}-0004 \mathrm{~nm}^{2}$ (Figure 27) respectively which is very high; this indicates that the surface of the cells is completely changed. Note that SKOV-3 cells incubated in the d-PLGA NPs solution for 24 hours were not alive to conduct AFM analysis. Power spectral density trend with respect to the incubation time is shown in the Figure 25. 


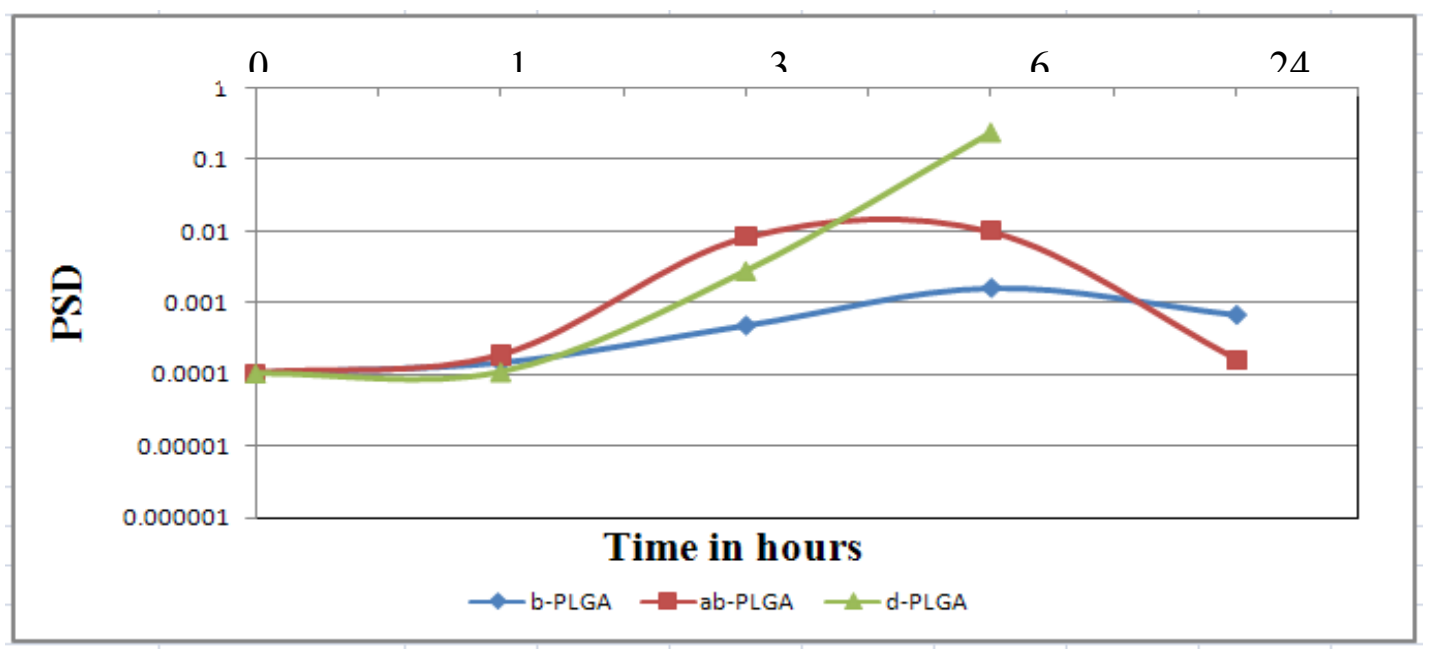

Figure 25: Change in power spectral density of SKOV-3 cells without $(t=0)$ and with NPs with respect to time.

Table 10: Total Power of SKOV-3 Cell Surface at Various Incubation Time Periods

\begin{tabular}{|c|c|c|c|}
\hline \multirow{2}{*}{$\begin{array}{c}\text { Incubation } \\
\text { Time }(\mathrm{t})\end{array}$} & \multicolumn{3}{|c|}{ Total Power } \\
\cline { 2 - 4 } & b-PLGA & ab-PLGA & d-PLGA \\
\hline 0 & $0.000106 \mathrm{~nm}^{2}$ & $0.000106 \mathrm{~nm}^{2}$ & $0.000106 \mathrm{~nm}^{2}$ \\
\hline 1 & $0.000148 \mathrm{~nm}^{2}$ & $0.000189 \mathrm{~nm}^{2}$ & $0.000111 \mathrm{~nm}^{2}$ \\
\hline 3 & $0.000487 \mathrm{~nm}^{2}$ & $0.00827 \mathrm{~nm}^{2}$ & $0.002854 \mathrm{~nm}^{2}$ \\
\hline 6 & $0.001613 \mathrm{~nm}^{2}$ & $0.00989 \mathrm{~nm}^{2}$ & $0.243 \mathrm{~nm}^{2}$ \\
\hline 24 & $0.000685 \mathrm{~nm}^{2}$ & $0.000163 \mathrm{~nm}^{2}$ & N/A \\
\hline
\end{tabular}

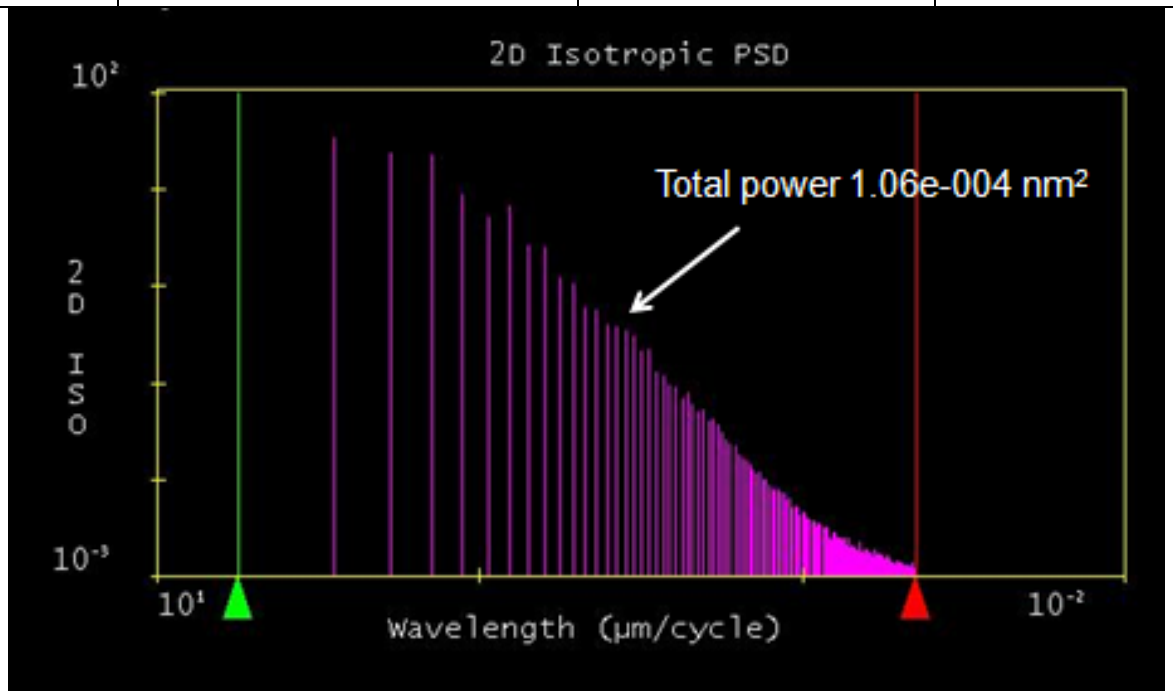

Figure 26: 2D PSD on entire scanned area of SKOV-3 cell without any NPs (incubation $t=0$ ). Note: PSD is plotted on $X$-axis (scale $10^{-3}$ to $10^{2}$ ) Vs wavelength on Y-axis (scale 10 to $10^{-2}$ ). 


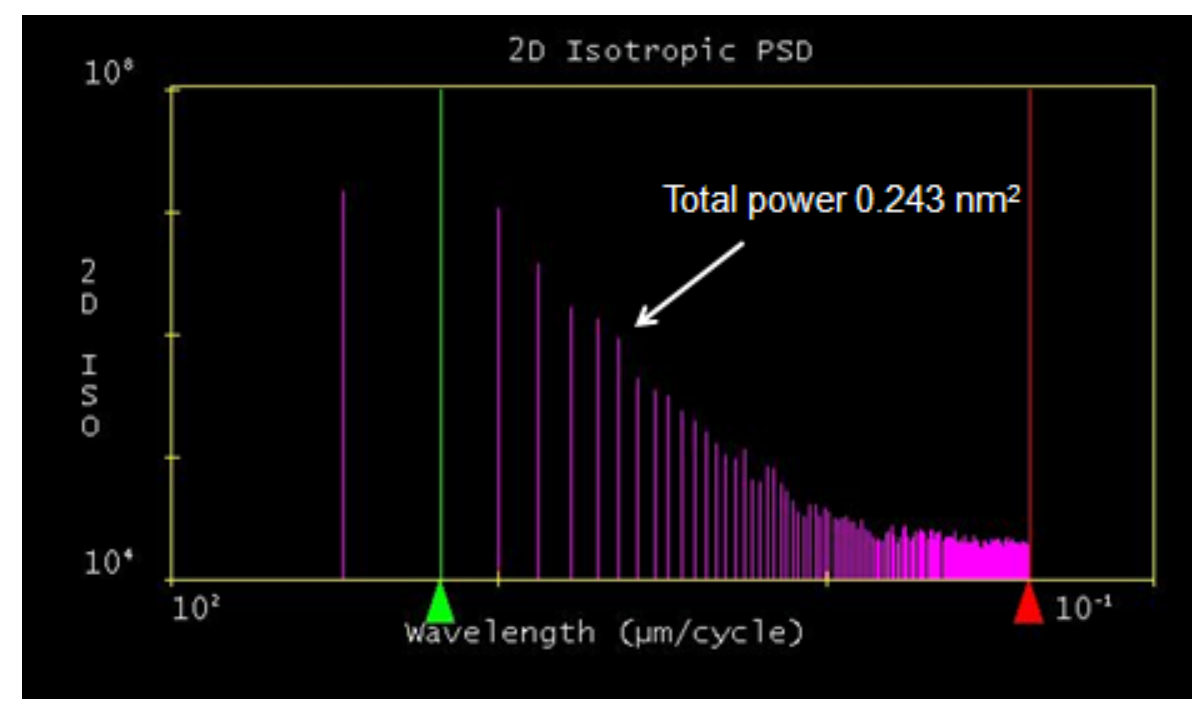

Figure 27: 2D PSD on entire scanned area of SKOV-3 cell incubated in d-PLGA NPs solution (incubation $t=6$ hours). Note: PSD is plotted on $X$-axis (scale $10^{4}$ to $10^{8}$ ) Vs wavelength on Y-axis (scale $10^{2}$ to $10^{-1}$ ).

\subsubsection{Particle analysis}

Particle analysis was performed on the height images obtained on five SKOV-3 cells incubated in NPs solution at four different incubation periods $(t=1, t=3, t=6$ and $t=24$ hours) to determine the dynamic change in the particle height throughout the internalization process. Amplitude images obtained on cells incubated for 1 hour in NPs solutions showed that only ab-PLGA NPs attach to the surface (cells incubated in bPLGA and d-PLGA particles solution did not show any particles on the surface), thus particle analysis was performed only on cells showing ab-PLGA NPs. From the analysis we determined that the size of ab-PLGA NPs on the cell surface is $154.4 \mathrm{~nm} \pm 21.01$ (Table 11). Our results indicate that the average size of b-PLGA, ab-PLGA and d-PLGA NPs on the SKOV-3 cell surface after 3 hours of incubation was determined as 138.24 $\mathrm{nm} \pm 7.39,112.46 \mathrm{~nm} \pm 30.88$, and $133.22 \mathrm{~nm} \pm 20.59$ (Table 12). After incubating 
further, (6 hours) the height of the ab-PLGA NPs on the surface of the cell was reduced to $57.44 \mathrm{~nm} \pm 13.03$ whereas that of b-PLGA and d-PLGA did not change significantly for more than six hours (Table 13).Particle analysis performed on NPs on the surface of SKOV-3 cells after 24 hour incubation showed the size of the NPs as $71.39 \mathrm{~nm} \pm 35.34$ whereas SKOV-3 cells incubated for 24 hours in ab-PLGA NPs solution showed no particles on the surface of the cell (Table 10). Hence, particle analysis was not performed. A similar trend was also observed in time based average surface roughness. Figure 28 \& Figure 29 show a typical particle analysis performed on SKOV-3 cells surface incubated in d-PLGA NPs solution for 3 hours and b-PLGA NPs for 24 hours, respectively. The particle height variation throughout the internalization process is shown in Figure 30. Note: Particle analysis was also not performed on SKOV-3 cells incubated in d-PLGA NPs solution for 24 hours as cells were not viable.

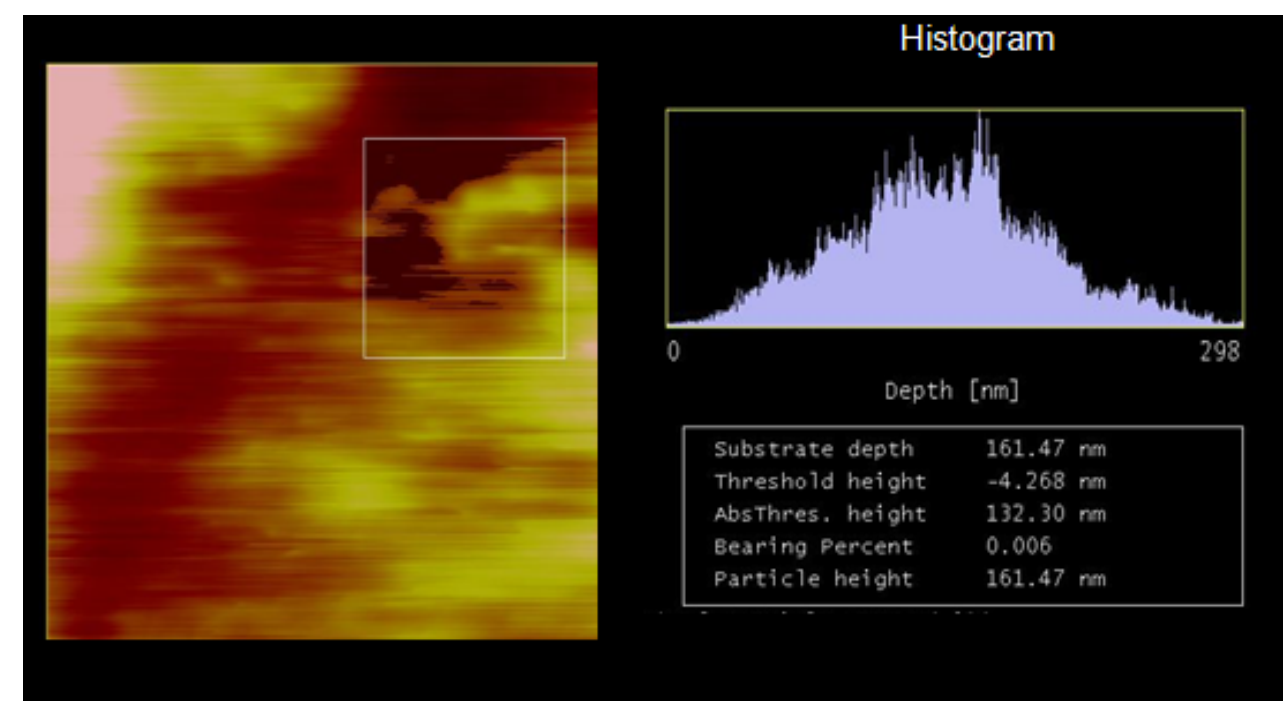

Figure 28: Particle analysis performed on SKOV-3 cells incubated in d-PLGA nanoparticle solution for 3 hour. Size of the image is $1 \mu \mathrm{m} \times 1 \mu \mathrm{m}$. Note: the particle analysis region was selected based on the corresponding phase contrast image. 


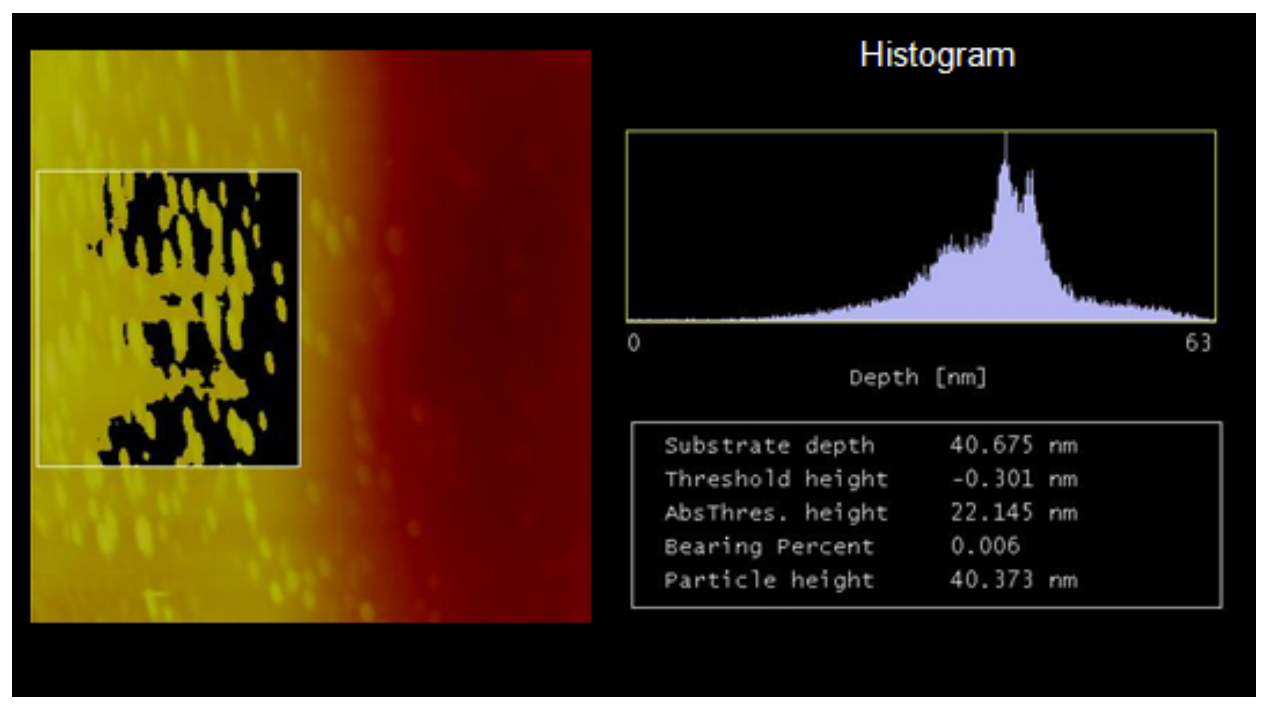

Figure 29: Particle analysis performed on SKOV-3 cells incubated in b-PLGA nanoparticle solution for 24 hour. Note that the particle height of d-PLGA nanoparticle on the cell surface is around 40.37nm.

Table 11: NPs height Obtained Using Particle Analysis Performed on SKOV-3 Cells after 1 Hour Incubation Time (Note: particle analysis)

\begin{tabular}{|c|c|c|c|c|c|c|c|}
\hline \multirow{2}{*}{ Type of particles } & \multicolumn{5}{|c|}{ NPs height in $\mathrm{nm}$ after 1 hour incubation } & \multirow{2}{*}{ Average } & \multirow{2}{*}{ SD } \\
\hline & Cell 1 & Cell 2 & Cell 3 & Cell 4 & Cell 5 & & \\
\hline ab-PLGA & 177.3 & 135.8 & 160.7 & 169.7 & 169.3 & 154.46 & 21.01 \\
\hline
\end{tabular}

Table 12: NPs height Obtained Using Particle Analysis Performed on SKOV-3 Cells after 3 Hour Incubation Time

\begin{tabular}{|c|c|c|c|c|c|c|c|}
\hline \multirow{2}{*}{ Type of particles } & \multicolumn{5}{|c|}{ NPs height in nm after 3 hour incubation } & \multirow{2}{*}{ Average } & \multirow{2}{*}{ SD } \\
\hline & Cell 1 & Cell 2 & Cell 3 & Cell 4 & Cell 5 & & \\
\hline ab-PLGA & 127.3 & 132.8 & 90.7 & 69.3 & 139.2 & 112.46 & 30.88 \\
\hline b-PLGA & 139.2 & 141.7 & 129.3 & 132.9 & 148.1 & 138.24 & 7.39 \\
\hline d-PLGA & 106.2 & 142.6 & 161.4 & 124.2 & 131.7 & 133.22 & 20.59 \\
\hline
\end{tabular}


Table 13: NPs height Obtained Using Particle Analysis Performed on SKOV-3 Cells after 6 Hour Incubation Time

\begin{tabular}{|c|c|c|c|c|c|c|c|}
\hline \multirow{2}{*}{ Type of particles } & \multicolumn{5}{|c|}{ NPs height in nm after 6 hour incubation } & \multirow{2}{*}{ Average } & \multirow{2}{*}{ SD } \\
\hline & cell 1 & cell 2 & cell 3 & cell 4 & cell 5 & & \\
\hline ab-PLGA & 59.9 & 45.5 & 68.2 & 71.2 & 42.4 & 57.44 & 13.03 \\
\hline b-PLGA & 152.1 & 122.7 & 169.3 & 129.2 & 138.3 & 142.32 & 18.68 \\
\hline d-PLGA & 132.5 & 145.1 & 95.4 & 133.7 & 117.2 & 124.78 & 19.18 \\
\hline
\end{tabular}

Table 14: NPs height Obtained Using Particle Analysis Performed on SKOV-3 Cells after 24 Hour Incubation Time

\begin{tabular}{|c|c|c|c|c|c|c|c|}
\hline \multirow[b]{2}{*}{ Type of particles } & \multicolumn{5}{|c|}{ NPs height in nm after 24 hour incubation } & \multirow[t]{2}{*}{ Average } & \multirow[t]{2}{*}{ SD } \\
\hline & cell 1 & cell 2 & cell 3 & cell 4 & cell 5 & & \\
\hline b-PLGA & 40.37 & 97.1 & 81.3 & 28.7 & 109.5 & 71.39 & 35.34 \\
\hline
\end{tabular}

NOTE: Table 11 to Table 14 represent data that was obtained by performing analysis on five different cells under similar experimental conditions. It is also noted that the particles analysis was not performed on SKOV-3 cells treated with ab-PLGA NPs solution for 24 hours because cells surface did not show any significant particles and particle analysis was also not performed on cells treated with d-PLGA NPs solution for 24 hours as they were not viable. 


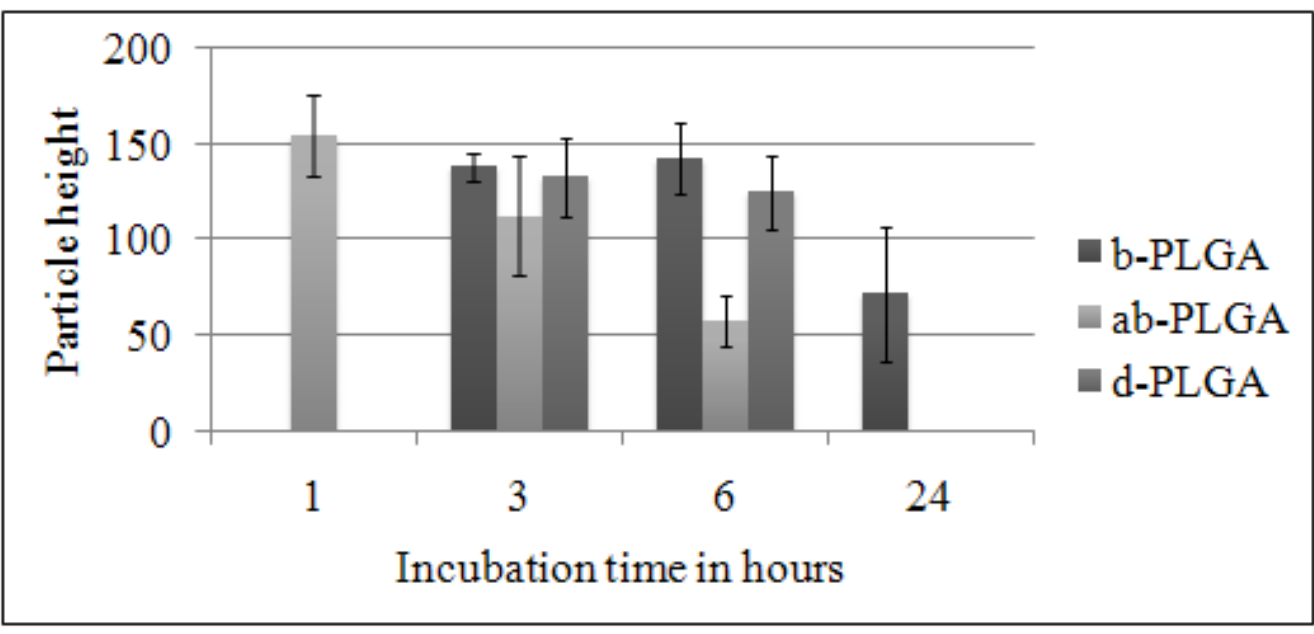

Figure 30: NPs height variation on the SKOV-3 cells with respect to incubation time. 


\section{DISCUSSION}

As NPs are widely used as drug delivery vehicles, it is essential to understand their interactions, distribution and internalization through the cell surface membrane. Several imaging techniques have been developed to understand these phenomena; however, these imaging techniques are limited by one or more disadvantages. It is impossible to study the interaction of NPs with cellular components by light microscopy because its resolution is limited by the wave length of light $(400 \mathrm{~nm})$. Immunofluorescence microscopy has been used to study the gene delivery process in rat cochlear cells via liposome NPs [95]. However, cells have to be fixed before staining, making it difficult to study the real time gene delivery process. Further these NPs have to have fluorescent properties or have to be tagged with special fluorescent dye. SEM is extensively used in providing insight to the NPs-membrane interactions in fixed cells [96]. However, it cannot be used as a model system for addressing the effect of (patho-) physiological conditions of the cell.

A method which helps in directly quantifying and characterizing this interaction phenomenon in cells native physiological conditions will provide a thorough understanding of cellular uptake. In this research, we presented two ways to characterize the interaction of NPs with cancer cells using AFM. Firstly, qualitative imaging was performed in order to track the dynamic changes on the cell membrane as a result of attachment of NPs. AFM lets one to qualitatively visualize the surface dependent

molecular event in $3 \mathrm{D}$ on a nanometer spatial resolution in aqueous environmental conditions [97]. AFM has been extensively used in imaging cells in both fixed and living 
states [98,99 ]. Imaging fixed cells in air is comparatively easier than imaging living cells in liquid. However, fixed cells cannot be used to study dynamic cell topographical changes as fixation introduces image artifacts (membrane cross linkage). Thus, to monitor the real time dynamic cell surface changes when treated with NPs, qualitative analysis was performed by monitoring 1) Height: represents the topographical data of the cell surface; 2) Phase: provides detailed information about the surface structure and its properties beyond the simple topography and 3) Amplitude images: is a derivative of height image, used for better visualization of surface. All the image data is obtained by performing AFM in McCoy's 5A media in order to maintain cell's natural environmental conditions. Secondly, in order to quantify the cell surface information we used three standard image analysis techniques: 1) Average cell surface roughness change; 2) Power spectral density for better understanding of surface roughness and 3) Particle analysis to monitor the dynamic height change of NPs throughout the internalization process.

\subsection{Qualitative analysis using AFM}

\subsubsection{Phase imaging}

Phase image provides the surface information beyond the simple topographical features to detect the variation in friction, elasticity, composition, adhesion and other properties by monitoring the phase-lag of the cantilever with respect to the piezo drive (refer section 4.9.2.2 for more detailed explanation). Monitoring the amplitude image alone cannot confirm the presence of foreign bodies (NPs) on the cell surface. Thus, it is important to perform phase imaging over a desired region in order to differentiate foreign 
bodies from the cell surface. The relation between the surface stiffness and the phase angle change in tapping mode AFM image is: brighter regions correspond to larger phase shifts and can be attributed to the region with higher Young's Modulus (stiffer surface). Similarly, the darker region represents lower Young's Modulus (softer surface). The results obtained using phase imaging on SKOV-3 cells incubated with no NPs show that the cell surface is homogeneous with no phase lag suggesting that the surface is not carrying NPs and the height variation on the surface is solely due to the membrane itself. However, phase images obtained on the SKOV-3 cells incubated in NPs solution showed dark spots on the surface of cells which confirms less positive phase corresponding to the soft or more elastic surface (i.e. PLGA NPs). This trend was observed on all SKOV-3 cells treated with all three types of PLGA NPs (ab-PLGA, b-PLGA and d-PLGA). Similar results were observed while characterizing thiolated gold NPs on solid surface using the phase imaging [100].

\subsubsection{Amplitude imaging}

Time based in vivo AFM imaging of SKOV-3 cells incubated in NPs solution suggests that the cellular uptake of NPs is a time dependent process and this time varies with the type of nanoparticle interacting with the cell. Amplitude images of SKOV-3 obtained at 3 hour incubation periods suggest that functionalized NPs (ab-PLGA) attach more compared to the other two types (b-PLGA \& d-PLGA). The reason for an increase in attachment is attributed to the surface charge properties of the cell. As functionalized NPs are less negatively charged $(-1.2 \pm 2.8 \mathrm{mV})$ when compared to the b-PLGA $(-14.7 \pm$ $2.5 \mathrm{mV})$ and $\mathrm{d}-\mathrm{PLGA}(-13.2 \pm 2.3 \mathrm{mV})$ they tend to attach to the complimentary 
receptors present on the surface of the tumor cell. This incorporation of moiety makes the ab-PLGA NPs positive which further enhances the interaction of NPs with the cancer cells (electrostatic interaction) (58). Amplitude images of SKOV-3 cells when incubated in NPs solution for 6 hours showed an accumulation of b-PLGA NPs on the surface of the cells before being significantly internalized whereas ab-PLGA NPs showed relatively less number of particles attached to the surface when compared to b-PLGA NPs. This may be due to the rapid internalization of ab-PLGA NPs.

The amplitude images of SKOV-3 cells incubated in d-PLGA NPs solution for 6 hours showed that the cells were contracted and appeared smaller compared to the healthy cells, probably due to the effect of drug leaching from the PLGA NPs. The amplitude images obtained at 24 hour incubation indicate that SKOV-3 cells incubated in ab-PLGA NPs showed no particles on the cell surface explaining complete internalization of ab-PLGA NPs in 24 hours. In contrast, the cells incubated in b-PLGA NPs solution showed large number of particles remained on the surface of the cells without being internalized. Unsuccessful internalization of b-PLGA NPs through cell surface membrane is associated with the huge size of the NPs $(>120 \mathrm{~nm})$. As b-PLGA NPs are too large to internalize passively through the cell membrane, most of the particles remained on the cell surface even after 24 hour incubation.

\subsection{Quantitative Analysis using AFM}

Quantitative information of cell surface was obtained to confirm the interaction of NPs with the cellular membrane other than qualitative visual representation by analyzing 
three of the most suitable measuring methods for AFM image analysis: 1) average roughness $\left(\mathrm{R}_{\mathrm{a}}\right)$; 2) power spectral density (PSD) and 3) particle analysis, performed before and after treating the cells with NPs.

\subsubsection{Average roughness $\left(R_{o}\right)$}

As the interaction of NPs with the cell surface is a surface phenomenon, the average cell surface roughness is affected by this interaction. Monitoring the change in surface roughness of a cell for a period of time ( 24 hours), one can correlate the process of attachment and internalization of NPs. Keeping this in mind, we performed roughness analysis on SKOV-3 cells before and after incubating in NPs solution for various incubation times $(0,1,3,6,24$ hours). Results from the roughness analysis performed on SKOV-3 cells without any NPs treatment (i.e. $\mathrm{t}=0$ hour) showed an average roughness of $9.22 \mathrm{~nm} \pm 1.66$. Average cell surface roughness when SKOV-3 cells were incubated in NPs solution for 1 hour did not show any significant change when the cells were treated with d-PLGA and b-PLGA NPs. That is $9.11 \%$ increase in $\mathrm{R}_{\mathrm{a}}$ for cells treated with $\mathrm{b}$ PLGA NPs solution ( $\mathrm{P}=0.15$; student's t-test), $2.49 \%$ increase for b-PLGA NPs ( $\mathrm{P}=$ 0.84). This suggests that the 1 hour incubation time for non-functionalized NPs may not be sufficient for firm attachment; as a result, particles might be washed away while the cells were subjected to DPBS treatment (washed thrice) before performing roughness analysis. The cells treated with ab-PLGA NPs showed a $25.37 \%(\mathrm{P}=0.091)$ increase in $\mathrm{R}_{\mathrm{a}}$, suggesting the ab-PLGA NPs tend to attach faster to the cell surface than other types of particles. Please refer to Table 9 for detailed information on time based percentage change in cell surface roughness. 
SKOV-3 cells treated with NPs solution for 3 hours showed a significant roughness change for all three types of NPs. That is increase in average roughness (from $t$ $=0$ ) for b-PLGA NPs is $38.28 \%(\mathrm{P}=0.018)$, increase for d-PLGA NPs is $107.37 \%$ $(\mathrm{P}=0.002)$ and the increase for ab-PLGA NPs is $112.68 \%(\mathrm{P}<0.001)$. Note: These results indicate that the ab-PLGA NPs incubated for 3 hours attach more in number than the bPLGA NPs for the same reason as explained previously in Section 6.1.2 and the cells incubated in d-PLGA NPs solution showed a maximum roughness change; that may be due to the wrinkled surface (effect of doxorubicin drug on cell morphology) shown in Figure 17 rather than due to NPs attachment. This roughness data indicates that the cells incubated in targeted particle solution showed higher roughness in the first three hours of incubation compared to the non-targeted NPs solution, indicating that the ab-PLGA particles bind to SKOV-3 cells through over expressed HER-2 receptors on the cell surface. This idea is conceptualized in the schematic shown in Figure 31.

Roughness analysis performed on SKOV-3 cells for 6 hour NPs incubation showed a very high increase (from $t=0$ to 6 hours) in roughness, i.e. $158 \%$ for cells treated with b-PLGA NPs solution due to the accumulation of NPs on the cell surface membrane as a result of poor internalization (shown in amplitude image Figure 20). However, cells incubated in ab-PLGA NPs showed a decrease from $112.68 \%$ at 3 hours to $79.26 \%(\mathrm{P}=0.001)$ at 6 hours. The small decrease in cell roughness may be due to the combined effect of internalization of attached particles. The average surface roughness of SKOV-3 cells incubated in d-PLGA NPs solution was higher than any other counter particles, due to the change in cell morphology and not due to the NP attachment to the cell surface. This can be explained by the visualizing phase images of SKOV-3 cell 
incubated in NPs solution for 6 hours. Figure 22 shows no particles attached on the surface which suggests that the increase in $R_{a}$ is due to morphological change of cell.

The average roughness analysis performed on SKOV-3 cells incubated in NPs solution for 24 hours, showed $10.74 \mathrm{~nm} \pm 1.65\left(\mathrm{R}_{\mathrm{a}}\right)$ for cells treated with ab-PLGA NPs which is only $16.48 \%(\mathrm{P}=0.165)$ more than the untreated cells $(\mathrm{t}=0)$. The higher Pvalue $(>0.01)$ suggests that the increase is insignificant; thus indicating a complete internalization of ab-PLGA NPs. The cells incubated in b-PLGA NPs solution showed $\mathrm{R}_{\mathrm{a}}$ of $18.88 \mathrm{~nm} \pm 4.02$ which is $99.06 \%(\mathrm{P}<0.001)$ increase from the untreated cell $(\mathrm{t}=0)$, indicating that the cell surface roughness is not similar to the untreated cells and b-PLGA NPs still remained on the cell surface without being internalized. Note: Roughness analysis was not performed on the SKOV-3 cells incubated in d-PLGA NPs because cells were not viable to perform the analysis, probably due to the leaching of doxorubicin drug from the NPs which is toxic to the cells.

\section{The roughness data shown in}

Table 5 to Table 8 also suggest that the distribution of NPs on the cell surface is uniform for all three types of NPs. This can be confirmed by low standard deviation values from region 1 to region 2 . 

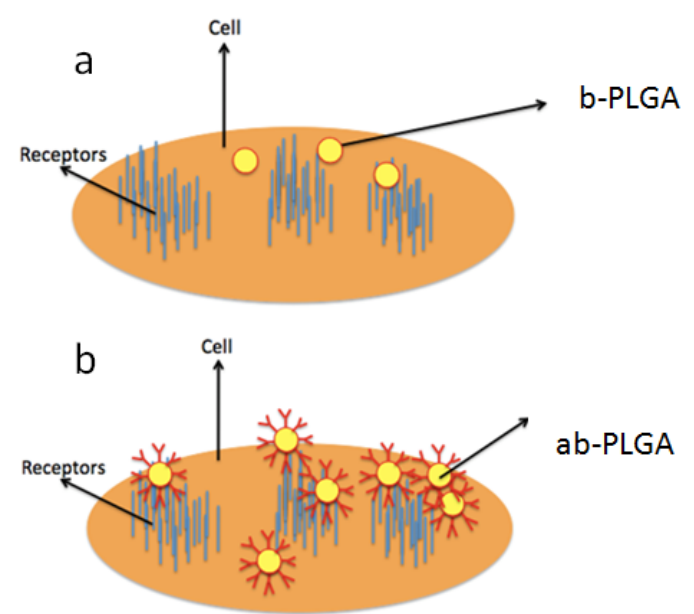

Figure 31: (a) b-PLGA NPS binding to the cell surface membrane randomly and (b) ab-PLGA particles attached to the receptors present on the cell surface membrane.

\subsubsection{Power spectral density}

The surface texture of the sample is characterized by the heights and depths of its peaks and valleys respectively. Besides, peaks and valleys it is also determined by the distances that separates the peaks and valleys. Power spectral density is primarily concerned with those distances. This can be further simplified to our situation (that is presence of NPs on the surface of the cell). Average roughness deals with the height variations of the particles rather than the horizontal variation (which corresponds to density of the particles) whereas; 2D-power spectral density deals with both the vertical and horizontal variations.

Following the roughness analysis, we also performed power spectral density analysis to characterize the surface to account for both horizontal and vertical variations. Our results showed an exponential increase in total power of SKOV-3 cells surface after incubating in NPs solution for 1 to 6 hours corresponding to the attachment and for 6 to 
24 hours showed an exponential decrease corresponding to internalization of NPs. This exponential increase and decrease was much higher for ab-PLGA NPs representing significance of receptor mediated endocytosis whereas wells treated with b-PLGA showed a very slow increase in PSD. This may be due to the very slow attachment of particles to the surface because b-PLGA NPs are more electronegative which thereby affects their interaction with the cells. Cells treated with d-PLGA NPs for 24 hours showed a very high total power $\left(0.843 \mathrm{~nm}^{2}\right)$ which indicates that the cell surface roughness were significantly changed. This may be more due to the toxic effect of drug on the cell rather than the particles' attachment to the surface.

\subsubsection{Particle analysis}

Performing particle analysis on the cell surface at various incubation periods can give better understanding of dynamic change of the NPs height as a result of particle internalization. Our data from particle analysis shows that the internalization of abPLGA NPs begins as early as three hours which is indicated by the drop in particle height from $154.4 \mathrm{~nm} \pm 21.01$ (at 1 hour) to $112.46 \mathrm{~nm} \pm 30.88$ (at 3 hours). The height of $\mathrm{b}$ PLGA and d-PLGA NPs did not decrease significantly for at least six hours. Particle analysis performed at 24 hour incubation showed that the height of b-PLGA NPs on the cell surface was $71.39 \mathrm{~nm} \pm 35.34$ which indicates a partial internalization of remaining particles on the cell surface. 
However, SKOV-3 cells did not show significant amount of NPs on the cells surface and hence we did not perform particle analysis. We also did not perform particle analysis for cells incubated in d-PLGA NPs solution for 24 hours as cells were not viable. 


\section{CONCLUSION AND FUTURE WORK}

The AFM technology was aimed at studying the NPs-membrane interactions on living tumor cells in order to account for internalization of targeted (functionalized), nontargeted (non-functionalized), and drug loaded NPs, both qualitatively and quantitatively. The following conclusions were reached:

- The attachment of NPs to the cell membrane causes a change in the average roughness of the cells. Therefore by monitoring the cells average roughness, one can monitor the NPs interaction and internalization phenomena.

- The amount of NPs that attach to the cell membrane depends on time as well as particle surface chemistry dependent process. The amount of NPs attaching to the cell membrane increases with increase in time. Surface functionalized (functionalized to target specific receptor of the cell surface) NPs attach more to the cell surface than the non-functionalized NPs.

- Surface functionalized NPs attach faster to the cell membrane than the nonfunctionalized NPs. That is, cells incubated in ab-PLGA NPs solution for 1 hour showed $25.37 \%(\mathrm{P}=0.091)$ increase in $\mathrm{R}_{\mathrm{a}}$, whereas, cells incubated in b-PLGA and d-PLGA NPs solution showed only $9.11 \%(\mathrm{P}=0.15)$ and $2.49 \%$ increase. This suggests ab-PLGA NPs attach faster than their counterparts.

- Surface functionalized NPs (ab-PLGA) tend to internalize more rapidly than the non-functional NPs (b-PLGA). Amplitude images of SKOV-3 cells incubated in ab-PLGA NPs solution for 24 hours showed either no particles or only a few particles on the cell surface; The corresponding roughness analysis values of cell 
surface were very close to untreated cell surface $\left(R_{a}\right.$ for untreated cells is $9.22 \mathrm{~nm}$ $\pm 1.66 ; \mathrm{R}_{\mathrm{a}}$ for ab-treated cells is $\left.10.74 \mathrm{~nm} \pm 1.65\right)$.

- It is difficult to monitor the process of internalization by monitoring the cell surface roughness change due to interaction of NPs if the particles exhibit the toxic effects. Amplitude images obtained on SKOV-3 cells incubated in drug encapsulated PLGA NPs (d-PLGA) solution show wrinkled cell surface and the corresponding cell roughness was found to be very high, in such cases it is difficult to interpret the internalization process by monitoring the roughness change at various incubation periods.

The conclusions presented in this work will be useful in monitoring the dynamic changes in the cell surface membrane when the cells are subjected to various kinds of NPs using atomic force microscopy. The qualitative and quantitative results obtained will be very useful in understanding the efficiency and biophysical interactions of the NPs with the cell surface membrane and therefore be critical for developing effective drug delivery vehicles.

As NPs play a crucial role in delivering drugs to the cancer cells, it is important to understand their interactions and internalization process in order to efficiently target to the specific sites of the cells. Understanding their efficiency and biophysical interactions with cell surface membranes will be critical in developing such effective drug carriers. In our future work we would like to test various physical properties of NPs such as size, charge, shape, etc in order to develop an ideal drug carrying vehicle based on the qualitative and quantitative AFM analysis. 


\section{BIBLIOGRAPHY}

1. Yih, T. C. and M. Al Fandi (2006). "Engineered nanoparticles as precise drug delivery systems." Journal of cellular biochemistry 97(2 1 6): 1184-1190.

2. Bivas-Benita, M., S. Romeijn, et al. (2004). "PLGA-PEI nanoparticles for gene delivery to pulmonary epithelium." European journal of pharmaceutics and biopharmaceutics 58(2 1$)$ : 1-6.

3. Babic, M., D. Horák, et al. (2008). "Poly (L-lysine)-modified iron oxide nanoparticles for stem cell labeling." Bioconjugate chemistry 19(3): 740-750.

4. Ohnesorge, F., J. Hörber, et al. (1997). "AFM review study on pox viruses and living cells." Biophysical journal 73(4): 2183-2194.

5. Domke, J., W. J. Parak, et al. (1999). "Mapping the mechanical pulse of single cardiomyocytes with the atomic force microscope." European Biophysics Journal 28(3): 179-186.

6. Kirby, A. R., A. P. Gunning, et al. (1996). "Visualization of plant cell walls by atomic force microscopy." Biophysical journal 70(3): 1138-1143.

7. Garrison, M. D. and B. D. Ratner (1997). "Scanning Probe Microscopy for the Characterization of Biomaterials and Biological Interactionsa." Annals of the New York Academy of Sciences 831(1): 101-113.

8. Yoshida, Y., B. V. Meerbeek, et al. (1999). "A novel approach to AFM characterization of adhesive tooth-biomaterial interfaces." Journal of biomedical materials research 47(1): 85-90.

9. Tapia-Tapia, M.; Batina, N. (2009). " Nanoscopic characterization of membrane surface of HeLa cancer cells in the presence of the gold nanoparticles." Revista Mexicana de fisica s 55(1): 64-67.

10. Scalf, J. and P. West (2006). "Part I: Introduction to nanoparticle characterization with AFM." Application Note-Pacific Nanotechnologies www. nanoparticles. org/pdf/scalf-west. pdf (last accessed November 23, 2009). 
11. Shukla, R., V. Bansal, et al. (2005). "Biocompatibility of gold nanoparticles and their endocytotic fate inside the cellular compartment: a microscopic overview." Langmuir 21(23): 10644-10654.

12. Vasir, J. K. and V. Labhasetwar (2008). "Quantification of the force of nanoparticlecell membrane interactions and its influence on intracellular trafficking of nanoparticles." Biomaterials 29(31): 4244-4252.

13. Hong, S., P. R. Leroueil, et al. (2006). "Interaction of polycationic polymers with supported lipid bilayers and cells: nanoscale hole formation and enhanced membrane permeability." Bioconjugate chemistry 17(3): 728-734.

14. Panyam, J. and V. Labhasetwar (2003). "Biodegradable nanoparticles for drug and gene delivery to cells and tissue." Advanced drug delivery reviews 55(3): 329-347.

15. Astete, C. E. and C. M. Sabliov (2006). "Synthesis and characterization of PLGA nanoparticles." Journal of Biomaterials Science, Polymer Edition 17(3): 247-289.

16. Liu, J. R., A. W. Opipari, et al. (2002). "Dysfunctional Apoptosome Activation in Ovarian Cancer." Cancer research 62(3): 924.

17. Wolf, B. B., M. Schuler, et al. (2001). "Defective cytochrome c-dependent caspase activation in ovarian cancer cell lines due to diminished or absent apoptotic protease activating factor-1 activity." Journal of Biological Chemistry 276(36): 34244.

18. Grama, C. N., D. D. Ankola, et al. "Poly(lactide-co-glycolide) nanoparticles for peroral delivery of bioactives." Current Opinion in Colloid \& Interface Science In Press, Corrected Proof.

19. Allen, T. M. (2002). "Ligand-targeted therapeutics in anticancer therapy." Nature Reviews Cancer 2(10): 750-763.

20. Feng, S. S. and S. Chien (2003). "Chemotherapeutic engineering: application and further development of chemical engineering principles for chemotherapy of cancer and other diseases." Chemical Engineering Science 58(18): 4087-4114.

21. Kim, C. K. and S. J. Lim (2002). "Recent progress in drug delivery systems for anticancer agents." Archives of pharmacal research 25(3): 229-239. 
22. Esfand, R. and D. A. Tomalia (2001). "Poly (amidoamine)(PAMAM) dendrimers: from biomimicry to drug delivery and biomedical applications." Drug Discovery Today 6(8): 427-436.

23. Quintana, A., E. Raczka, et al. (2002). "Design and function of a dendrimer-based therapeutic nanodevice targeted to tumor cells through the folate receptor." Pharmaceutical research 19(9): 1310-1316.

24. Liu, H., S. Farrell, et al. (2000). "Drug release characteristics of unimolecular polymeric micelles." Journal of controlled release 68(2): 167-174.

25. Sahoo, S. K. and V. Labhasetwar (2003). "Nanotech approaches to drug delivery and imaging." Drug Discovery Today 8(24): 1112-1120.

26. Howe, A., A. E. Aplin, et al. (1998). "Integrin signaling and cell growth control." Current opinion in cell biology 10(2): 220-231

27. Aplin, A., A. Howe, et al. (1998). "Signal transduction and signal modulation by cell adhesion receptors: the role of integrins, cadherins, immunoglobulin-cell adhesion molecules, and selectins." Pharmacological reviews 50(2): 197

28. Liu, X., C. Gao, et al. (2005). "Multilayer Microcapsules as Anti Cancer Drug Delivery Vehicle: Deposition, Sustained Release, and in vitro Bioactivity." Macromolecular bioscience 5(12): 1209-1219.

29. Muller, R., K. Mader, et al. (2000). "Solid lipid nanoparticles (SLN) for controlled delivery-a review of the state of the art." Eur. J. Pharm. Biopharm 50: 161-177.

30. Zahr, A. S., M. de Villiers, et al. (2005). "Encapsulation of drug nanoparticles in selfassembled macromolecular nanoshells." Langmuir 21(1): 403-410.

31. Lasic, D., J. Vallner, et al. (1999). "Sterically stabilized liposomes in cancer therapy and gene delivery." Current opinion in molecular therapeutics 1(2): 177

32. Brigger, I., J. Morizet, et al. (2002). "Poly (ethylene glycol)-coated hexadecylcyanoacrylate nanospheres display a combined effect for brain tumor targeting." Journal of Pharmacology and Experimental Therapeutics 303(3): 928. 
33. O'Donnell, P. B. and J. W. McGinity (1997). "Preparation of microspheres by the solvent evaporation technique." Advanced Drug Delivery Reviews 28(1): 25-42.

34. Ruan, G., S. S. Feng, et al. (2002). "Effects of material hydrophobicity on physical properties of polymeric microspheres formed by double emulsion process." Journal of controlled release 84(3): 151-160.

35. Unfried, K., C. Albrecht, et al. (2007). "Cellular responses to nanoparticles: Target structures and mechanisms." Nanotoxicology 1(1): 52-71.

36. Hong, S., A. U. Bielinska, et al. (2004). "Interaction of poly (amidoamine) dendrimers with supported lipid bilayers and cells: hole formation and the relation to transport." Bioconjugate chemistry 15(4): 774-782.

37. Hong, S., P. R. Leroueil, et al. (2006). "Interaction of polycationic polymers with supported lipid bilayers and cells: nanoscale hole formation and enhanced membrane permeability." Bioconjugate chemistry 17(3): 728-734.

38. Mecke, A., S. Uppuluri, et al. (2004). "Direct observation of lipid bilayer disruption by poly (amidoamine) dendrimers." Chemistry and physics of lipids 132(1): 3-14.

39. Kirchner, C., T. Liedl, et al. (2005). "Cytotoxicity of colloidal CdSe and CdSe/ZnS nanoparticles." Nano Letters 5(2): 331-338.

40. Schellenberger, E. A., D. Sosnovik, et al. (2004). "Magneto/optical annexin V, a multimodal protein." Bioconjugate chemistry 15(5): 1062-1067.

41. Chithrani, B. D. and W. C. W. Chan (2007). "Elucidating the mechanism of cellular uptake and removal of protein-coated gold nanoparticles of different sizes and shapes." Nano letters 7(6): 1542-1550.

42. Chithrani, B. D., A. A. Ghazani, et al. (2006). "Determining the size and shape dependence of gold nanoparticle uptake into mammalian cells." Nano letters 6(4): 662668.

43. Jiang, W., B. Y. S. Kim, et al. (2008). "Nanoparticle-mediated cellular response is size-dependent." Nature Nanotechnology 3(3): 145-150. 
44. Ghitescu, L. \& Bendayan, M. Immunolabeling efficiency of protein A-gold complexes. J. Histochem. Cytochem. 38, 1523-1530 (1990).

45. Duan, H. and S. Nie (2007). "Cell-penetrating quantum dots based on multivalent and endosome-disrupting surface coatings." Journal of the American Chemical Society 129(11): 3333-3338.

46. Mattoussi, H., J. M. Mauro, et al. (2000). "Self-assembly of CdSe-ZnS quantum dot bioconjugates using an engineered recombinant protein." Journal of the American Chemical Society 122(49): 12142-12150.

47. De la Fuente, M., B. Seijo, et al. (2008). "Bioadhesive hyaluronan-chitosan nanoparticles can transport genes across the ocular mucosa and transfect ocular tissue." Gene therapy 15(9): 668-676.

48. Choi, A. O., S. E. Brown, et al. (2008). "Quantum dot-induced epigenetic and genotoxic changes in human breast cancer cells." Journal of Molecular Medicine 86(3): 291-302.

49. Choi, A. O., S. J. Cho, et al. (2007). "Quantum dot-induced cell death involves Fas upregulation and lipid peroxidation in human neuroblastoma cells." Journal of nanobiotechnology 5(1): 1 .

50. Cho, E. C.; Xie, J.; Wurm, P. A.; Xia, Y., Understanding the role of surface charges in cellular adsorption versus internalization by selectively removing gold nanoparticles on the cell surface with a I2/KI etchant. Nano letters 2009, 9, (3), 1080-1084.

51. Morris, V. J., A. R. Kirby, et al. (1999). Atomic force microscopy for biologists, Imperial College Press London.

52. Haberle, W., J. Horber, et al. (1991). "Force microscopy on living cells." Journal of Vacuum Science \& Technology B: Microelectronics and Nanometer Structures 9(2): 1210-1213.

53 . Schneider, S. W.; Sritharan, K. C.; Geibel, J. P.; Oberleithner, H.; Jena, B. P., Surface dynamics in living acinar cells imaged by atomic force microscopy: identification of plasma membrane structures involved in exocytosis. Proceedings of the National Academy of Sciences 1997, 94, (1), 316. 
54. Albrecht, T., S. Akamine, et al. (1990). "Microfabrication of cantilever styli for the atomic force microscope." Journal of Vacuum Science \& Technology A: Vacuum, Surfaces, and Films 8(4): 3386-3396.

55. Radmacher, M. (1997). "Measuring the elastic properties of biological samples with the AFM." Engineering in Medicine and Biology Magazine, IEEE 16(2): 47-57.

56. Radmacher, M., M. Fritz, et al. (1995). "Imaging soft samples with the atomic force microscope: gelatin in water and propanol." Biophysical journal 69(1): 264-270.

57. Pralle, A., M. Prummer, et al. (1999). "Three-dimensional high-resolution particle tracking for optical tweezers by forward scattered light." Microscopy Research and Technique 44(5): 378-386.

58. Engel, A. and D. J. Müller (2000). "Observing single biomolecules at work with the atomic force microscope." Nature Structural \& Molecular Biology 7(9): 715-718.

59. Wagner, P. (1998). "Immobilization strategies for biological scanning probe microscopy1." FEBS letters 430(1-2): 112-115.

60. Bolshakova, A. V., O. I. Kiselyova, et al. (2004). "TOPICAL PAPER." Biotechnol. Prog 20: 1615-1622.

61. Moreno-Herrero, F., J. Colchero, et al. (2004). "Atomic force microscopy contact, tapping, and jumping modes for imaging biological samples in liquids." Physical Review E 69(3): 031915.

62. Tomaselli, K. J., C. H. Damsky, et al. (1987). "Interactions of a neuronal cell line (PC12) with laminin, collagen IV, and fibronectin: identification of integrin-related glycoproteins involved in attachment and process outgrowth." The Journal of cell biology 105(5): 2347.

63. McPherson, A., Y. G. Kuznetsov, et al. (2003). "Macromolecular crystal growth as revealed by atomic force microscopy." Journal of structural biology 142(1): 32-46.

64. Kuznetsov, Y., A. Low, et al. (2004). "Atomic force microscopy investigation of wild-type Moloney murine leukemia virus particles and virus particles lacking the envelope protein." Virology 323(2): 189-196. 
65. Kuznetsov, Y. G., J. R. Gurnon, et al. (2005). "Atomic force microscopy investigation of a chlorella virus, PBCV-1." Journal of structural biology 149(3): 256-263.

66. Moreno-Herrero, F., J. Colchero, et al. (2004). "Atomic force microscopy contact, tapping, and jumping modes for imaging biological samples in liquids." Physical Review E 69(3): 031915.

67. Tomaselli, K. J., C. H. Damsky, et al. (1987). "Interactions of a neuronal cell line (PC12) with laminin, collagen IV, and fibronectin: identification of integrin-related glycoproteins involved in attachment and process outgrowth." The Journal of cell biology 105(5): 2347.

68. McPherson, A., Y. G. Kuznetsov, et al. (2003). "Macromolecular crystal growth as revealed by atomic force microscopy." Journal of structural biology 142(1): 32-46.

69. Kuznetsov, Y., A. Low, et al. (2004). "Atomic force microscopy investigation of wild-type Moloney murine leukemia virus particles and virus particles lacking the envelope protein." Virology 323(2): 189-196.

70. Kuznetsov, Y. G., J. R. Gurnon, et al. (2005). "Atomic force microscopy investigation of a chlorella virus, PBCV-1." Journal of structural biology 149(3): 256-263.

72. Nagayama, S., M. Morimoto, et al. (1996). "AFM observation of three-dimensional fine structural changes in living neurons." Bioimages 4(3): 111-116.

73. Langer, M., A. Koitschev, et al. (2000). "Mechanical stimulation of individual stereocilia of living cochlear hair cells by atomic force microscopy." Ultramicroscopy 82(1-4): 269-278.

74. Rotsch, C., K. Jacobson, et al. (1999). "Dimensional and mechanical dynamics of active and stable edges in motile fibroblasts investigated by using atomic force microscopy." Proceedings of the National Academy of Sciences of the United States of America 96(3): 921.

75. Lal, R., B. Drake, et al. (1995). "Imaging real-time neurite outgrowth and cytoskeletal reorganization with an atomic force microscope." American Journal of Physiology-Cell Physiology 269(1): C275. 
76. Gad, M. and A. Ikai (1995). "Method for immobilizing microbial cells on gel surface for dynamic AFM studies." Biophysical journal 69(6): 2226-2233.

77. Spudich, A. and D. Braunstein (1995). "Large secretory structures at the cell surface imaged with scanning force microscopy." Proceedings of the National Academy of Sciences of the United States of America 92(15): 6976.

78. Anselme, K.; Noe* 1, B.; Hardouin, P., Human osteoblast adhesion on titanium alloy, stainless steel, glass and plastic substrates with same surface topography. Journal of Materials Science: Materials in Medicine 1999, 10, (12), 815-819.

79. Panyam, J.; Labhasetwar, V., Biodegradable nanoparticles for drug and gene delivery to cells and tissue. Advanced drug delivery reviews 2003, 55, (3), 329-347.

80. Astete, C. E.; Sabliov, C. M., Synthesis and characterization of PLGA nanoparticles. Journal of Biomaterials Science, Polymer Edition 2006, 17, (3), 247-289.

81. Vermorken, J. B., The role of anthracyclines in second line therapy of ovarian cancer. International Journal of Gynecological Cancer 2003, 13, 178-184.

82. Lei, T., S. Srinivasan, et al. (2010). "Comparing cellular uptake and cytotoxicity of targeted drug carriers in cancer cell lines with different drug resistance mechanisms." Nanomedicine: Nanotechnology, Biology and Medicine.

83. Mo, Y.; Lim, L. Y., Preparation and in vitro anticancer activity of wheat germ agglutinin (WGA)-conjugated PLGA nanoparticles loaded with paclitaxel and isopropyl myristate. Journal of controlled release 2005, 107, (1), 30-42.

84. Panyam, J. and V. Labhasetwar (2003). "Dynamics of endocytosis and exocytosis of poly (D, L-lactide-co-glycolide) nanoparticles in vascular smooth muscle cells." Pharmaceutical research 20(2): 212-220.

85. Veeco metrology support note no.290, Rev.c.

86. Hansma, P., J. Cleveland, et al. (1994). "Tapping mode atomic force microscopy in liquids." Applied Physics Letters 64(13): 1738-1740. 
87. Jungmann, P., M. Wilhelmi, et al. (2008). "Bradykinin does not induce gap formation between human endothelial cells." Pflügers Archiv European Journal of Physiology 455(6): 1007-1016.

88. Ma, W., Y. Sun, et al. (2006). "Cytoskeletal response of microvessel endothelial cells to an applied stress force at the submicrometer scale studied by atomic force microscopy." Microscopy Research and Technique 69(10): 784-793.

89. Fang, S., S. Haplepete, et al. (1997). "Analyzing atomic force microscopy images using spectral methods." Journal of applied physics 82: 5891.

90. Kitching, S., P. Williams, et al. (1999). "Quantifying surface topography and scanning probe image reconstruction." Journal of Vacuum Science \& Technology B: Microelectronics and Nanometer Structures 17: 273.

91. Schneider, S. W., K. C. Sritharan, et al. (1997). "Surface dynamics in living acinar cells imaged by atomic force microscopy: identification of plasma membrane structures involved in exocytosis." Proceedings of the National Academy of Sciences 94(1): 316.

92. Cho, S. J., J. Cho, et al. (2002). "The number of secretory vesicles remains unchanged following exocytosis." Cell biology international 26(1): 29-33.

93. Marchant, R., I. Kang, et al. (2002). "Molecular views and measurements of hemostatic processes using atomic force microscopy." Current Protein and Peptide Science 3(3): 249-274.

94. Panyam, J.; Labhasetwar, V., Dynamics of endocytosis and exocytosis of poly (D, L-lactide-co-glycolide) nanoparticles in vascular smooth muscle cells. Pharmaceutical research 2003, 20, (2), 212-220.

95. Zou, J.; Zhang, Y.; Zhang, W.; Ranjan, S.; Sood, R.; Mikhailov, A.; Kinnunen, P.; Pyykko, I., Internalization of liposome nanoparticles functionalized with TrkB ligand in rat cochlear cell populations. European Journal of Nenomedicine 2009, 3, 8-14.

96. Zhao, Y.; Sun, X.; Zhang, G.; Trewyn, B. G.; Slowing, I. I.; Lin, V. S. Y., Interaction of Mesoporous Silica Nanoparticles with Human Red Blood Cell Membranes: Size and Surface Effects. ACS nano.

97. Schneider, S. W.; Sritharan, K. C.; Geibel, J. P.; Oberleithner, H.; Jena, B. P., Surface dynamics in living acinar cells imaged by atomic force microscopy: 
identification of plasma membrane structures involved in exocytosis. Proceedings of the National Academy of Sciences 1997, 94, (1), 316.

98. You, H. X.; Yu, L., Atomic force microscopy imaging of living cells: progress, problems and prospects. Methods in cell science 1999, 21, (1), 1-17.

99. Sinniah, K.; Paauw, J.; Ubels, J., Investigating live and fixed epithelial and fibroblast cells by atomic force microscopy. Current eye research 2002, 24, (3), 188-195.

100. Jiang, P.; Xie, S.; Pang, S.; Gao, H., The combining analysis of height and phase images in tapping-mode atomic force microscopy: a new route for the characterization of thiol-coated gold nanoparticle film on solid substrate. Applied surface science 2002, 191, (1-4), 240-246. 